\title{
Experimental Verification of Theoretical Ageing and Service Life Prediction Model for Vacuum Insulation Panels
}

\author{
By \\ Mahsa Nikafkar \\ Master of Environmental Design Engineering \\ University of Tehran, Iran, 2011 \\ A thesis \\ presented to Ryerson University \\ in partial fulfilment of the requirements for the degree of \\ Master of Applied Science \\ in the program of \\ Building Science
}

Toronto, Ontario, Canada, 2019

oMahsa Nikafkar, 2019 


\section{Author's Declaration for Electronic Submission of a Thesis}

I hereby declare that I am the sole author of this thesis. This is a true copy of the thesis, including any required final revisions, as accepted by my examiners.

I authorize Ryerson University to lend this thesis to other institutions or individuals for the purpose of scholarly research.

I further authorize Ryerson University to reproduce this thesis by photocopying or by other means, in total or in part, at the request of other institutions or individuals for the purpose of scholarly research.

I understand that my thesis may be made electronically available to the public. 


\title{
Experimental Verification of Theoretical Ageing and Service Life Prediction Model for Vacuum Insulation Panels
}

Master of Applied Science 2019

Mahsa Nikafkar

Building Science, Ryerson University

\begin{abstract}
Vacuum Insulation Panels (VIPs) are a kind of the super-insulated materials (SIMs). VIPs are innovative material in various fields like the building sector as it encompasses a higher thermal resistance per unit of thickness compared to conventional insulation. To extensively use VIPs in the building sector, comprehensive performance analysis, and their properties such as thermal conductivity valuations are required to be done under simulated conditions to evaluate its longterm performance. However, different VIPs have varying durability, and as it stands, there is no comprehensive understanding of how all VIPs will behave in real conditions. This research investigates the effect of multiple variables (such as temperature, relative humidity) on VIP service life. The purpose of this research is to validate the theoretical ageing model of VIPs. First, the experimental thermal conductivity results from seven samples of three different VIP categories are collected using a heat flow meter. To measure the accelerated ageing results over 25 years, Arrhenius equation is applied. Next, NRC theoretical model is used to predict the ageing response of the samples. Finally, an analytical method is employed to verify and validate this model based on the collected data. Results shows that effect of ageing and environmental temperature have higher impacts on the performance of fibreglass panels than the fumed silicas. Additionally, the aging effects analysis reveals that microporous silica VIP products would maintain their superior thermal performance over time.
\end{abstract}

Keywords: Vacuum insulation panel, Ageing, Thermal conductivity, accelerated ageing, modelling 


\section{Acknowledgements}

First of all, I would like to thank my supervisor, Dr. Umberto Berardi for his continuous support throughout our research. I want to thank him for his supervision, guidance, and encouragement that made the completion of this research possible. I am also indebted to him for his generous commitment of time and availability whenever I needed him.

I would also like to thank my second reader, Prof. Vera Straka for her valuable academic insight and critical review of this project.

It would be not possible for me to follow a research career without the support and encouragement from my family. I am very much thankful to all of them for their love and support.

Finally, I would like to thank my friends and colleagues from Ryerson University for their constant support and for keeping me motivated. 


\section{Table of Contents:}

Author's Declaration for Electronic Submission of a Thesis ................................................ii

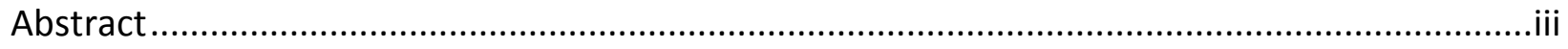

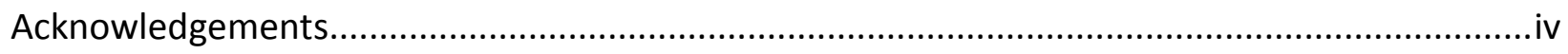

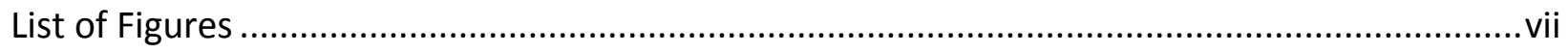

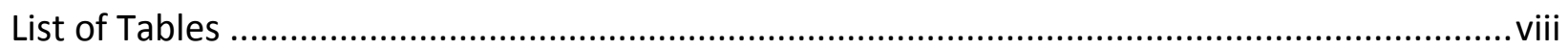

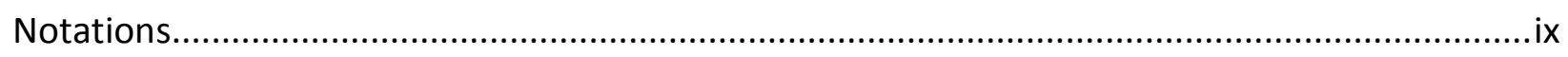

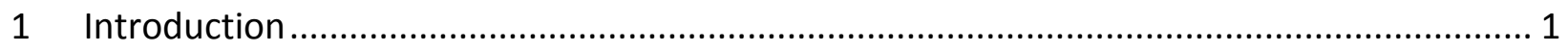

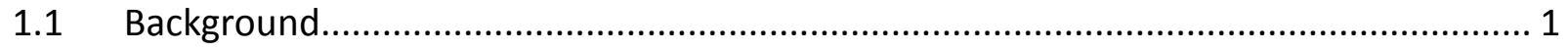

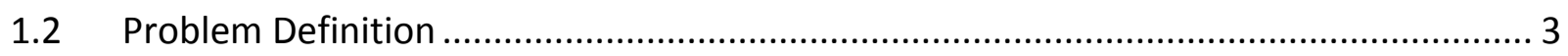

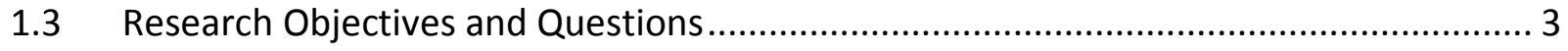

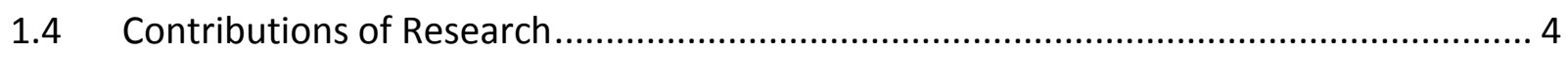

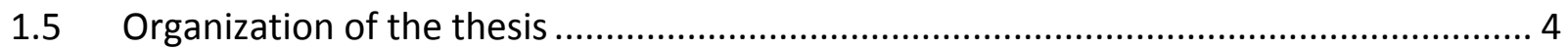

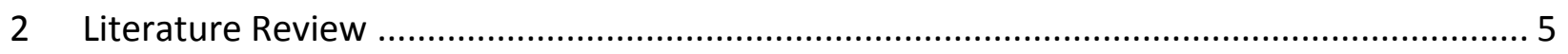

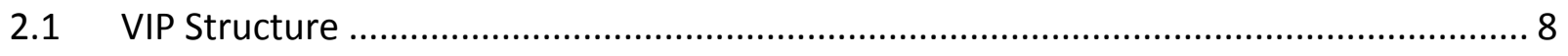

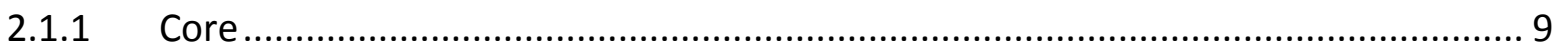

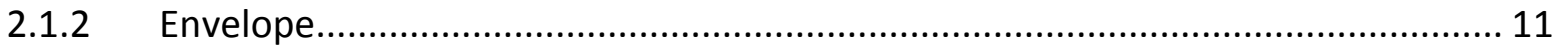

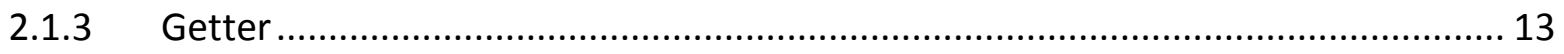

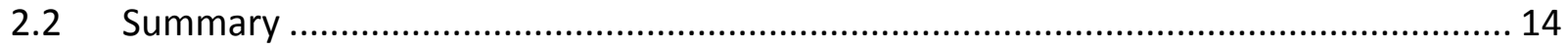

2.3 Mathematical Model for VIP Thermal Conductivity and long-term performance ........ 17

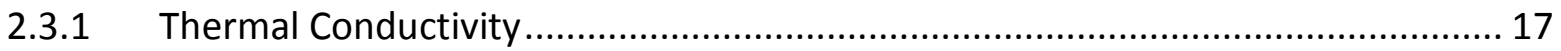

2.4 Mathematical Model for Thermal Conductivity of VIPs .......................................... 19

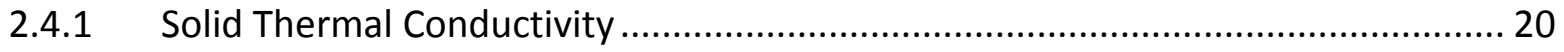

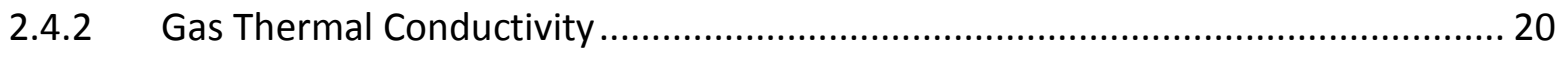

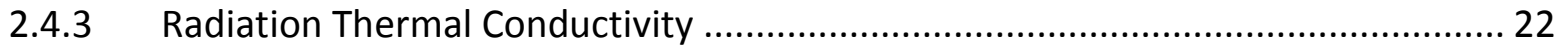

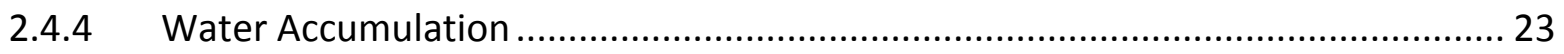




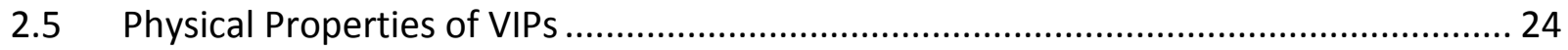

2.5.1 Thermal transport through Core Material Properties ...................................... 26

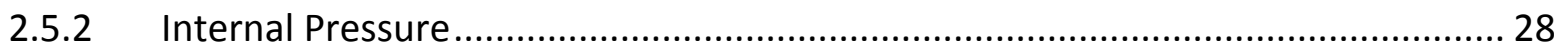

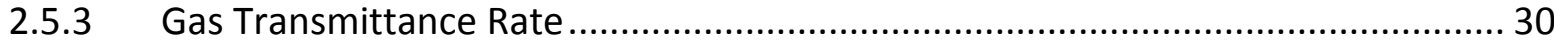

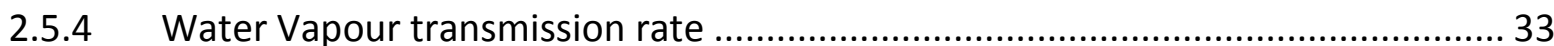

2.5.5 Moisture Permeability and Water Content .................................................. 34

2.6 Effective Thermal Conductivity and Service Life ...................................................... 34

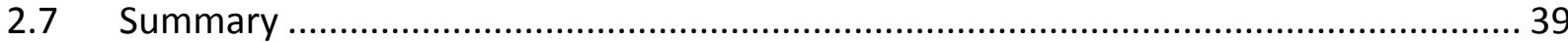

3 Laboratory Measurement and Data Collection Methodology .......................................... 40

3.1.1 Laboratory Characterization ....................................................................... 41

3.1.2 Correlation between Thermal conductivity and Internal pressure ..................... 45

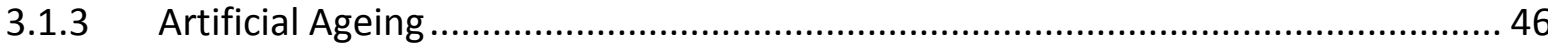

3.1.4 Moisture storage function and hygroscopic sorption ...................................... 49

$4 \quad$ Experimental Results and Data Analysis.................................................................. 52

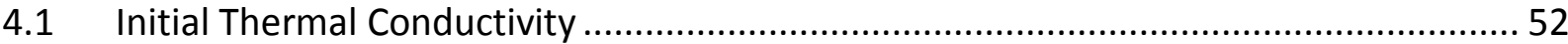

4.2 Ageing Results of Thermal Conductivity ................................................................. 55

4.2.1 Thermal Conductivity Ageing Model Verification................................................ 58

4.3 Effective Thermal Conductivity and Service Life ................................................... 64

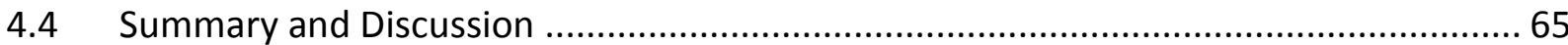

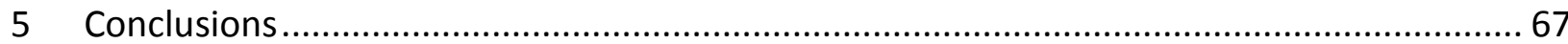

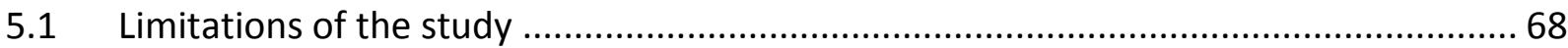

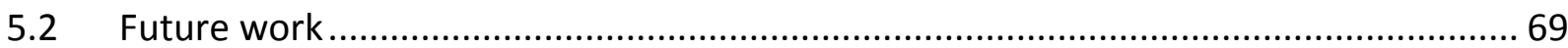

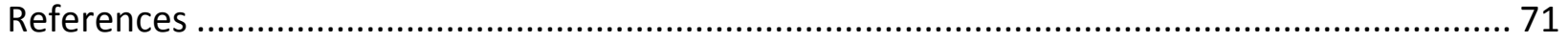




\section{List of Figures}

Figure 1.1: Schematic of general VIP layers.......................................................................... 2

Figure 2.1: Comparison of thermal conductivity of VIPs to other conventional Insulations ........ 6

Figure 2.2: Thermal conductivity characteristics of various core materials .............................. 10

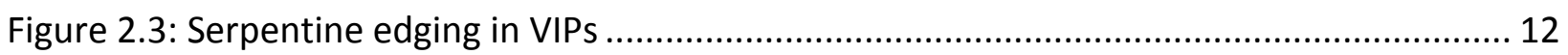

Figure 2.4: Some typical films for vacuum insulation panel .................................................... 12

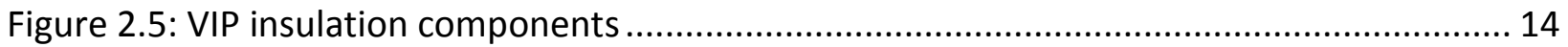

Figure 2.6: A regular VIP panel with a fumed silica core ...................................................... 18

Figure 2.7: Thermal conductivity of a porous material as a function of pore size and gas pressure

Figure 2.8: Radiation thermal conductivity versus temperature .......................................... 23

Figure 2.9: Thermal Conductivity for various density............................................................ 25

Figure 2.10: Outgassing sources from a material in a vacuum........................................... 27

Figure 2.11: Thermal conductivity of different insulation materials as a function of the

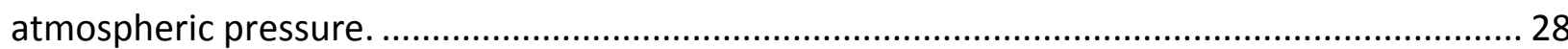

Figure 2.12: Conceptual diagram of the vacuum chamber equipment based on pressure

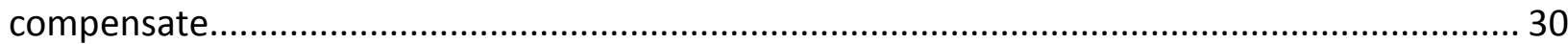

Figure 2.13: Air pressure for various laminate types.......................................................... 32

Figure 3.1: Prepared VIP Specimen Table........................................................................... 41

Figure 3.2: Heat flow meter NETZSCH HFM 436 Lambda apparatus ................................... 43

Figure 3.3: Schematic design of Heat flow meter.................................................................. 44

Figure 3.4: Insulating frame foam for avoiding lateral heat flow ............................................. 44

Figure 3.5: Mechanical convection oven used for elevated temperature ageing ...................... 48

Figure 3.6: Custom Built Environmental Chamber ................................................................ 50

Figure 4.1: Value of thermal conductivity for five types of VIP samples.................................... 53

Figure 4.2: The results of thermal conductivity changes over 25 years of ageing ..................... 56

Figure 4.3: Thermal Conductivity of different samples over 25 years in different temperature. 58

Figure 4.4: Thermal Conductivity trend for Type 1 Versus time (year) .................................... 61

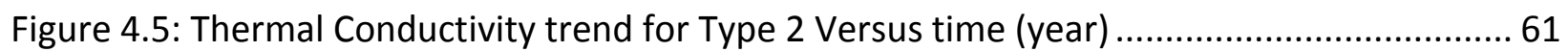

Figure 4.6: Thermal Conductivity trend for Type 3 Versus time (year) ....................................6. 62

Figure 4.7: Thermal Conductivity trend for Type 4 Versus time (year) ...................................... 62

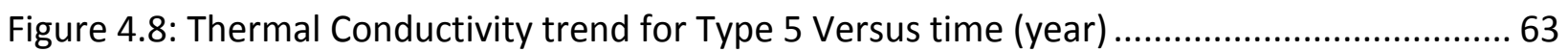




\section{List of Tables}

Table 2.1: List of research and studies related to this work................................................... 15

Table 2.2: Thermal Conductivity of various core materials with different characteristics .......... 19

Table 3.1: Experimentally assessed characteristics of VIPs provided by manufactures ............. 42

Table 3.2: Vaious types of VIP samples characterization ......................................................... 45

Table 3.3: The required stressed period based on acceleration factors( based on Equation 24) 49

Table 4.1: Measured Mean thermal conductivity in various test temperature ........................ 54

Table 4.2: Parameters used for silica core material ................................................................. 59

Table 4.3: Parameters estimated for samples under test ....................................................... 59

Table 4.4: Volume of porosity for various specimens .................................................... 64

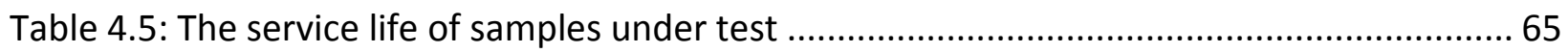




\section{Notations}

\begin{tabular}{|c|c|c|}
\hline Symbol & Definition & Units \\
\hline$\lambda$ & Thermal Conductivity & $\mathrm{W} / \mathrm{mK}$ \\
\hline$\lambda_{\text {eq }}$ & Equivalent thermal conductivity of VIP assembly & $\mathrm{W} / \mathrm{mK}$ \\
\hline$\lambda_{\mathrm{COP}}$ & VIP Center of Panel thermal conductivity & $\mathrm{W} / \mathrm{mK}$ \\
\hline$\lambda_{g 0}$ & the conductivity of air for atmospheric pressure & $\mathrm{W} / \mathrm{mK}$ \\
\hline$\lambda g$ & gas thermal conductivity & $\mathrm{W} / \mathrm{mK}$ \\
\hline$\lambda_{\text {crit }}$ & Critical thermal conductivity & $\mathrm{W} / \mathrm{mK}$ \\
\hline$\lambda e f f$ & Effective thermal conductivity or service life & $\mathrm{W} / \mathrm{mK}$ \\
\hline$\lambda_{r}$ & Radiation conductivity & $\mathrm{W} / \mathrm{mK}$ \\
\hline$\lambda_{w}$ & the water-content thermal conductivity & $\mathrm{W} / \mathrm{mK}$ \\
\hline$\rho$ & density & $\mathrm{kg} / \mathrm{m}^{3}$ \\
\hline y & Linear thermal transmittance due to the thermal bridge & $\mathrm{W} / \mathrm{mK}$ \\
\hline A & Panel area & $\mathrm{m}^{2}$ \\
\hline$\phi$ & The pore size of the pores & $\mathrm{m}$ \\
\hline $\mathrm{P}$ & Panel perimeter & $\mathrm{m}$ \\
\hline d & Layer thickness & $\mathrm{m}$ \\
\hline Q & Heat flow & W \\
\hline$\beta$ & Knudsen equation parameter & - \\
\hline$K_{B}$ & Stefan-Boltzmann constant & $W /\left(m^{2} K^{4}\right)$ \\
\hline Kn & Knudsen number & - \\
\hline$\beta$ & Knudsen equation parameter & - \\
\hline$P$ & Gas pressure & $\mathrm{Pa}$ \\
\hline$E_{a}$ & Activation energy & $\mathrm{J} / \mathrm{mol}$ \\
\hline $\mathrm{T}$ & Temperature & K \\
\hline k & reaction constant factor or reaction speed & $1 / \mathrm{s}$ \\
\hline$A F_{\text {temp }}$ & Acceleration factor under stressed temperature & - \\
\hline $\mathrm{T}_{\mathrm{A}}$ & Accelerated temperature & K \\
\hline
\end{tabular}




\begin{tabular}{|l|l|c|}
\hline Tu & Use condition temperature & $\mathrm{K}$ \\
\hline WVTR & Water Vapour Transmittance Rate & $\mathrm{Kg} / \mathrm{s}$ \\
\hline$G T R$ & Gas Transmittance Rate & $\mathrm{m}^{3} / \mathrm{m}^{2} \mathrm{~s}$ \\
\hline
\end{tabular}




\section{Introduction}

Energy consumption of residential sectors of Canada accounts for $17 \%$ of secondary energy use and this sector emits $13.6 \%$ of total GHG to the environment (Natural Resources Canada 2014). Statistics illustrate that space heating and cooling encompass $60 \%$ of energy consumption and GHG emissions, which was higher than the total greenhouse gases emitted from passenger cars in Canada in 2013. The main GHGs emitted by buildings come from fossil fuel combustion for generating energy in the form of electricity or gas. Energy is consumed by buildings to provide a suitable environmental condition for people who live or work there, so $\mathrm{CO}_{2}$ emissions are produced by heat transfer through the buildings.

Therefore, reducing energy consumption in the building sector globally could be a proper strategy to reach the target of the Kyoto pyramid (Kalnæs et al, 2014). Heat transfer through the envelope of a building has been determined as a significant energy loss source compared to the roof component (Isaia et al., 2015). Besides, using efficient mechanical equipment for making the indoor environment of the building comfortable is another method to reduce energy consumption in buildings. VIPs have a main characteristic, i.e. low thermal conductivity (about five times less than traditional ones), but applying VIPs material is not common and widespread since a reliable testing method, and thermal performance assessment does not exist (Lorenzati et al., 2015). In other words, one of the critical issues of using VIPs panel in buildings is the integrity of the panels, which influences thermal conductivity and consequently the service life of a building.

\subsection{Background}

Usage of vacuum insulation was proposed by James Dewar more than a hundred years ago, when he used glass and metal to make a vacuum flask (Winsniak, 2003). This vacuum flask could control the compression force generated by the pressure difference between flask walls and the outside environment. In this setup, radiation is the only possible way for heat to transfer between the layers of metal and glass, and heat loss resultant of this is a negligible amount at room temperature. Dewar's creation was not manufactured until 1904 when two German glass 
blowers founded the 'Thermos' company and later sold the trademark to three independent companies in United States, Canada, and England in 1907 (Fricke et al., 2008).

VIPs are non-homogeneous insulation materials consisting of a porous core which is laminated by air and vapour, tightened, and then heat-sealed, as shown in Figure 1.1 (Kalnæs and Jelle 2014). VIP can offer a solution to reduce building energy demand (Wegger et al., 2011). VIP usage also provides a solution where not much space is available for insulation but high thermal resistance is desired (Karami et al., 2015).

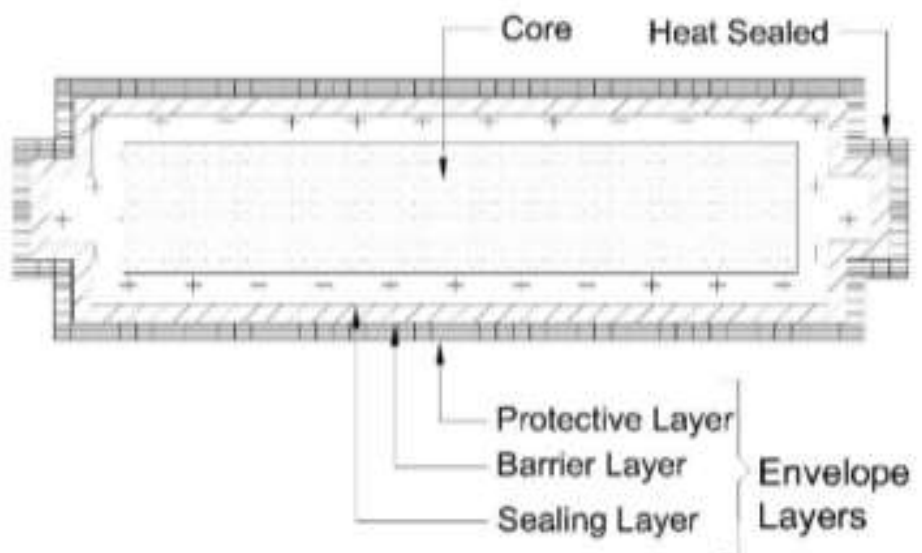

Figure 1.1: Schematic of general VIP layers (S. Kalnæs and Jelle 2014)

Previously, a multitude of studies and research projects have been done regarding VIPs (Isaia et al., 2015). More recently, several studies were conducted to introduce VIPs to the building market. The research was initially started in Germany and Switzerland, and now many studies are being led by International Energy Agency (IEA), Energy Conservation in Buildings and Community Systems (ECBS), and National Research Council (NRC) (Wegger et al., 2011). Since the thermal property such as thermal conductivity is significant to evaluate the service life, IEA and NRC studies have been performed to assess the thermal properties of VIPs over time. 


\subsection{Problem Definition}

At the current standard of Ontario Building Codes (OBC) set for conventional insulating materials, building envelopes cannot achieve the necessary RSI-value of $4.9 \mathrm{~m}^{2} . \mathrm{K} / \mathrm{W}\left(27.7\right.$ (hr. $\left.\left.{ }^{\circ} \mathrm{F} \cdot \mathrm{ft} 2\right) / \mathrm{BTU}\right)$ for cold climate like Canada without significantly increasing envelope thickness. The overall objective of this research is to investigate the thermal performance modelling over time for VIPS using experimental results. While VIPs have high thermally resistive properties, before VIPs can be widely integrated into buildings to reduce home energy consumption and the usable space in a building, better modelling methods and creative implementations are required because new VIPs produced by manufactures. Since fragile and thermally non-homogeneous materials have not been conventionally used within building envelopes, it is essential to develop an effective technique to evaluate the long-term thermal performance modelling of VIPs. This thesis addresses the validation and development of the service life of VIPs to encourage the use of said high-performance insulation in the building market.

\subsection{Research Objectives and Questions}

The main objective of this study is to study, characterize and experimentally evaluate the thermal conductivity of VIP over their service life.

- What properties of VIPs and empirically investigate the performance of VIPs over the life cycle of buildings to verify the theoretical service life prediction model? (Different parameters such as temperature, moisture, ageing, and production process should be examined to analyze the effective VIPs performance over time).

- What is the thermal performance of VIPs insulation under environmental weather such as temperature and moisture?

- What material characteristic properties can be measured in terms of their ageing?

- How accurate is the ageing model prediction for VIP?

- How does the hygro-thermal behaviour of VIP change over the time?

- How accurate is the theoretical thermal conductivity model for other types of core materials? 


\subsection{Contributions of Research}

The outcomes of this work result in:

1. a value of thermal resistance/ conductivity at the centre for each of seven VIP samples;

2. a value of moisture content VIP sample;

3. thermal performance of VIP samples with ageing process;

4. Investigation and validation of the existing service life model for VIPs or non-homogenous properties.

\subsection{Organization of the thesis}

The thesis material is structured in seven chapters as the following:

Chapter 1 provides a background on vacuum insulation panels. It also outlines the scope and objectives of the thesis.

Chapter 2 presents previous research relevant to this study.

Chapter 3 presents the theoretical thermal conductivity modelling methodologies developed to evaluate the parameters which affect the performance of VIPs over time.

Chapter 4 describes the experimental tests and methods used to evaluate the thermal conductivity of VIPs at steady-state conditions.

Chapter 5 presents the results of the experimental evaluation of VIPs individually.

Chapter 6 provides a discussion and analysis of the experimental results and validation of the current theoretical thermal conductivity model and reports the accuracy of the model.

Chapter 7 presents conclusions based on the work described in the previous sections and makes recommendations for future areas of research. 


\section{Literature Review}

The application of VIPs in the building sector originated in the early 1990s (Johansson et al., 2015). Since VIPs provide a low thermal conductivity, they not only have the potential to be utilized in the building sector, but also could be used for appliances such as refrigerators. This low thermal conductivity material synchronizes with the sustainability approach which all markets and governments are encouraged to pursue and uphold. However, the usage of VIPs in buildings is controversial due to the existence of thermal bridges between VIP panels, VIP service life, and fragility (Tenpierik et al., 2009). Only 10\% of VIPs produced were used as building insulation in 2014, while the primary usage of VIPs was in the refrigeration and transportation industry (Alam et al., 2017). Currently, VIPs are employed in a few construction setups such as heritage and dense city center buildings which usually have limited indoor space, attributable to the high product and installation cost (Kucukpinar et al., 2015).

A comparison of the thermal conductivity of VIPs into the conventional insulations materials is demonstrated in Figure 2.1 to illustrate the differences between the thermal conductivity of VIPS and other insulation materials (Aegerter et al., 2011). Figure 2.1 shows that the vacuum insulation panel would be an alternative to the conventional thermal insulation since it encompasses higher thermal conductivity and requires less space. 


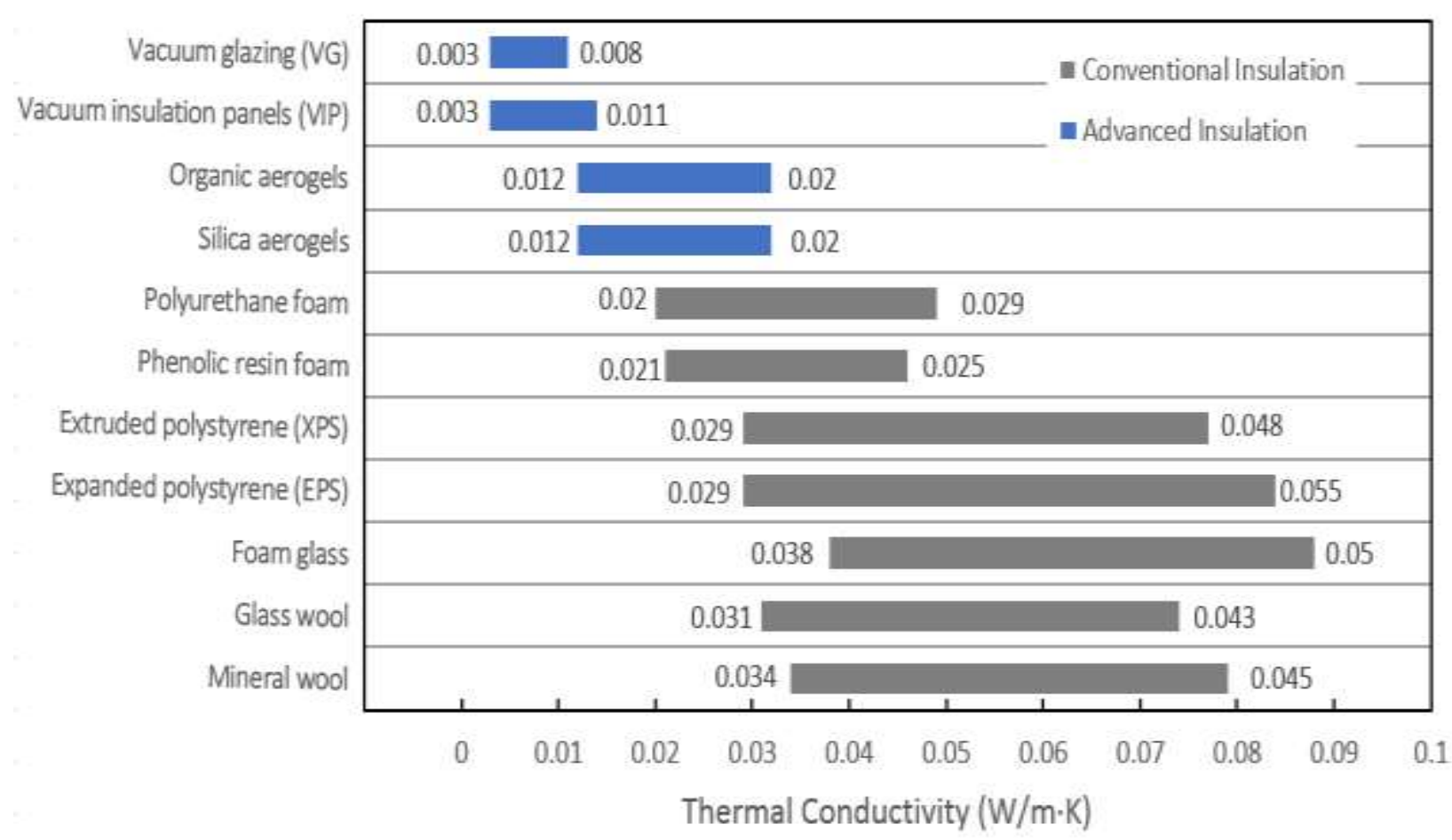

Figure 2.1: Comparison of thermal conductivity of VIPs to other conventional Insulations

(Aegerter, Michel et al. 2011)(Ruben Baetens et al. 2010)

Figure 2.1 shows the thermal conductivity for various insulations used in buildings and highlights the advantages of VIPs compared to batt insulation installed between studs. The value of VIPs thermal conductivity is even less than that of the still air under the same condition $(\sim 0.025$ $\mathrm{W} / \mathrm{m} \cdot \mathrm{K})$; therefore, VIPs are among the best-known thermal insulating materials (Aegerter et al., 2011; Baetens et al., 2010).

In 1998, ZAE Bayern reported the first application of VIP in a building to insulate a test façade (Fricke et al. 2008). Also, other research showed that VIPs provide highly insulated new construction walls and roofs or offer high insulation for retrofitting older buildings with space limitation (Tenpierik et al., 2009; Johansson et al., 2015; Karami et al., 2015). As a result, VIPs have been introduced as a super insulation for sustainable buildings (Ruben Baetens et al., 2010; Sultan Sanat Alotaibi, 2014), but these insulations are in the early market stages because of the lack of data on VIP thermal performance over building lifetime in which they were 
implemented.(Kalnæs et al., 2014). Some in-situ studies have been conducted to assess the longterm performance of VIPs in building envelopes (Simmler et al., 2005).

In 2005, Simmler and Brunner described the ageing mechanisms for different temperatures and relative humidities and concluded that, although new multi-layer metallized polymer films have the minimum thermal bridge, still there is a risk of moisture permeance through the barriers. Another in-situ study investigated VIPs sandwiched within Expanded Polystyrene (EPS) insulation as a compound material for concrete wall and achieved a significant improvement of thermal performance for the wall (Nussbaumer, Wakili, and Tanner 2006). In 2015, Johnsson et al. performed a field study on VIPs long-term performance evaluation of the wall assembly by measuring and monitoring the relative humidity and temperature over five years. This study showed no evidence of degradation of VIPs in the wall during the mentioned time. Also, no condensation was observed (Johansson et al. 2015).

Moreover, Saber et al. (2015) investigated R-value and consequent heat transfers. Finally, the National Research Council Canada (NRC) studied the use of VIPs in a wood-frame wall with three different types of wall assemblies. The results of the model calculations showed the superior performance of the VIP composite by modeling the yearly heat loss through the wall system. A numerical model was applied in this study named "hygIRC-C," which usually is used for assessing the thermal and hygrothermal performance of wall and roofing systems. This mathematical model could simulate nonlinear two dimensional (2D) or three dimensional (3D), heat, air and moisture equations. This model could predict the effective thermal conductivity using this mathematical model. It is been resulted that the wall with XPS as retrofit has the lowest R-value and the wall with VIP as the retrofit has the highest R-value. Therefore, VIPs have a significant thermal performance which is conducted saving energy consumption for heating and cooling of the building.

In 2018, Pons and his team reported mild ageing of 10 years artificial evaluation of VIPs in the laboratory and indicated that moisture content inside VIPs was equal to the water sorption in $44 \%$ relative humidity for silica core types (Pons et al., 2018). 
Another investigation has been done to observe the performance of VIPs together with Extruded Polystyrene (XPS) in a retrofitted wall assembly in the Yukon over five years (MacLean et al., 2017). This study showed that the performance of VIPs in subarctic climate was not affected by ageing.

Other research was conducted to evaluate the energy saving potential of VIPs and consequently, economic analysis on domestic buildings. The result showed a $25 \%$ reduction in energy consumption for 2 mock-up rooms in Poland and Spain (Cho et al., 2014). The other study resulted in an energy consumption reduction of $0.62 \%$ for a single office building by using ECOTECT software, which has VIPs in the roof assembly and in external wall. Also, $0.79 \%$ reduction of energy consumption reported for a multi-story office building in comparison to EPS as one of the controversial insulation (Abdul Mujeebu et al., 2016).

Finally, current developments in construction materials have resulted in the generation of new building insulation materials which provide lower thermal conductivity rates than the traditional ones.

Many streams of research have been carried out to show the thermal resistance of VIPs; for example, in 2010, Baetens organized a complete assessment on VIP requirements for building applications and highlighted thermal-bridges, and depreciation with time. Similarly, it was stated that the lower thermal conductivity of VIPs came from reducing gas conduction and convention, which caused heat transfer through the core material as the gas evacuated from the porous material. Also, the metal foil or metalized polymer envelopes with in VIPs prevent gas and water vapour transmission into the VIP's core. Therefore, considering the structure of VIPs is necessary to get more familiar to this super insulation ( Baetens et al. 2010).

\subsection{VIP Structure}

A VIP consists of a porous material core which is enveloped by air and vapour barrier. This barrier is usually a metallic foil that all the internal air is evacuated and sealed (Molleti et al., 2018). The open porous core material is usually used to allow all the air to leave and create a vacuum (Kalnæs 
et al., 2014). The pressure for the core material to be evacuated is usually 0.2 to 3 mbar, which results in thermal conductivity in the range of 0.002-0.004 $\mathrm{W} /(\mathrm{mK})$ depending on different core materials (Berge et al., 2012). Previous studies have been done on VIP with Fumed Silica (FS) because it has excellent thermos-physical properties (Kucukpinar et al., 2015). However, FS is expensive, and some other alternative materials have been applied as the core of VIPs. Different types of VIPs exist and will be explained in the following section.

\subsubsection{Core}

It is assumed that $45 \%$ of the total VIP cost is related to its core (Abdul Mujeebu et al. 2016). The essential characteristics of core material include low thermal conductivity, bearing atmospheric pressure, and encompassing the high porosity (Wegger et al. 2011). There are various materials which are used as the core of VIP such as polyurethane (PU), expanded perlite (EP), Extruded Polystyrene (XPS), glass fibre (GF) and different forms of silica as shown in Figure 2.2. As it can be seen glassfiber core has the lowest thermal conductivity at 0.1 mbar which is usually is the initial thermal conductivity of the panel. 


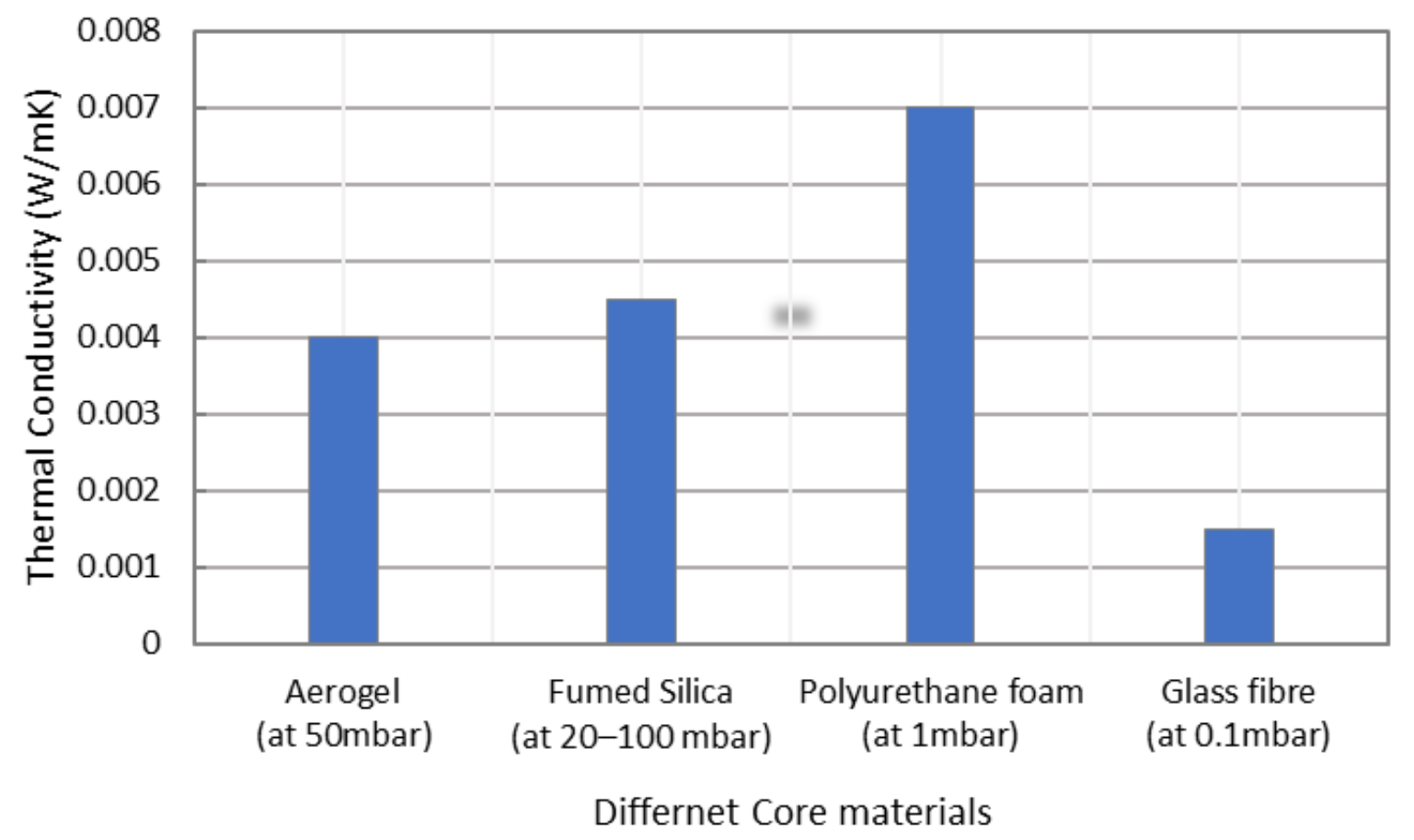

Figure 2.2: Thermal conductivity characteristics of various core materials

The smaller the porous size of the core material is, the lower the thermal conductivity is (Peng et al., 2016). However, the core material has to be an open cell to evacuated air entirely to eliminate convection and conduction through it. The core material also needs to have a particular geometric skeleton to maintain small contact points to minimize the conductive heat transfer (Alotaibi, 2014).

Moreover, the core material has to support the lowest radiation transfer between the panels, and the core has to be resistant under the internal pressure of the panel which is in the range of 0.2- 3 mbar (Thorsell, 2012). The core materials used in the 1990s were precipitated silica, fiber 
or diatomite ${ }^{1}$ (Berge et al., 2012). The impact of the core material types on thermal conductivity has been studied, and it is showed that the fiber insulation has lower initial thermal conductivity compared the powder and foam (Kwon et al., 2009).

Core materials which maintain the vacuum well, such as Nano Insulation Material (NIM) and Vacuum Insulation Material (VIM), could help in the development of VIPs. These materials do not need a vacuum or envelope to maintain the vacuum, and they are robust (Kalnæs et al., 2014; Baetens et al., 2010). In 2013, Simen \& Jelle presented that VIPs could be a reliable option for thermal insulation if the moisture and air diffusion into the core reach to zero, while it was still considered as inflexible insulation (Kalnæs et al., 2014).

\subsubsection{Envelope}

To preserve the vacuum in VIP, using an envelope is essential. Otherwise, water vapour and air can easily penetrate the core. VIP is evacuated efficiently under a pressure of about 10 mbar (Mukhopadhyaya \& et al., 2017). This amount of pressure is about $100 \mathrm{kPa}$ less than the actual ambient pressure (in Toronto); therefore, this low-pressure condition can provide a high thermal resistance per unit thickness and consequently reduces energy consumption.

Various materials could be employed to act as an envelope, such as Aluminum and Steel (Berge et al., 2012). Although metals used in the envelope provide the best barrier against air and vapour, they have a high thermal conductivity (Wegger et al., 2011).

The envelope consists of a sealing layer, a barrier layer, and a protective layer (Ruben Baetens et al. 2010). The sealing layer is the inner layer which seals the core material. Usually, this layer consists of a low or high-density polyethylene. The protective layer is heat-sealed and guards the

\footnotetext{
${ }^{1}$ Sedimentary rock which is composed of 80 to $90 \%$ silica, 2 to $4 \%$ alumina and 0.5 to $2 \%$ iron oxide. The thermal conductivity is $0.06 \mathrm{~W} /(\mathrm{mK})$ and the density is $400 \mathrm{~kg} / \mathrm{m}^{3}$.
} 
panel against the environmental stresses and damages, so this protective layer should be able to tolerate handling during installation or transportation without tearing. VIPs envelope layers were made of films which are commonly made of plastics and metal foils with 100-200 nm thickness (Baetens et al., 2010; Thorsell, 2006) conducted a study to improve the envelope by serpentine edging to diminish edge loss, shown in Figure 2.3.

The barrier layer is in the middle, and it protects against water and air transmission through the envelope, as demonstrated in Figure 2.4 (Kalnæs et al., 2014). As the envelope deteriorates, the VIP performance changes and thermal conductivity increases (Wakili et al., 2011). The envelope deterioration is a limitation of VIP insulation and makes VIPs fragile thermal insulation in comparison to conventional ones (Wegger et al., 2011). However, the main factors effect on heat sealing process are previously studied (Marouani 2012).

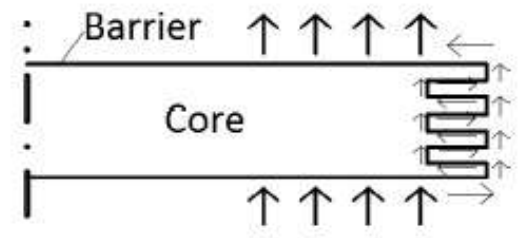

Figure 2.3: Serpentine edging in VIPs

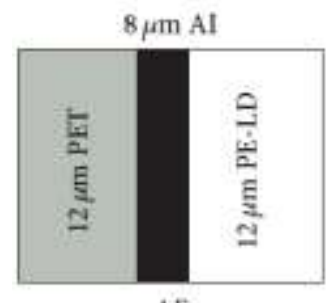

AF

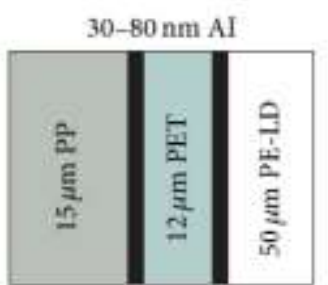

MF1

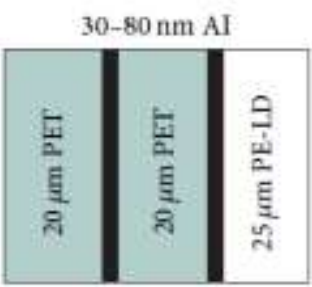

MF2

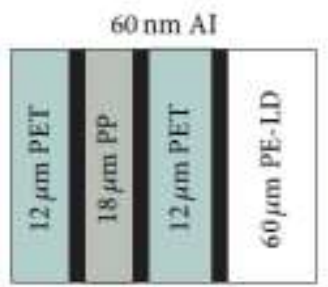

MF3

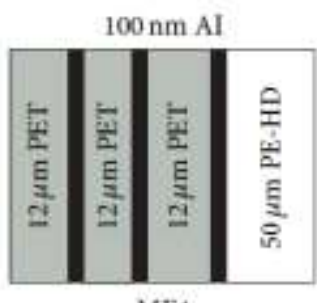

MF4

Figure 2.4: Some typical films for vacuum insulation panel (Ghazi Wakili et al. 2011)

Cross-sections in Figure 2.4 showed four types of multilayer films which are common in the market. The employed films in these applications include 1-metal foils (AF), 2- metalized films (MFs), and 3-polymer films. These layers can be described as follows: 
- $\mathrm{AF}$ : The thickness of the aluminum in the center is up to 5-10 $\mu \mathrm{m}$ and this layer is laminated by a polyethylene terephthalate (PET) as a protective layer in outer and polyethylene in inner side of the layer (Wegger et al., 2011; Kalnæs et al., 2014).

- MFs: There are three barrier layers of aluminum metalized PET and polyethylene (PE) sheets on the inner side with an aluminum coat of $20-100 \mathrm{~nm}$ thickness. This is a standard solution to make VIPs applicable in buildings because multiple aluminum layers provide a better impermeable layer in comparison to one-layer aluminum. However, MF type has low thickness which is an issue during the time. This low thickness results in higher gas and moisture permeance compared to the AF laminates (Simmler et al., 2005; Sultan Sanat Alotaibi 2014). The performance of each layer will be discussed in section 2.5.3.

Alam determined in his research that PET multiple sheets coated with $\mathrm{SiO}_{\mathrm{x}}$ and $\mathrm{SiN}_{\mathrm{x}}$ would be an improved alternative for the VIP envelope since the research group work on developing the thermal and barrier performance of VIP envelope. Finally, this type of casing would provide over fifty years of VIP service life (Alam et al., 2011).

In addition, a research group of building physics in Belgium reprted on particular type of VIPs with MF2 envelope to determine their Sd- value of the envelope in four different climates for periods up to 4 years and the results showed that the hygro-thermal loading has a small effect on the stability of the envelope (Meersman et al., 2015). In 2018, Batard et al. made a prediction model of long- term hygro-thermal behaviour of VIPs and the study was carried out in a constant temperature and relative humidity and found that the result of VIPs thermal conductivity in real condition is not a linear extension of its short-term behaviour (Batard et al., 2018).

\subsubsection{Getter}

For specific core materials such as glass fibre which has a large pore size, a high amount of vacuuming is required. The getter is applied to remove water and then gases from the panel under this condition. It helps to increase the service life since it prevents an increase in the internal pressure (Molleti et al. 2018). 


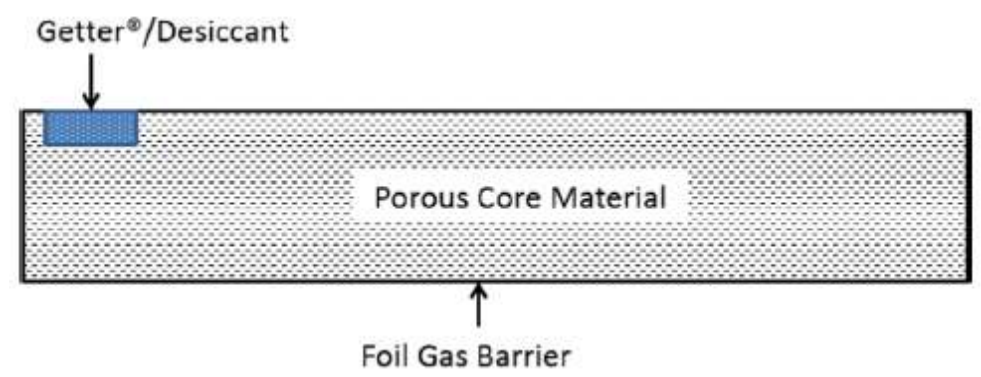

Figure 2.5: VIP insulation components(Molleti et al. 2018)

\subsection{Summary}

Table 2.1 lists the work and research conducted to study the ageing and service life of the VIPS that build a foundation of this thesis. Here using the models developed in this research list, experimental results are collected and verified for some innovative VIP products as a part of an assembly or individual panel. These products have advanced envelope material compared to the specimens used in these studies mentioned in literature review. Also, some of the tested samples consist of novel core composites which were not studied in previous research listed in the following Table 2.1. Here, the investigation of the sample performance and the validation of the theoretical models are conducted over a broader range of time using accelerated ageing methods, which will be discussed in Section 3.1.3, to obtain a better understanding of these samples' performance. As discussed earlier, unlike most of the researches performed before, a more accurate heat flow meter machine. 
Table 2.1: List of research and studies related to this work

\begin{tabular}{|c|c|c|c|c|c|}
\hline Study & Core type & Test Type & Test Period & Parameters of study results & Results \\
\hline $\begin{array}{l}\text { Baldinelli } \\
\text { et al., } \\
2019\end{array}$ & $\begin{array}{l}\text { aerogel, VIP, } \\
\text { polystyrene } \\
\text { and birch } \\
\text { wood fibre }\end{array}$ & $\begin{array}{l}\text { laboratory } \\
\text { work and } \\
\text { data } \\
\text { analysis }\end{array}$ & & $\begin{array}{l}\text { measure the thermal } \\
\text { conductivity }\end{array}$ & $\begin{array}{l}\text { The reproducibility is satisfactory as well, } \\
\text { except for vacuum insulation panels }\end{array}$ \\
\hline $\begin{array}{l}\text { Batard et } \\
\text { al., } 2018\end{array}$ & $\begin{array}{l}\text { FS with } \\
\text { various } \\
\text { porous }\end{array}$ & $\begin{array}{l}\text { laboratory } \\
\text { work }\end{array}$ & $\begin{array}{l}25 \text { years at } 23 \\
{ }^{\circ} \mathrm{C} \text { for } 80 \% \mathrm{RH}\end{array}$ & $\begin{array}{l}\text { - long-term hygro-thermal } \\
\text { behavior } \\
\text { - Comparison data of Linear } \\
\text { model and dynamic one }\end{array}$ & $\begin{array}{l}\text { - Showed similar results for linear and } \\
\text { dynamic models } \\
\text { - Increase of thermal conductivity over } \\
\text { time }\end{array}$ \\
\hline $\begin{array}{l}\text { Pons et } \\
\text { al.,2018 }\end{array}$ & FS & $\begin{array}{l}\text { laboratory } \\
\text { work }\end{array}$ & $\begin{array}{l}10 \text { years } \\
\text { At } 23^{\circ} \mathrm{C} \text { at } 33 \\
\text { and } 80 \% \mathrm{RH}\end{array}$ & $\begin{array}{l}\text { Mild artificial ageing of } 6 \text { VIPs } \\
\text { samples }\end{array}$ & $\begin{array}{l}\text { - FS VIPs will be partially aged at } 80 \% \mathrm{RH} \\
\text { - The surface hydrophilicity of core aged } \\
\text { VIPs is } 2 \text { times higher than the new one }\end{array}$ \\
\hline $\begin{array}{l}\text { Alam et } \\
\text { al., } 2017\end{array}$ & $\mathrm{FS}$ and $\mathrm{FG}$ & $\begin{array}{l}\text { Non- } \\
\text { domestic } \\
\text { buildings }\end{array}$ & & $\begin{array}{l}\text { Comparison of heating energy } \\
\text { in building with VIPs to } \\
\text { conventional insulation (EPS) }\end{array}$ & $\begin{array}{l}\text { - VIP insulation reduced the space heating } \\
\text { energy and carbon dioxide emissions } \\
\text { - FS VIPs had the shortest payback period }\end{array}$ \\
\hline $\begin{array}{l}\text { MacLean } \\
\text { et al., } \\
2017\end{array}$ & VIP & Pilot wall & & $\begin{array}{l}\text { - long-term thermal } \\
\text { performance of VIPs } \\
\text { Best ways to install VIPs }\end{array}$ & $\begin{array}{l}\text { - Confirming the good performance of the } \\
\text { VIPs compared to XPS }\end{array}$ \\
\hline $\begin{array}{l}\text { Saber et } \\
\text { al., } 2015\end{array}$ & VIP & In-situ test & A year & $\begin{array}{l}\text { - Effects of thickness and } \\
\text { thermal conductivity on } \\
\text { effective thermal resistance }\end{array}$ & $\begin{array}{l}\text { - The thermal resistance of the wall with } \\
\text { VIP is higher than the wall with failed VIP } \\
\text { or XPS }\end{array}$ \\
\hline
\end{tabular}




\begin{tabular}{|c|c|c|c|c|c|}
\hline Study & Core type & Test Type & Test Period & Parameters of study results & Results \\
\hline $\begin{array}{l}\text { Kucukpin } \\
\text { ar et al., } \\
2015\end{array}$ & $\begin{array}{l}\text { Organic } \\
\text { nano-porous } \\
\text { foam }\end{array}$ & $\begin{array}{l}\text { Mockup } \\
\text { test }\end{array}$ & $\begin{array}{l}\text { More than a } \\
\text { year }\end{array}$ & $\begin{array}{l}\text { Monitoring heat flow through } \\
\text { the panels over months }\end{array}$ & $\begin{array}{l}\text { - Nanoporous foam VIPs are more effective } \\
\text { than conventional polyurethane } \\
\text { insulation }\end{array}$ \\
\hline $\begin{array}{l}\text { Wegger } \\
\text { et al., } \\
2011\end{array}$ & $\begin{array}{l}\text { Va-q- } \\
\text { VIPB2009 }\end{array}$ & $\begin{array}{l}\text { laboratory } \\
\text { work }\end{array}$ & 25 years & $\begin{array}{l}\text { Evaluating the accelerated } \\
\text { ageing of VIPs for various } \\
\text { procedures }\end{array}$ & $\begin{array}{l}\text { - Acceptable agreement with that of the } \\
\text { accompanying theoretical analysis } \\
\text { - The CUAP experiment gave the highest } \\
\text { significant increase in thermal } \\
\text { conductivity }\end{array}$ \\
\hline $\begin{array}{l}\text { Alam, } \\
\text { Singh, } \\
2011\end{array}$ & $\begin{array}{l}\text { FG, foam, } \\
\text { Powder and } \\
\text { fibre/powder } \\
\text { composites }\end{array}$ & $\begin{array}{l}\text { Review of } \\
\text { various } \\
\text { core and } \\
\text { envelop }\end{array}$ & & $\begin{array}{l}\text { Computer models } \\
\text { experimentally validated for } \\
\text { new materials }\end{array}$ & $\begin{array}{l}\text { Validation of new materials, concepts and } \\
\text { computer models under realistic climatic } \\
\text { conditions is required }\end{array}$ \\
\hline $\begin{array}{l}\text { Simmler } \\
\text { et al., } \\
2005\end{array}$ & VIP & $\begin{array}{l}\text { laboratory } \\
\text { work }\end{array}$ & $\begin{array}{l}5.5 \mathrm{~d} \text { at } 23^{\circ} \mathrm{C} \\
/ 80 \% \mathrm{RH}, 9 \mathrm{~h} \text { at } \\
30{ }^{\circ} \mathrm{C} / 90 \% \mathrm{RH}, \\
65 \mathrm{~h} \text { at } 65^{\circ} \mathrm{C} / \\
75 \% \mathrm{RH}, 152 \mathrm{~h} \\
\text { at } 80^{\circ} \mathrm{C} / 80 \% \\
\mathrm{RH}\end{array}$ & $\begin{array}{l}\text { - Ageing Mechanism } \\
\text { - Experimental results for } \\
\text { different temperature and } \\
\text { humidity. }\end{array}$ & $\begin{array}{l}\text { - The mean pressure increase rate } \mathrm{Pa} \text { is } \\
\text { about } 2.1 \text { mbar per year, } \\
\text { - the initial moisture accumulation rate is } \\
0.18 \text { mass\% per year }\end{array}$ \\
\hline
\end{tabular}




\subsection{Mathematical Model for VIP Thermal Conductivity and long-term performance}

It is necessary to consider three essential characteristics of VIPs to be able to evaluate the physical properties of VIPs. The first feature is VIPs thermal conductivity, which is the most critical variable in being able to determine the relationship between insulation and heat flow. It shows the amount of heat transferred through the material per unit thickness and unit temperature difference. The second feature is the porosity of the core material, and the third feature, is the size of pores; illustrated in Table 2.2. However, three variables mentioned before impact the performance of VIPs, which will be discussed in detail in this research. The service life of VIPs is sturdily related to the thermal performance of the core material, and it is not a constant parameter. Moreover, the structural behaviour of VIPs needs to be evaluate. It is essential to consider VIPs as a composite system.

\subsubsection{Thermal Conductivity}

Thermal conductivity is the primary property of building insulation materials defined as material thickness divided by thermal resistance. Several internal and external factors including pressure, temperature and moisture influence the thermal conductivity of VIPs. Moreover, since VIPs are not homogenous material, they should be considered as two different segments, i.e. center of the panel and the barrier (Wegger et al. 2011). Therefore, as can be seen in Table 2.2, several parameters affect the thermal conductivity of VIPs.

VIP is a heterogeneous material as it shows in Figure 2.6, and evaluating its thermal conductivity is different from other existing insulating material, which is often homogeneous. 


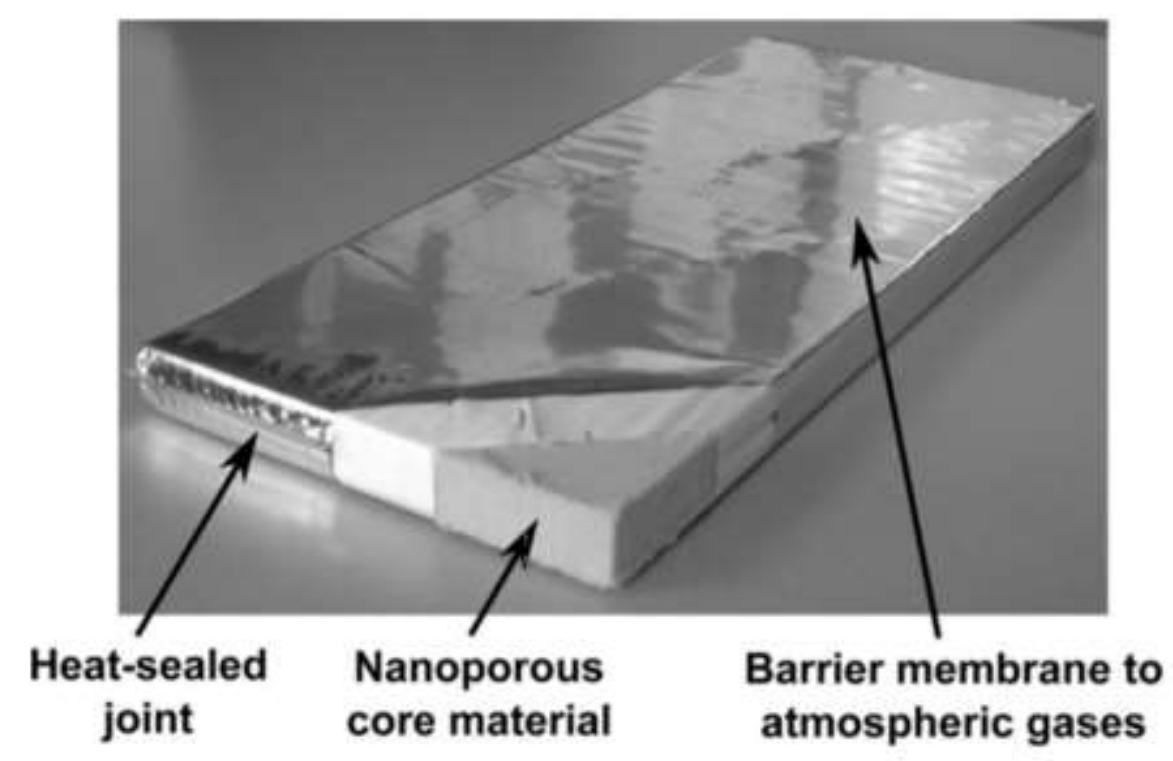

Figure 2.6: A regular VIP panel with a fumed silica core (Bouquerel et al., 2011)

Most of VIPs products consist of different mediums which are interconnected to each other.

Therefore, the overall conductivity of VIPs depends on each specific material (Kim 2017). Due to the thermal bridge at the edges, the effective thermal conductivity is higher than the thermal conductivity in the central area.

In Table 2.2, it is shown that the total thermal conductivity of VIPs is affected by absorbed water in the core material, especially for silica (Morel et al., 2007). As it can be seen, the initial total thermal conductivity of fiberglass core is low compared to the two other core materials. Since fiberglass core porous size is big, the air could be evacuated efficiently. However, because of the hydrophilicity characteristics of fiberglass, the moisture can be absorbed over the time and the value of thermal conductivity increases. Moreover, because of the small porous size of aerogel and fumed silica, the amount of moisture which can be absorbed is less than the fiberglass one. Other areas such as permeation rates for different envelope types of VIP in different temperature and moisture conditions have been evaluated, and it was found that the durability of the envelope is one of the essential factors affecting the service life of VIPs (Simmler et al., 2005). 
Table 2.2: Thermal Conductivity of various core materials with different characteristics (Duong and Nguyen 2016), (M. Alam, H. Singh, 2011)

\begin{tabular}{|c|c|c|c|}
\hline Core Type & $\begin{array}{l}\text { Aerogels } \\
\text { (Duong et al., } \\
2016 \text { ) }\end{array}$ & $\begin{array}{l}\text { Aerogels } \\
\text { (Duong et al., } \\
2016 \text { ) }\end{array}$ & $\begin{array}{l}\text { Glass fibre } \\
\text { Alam et al., } \\
\text { 2011) }\end{array}$ \\
\hline Pore size & 30 to $100 \mathrm{~nm}$ & $20 \mathrm{~nm}$ & 1 to $12 \mu \mathrm{m}$ \\
\hline Density $\left(\mathrm{kg} / \mathrm{m}^{3}\right)$ & 200 & 3 to 350 & 250 \\
\hline Initial gas pressure (mbar) & $20-100$ & 50 & 0.1 \\
\hline $\begin{array}{l}\text { Initial thermal conductivity at the core } \\
(\mathrm{W} /(\mathrm{m} . \mathrm{K}))\end{array}$ & 0.004 & 0.004 & 0.0015 \\
\hline Thermal Conductivity (W/ (m. K)) & $0.003-0.006$ & $0.004-0.0135$ & 0.0007 \\
\hline
\end{tabular}

In Baldinelli et al. (2019), the authors study the thermal conductivity measurement methods of innovative materials such as aerogel, VIPs, polystyrene and birch wood fibre boards in different universities laboratories. Results show that the most accurate instrument for measuring the thermal conductivity of VIPs is Heat Flow Metter method because of the results show a very small standard variation which will be explained in section 3.

\subsection{Mathematical Model for Thermal Conductivity of VIPs}

Thermal conductivity of fibrous and powdery materials as a function of time is given by Equation 1 which depends on gas pressure, external load, and temperature (Alotaibi et al., 2014).

$$
\lambda_{t o t}=\lambda_{s}+\lambda_{g}+\lambda_{r}+\lambda_{w v}+\lambda_{w}+\lambda_{c o p}
$$

In this equation, $\lambda_{s}$ represents solid conduction through the material $\left(\frac{W}{m K}\right), \lambda_{g}$ shows gas conduction through the porous of material $\left(\frac{W}{m K}\right), \lambda_{r}$ presents radiation heat transfer between inner pore $\left(\frac{W}{m K}\right), \lambda_{w v}$ is the permeation of air and moisture through pores $\left(\frac{W}{m K}\right), \lambda_{w}$ is the thermal 
conduction over time based on adsorbed water within the core material, and $\lambda_{\text {cop }}$ is the thermal conductivity accounting for second order effects between the mentioned thermal conductivities. It is worth noting that in this equation, for simplicity, it is assumed that the gas pressure and water content independently contribute to thermal conductivity. The initial (or evacuated) thermal conductivity of the evacuated panel is also given based on the thermal conductivity of radiation and solid as:

$$
\lambda_{\text {init }}=\lambda_{s}+\lambda_{r}
$$

In this thesis since $\lambda_{w v}$ and $\lambda_{\text {cop }}$ components are negligible because of the low value compared to other terms over the desired experimentation duration; a simplified form of Equation 1 is considered (Wegger et al. 2010). Thus, the total thermal conductivity model can be given by:

$$
\lambda_{\text {tot }}=\lambda_{\text {init }}+\lambda_{g}+\lambda_{w}
$$

Equation 3

\subsubsection{Solid Thermal Conductivity}

Solid thermal conductivity $\left(\lambda_{s}\right)$ is a function of the core material density $(\rho)\left(\mathrm{kg} / \mathrm{m}^{3}\right)$ and external pressure defined as:

$$
\lambda_{s}=\rho^{\alpha}
$$

Equation 4

where $\alpha$ is a constant for foam material; for foams, it is approximately 1 , for fumed silica and aerogels is around 1.5 - 2 (Fricke et al., 2006).

\subsubsection{Gas Thermal Conductivity}

Gas conductivity $\left(\lambda_{g}\right)$ is calculated based on Knudsen number as Equation 5 and is a function of mean free path of gas and the ratio of the path to the pore size of the core material as:

$$
\lambda_{g}=\frac{\lambda_{g_{0}}}{1+2 \beta K n}
$$

Equation 5 
Where $\lambda_{g o}$ is the conductivity of air for atmospheric pressure $(\mathrm{W} / \mathrm{m} . \mathrm{K}), \beta=1.6$ for air and $K n$ is Knudsen effect and is defined by Equation 6 (ratio of the molecular mean free path and pore width $\Phi)$.

$$
K n=\frac{1}{\phi}=\frac{k_{B} T}{\sqrt{2 \phi d^{2} P \Phi}}
$$

Equation 6

Where $\mathrm{k}_{\mathrm{B}}$ is the Boltzmann constant which equals to $1.38 \times 10^{-23} \mathrm{JK}^{-1}, T$ is temperature (K), $\Phi$ is the pore size of the pores $(\mathrm{m})$, and $P$ is gas pressure $(\mathrm{Pa}), \mathrm{d}$ is the diameter of the gas molecule $(\mathrm{m})$ (Caps et al., 2008; Kwon et al., 2009; Baetens et al., 2010; Wegger et al., 2011; Alotaibi et al., 2014;Peng et al., 2016). Equation 6 is used to evaluate the Knudsen number for VIPs at $25^{\circ} \mathrm{C}$.

$$
\lambda_{g}=\frac{\lambda_{0}}{1+\frac{0.032}{P \Phi}}
$$

Equation 7

Where $\lambda_{0}$ is initial thermal conductivity. Figure 2.7 depicts gas thermal conductivity as a function of gas pressure and pore diameters. As can be seen from this figure, fumed silica with lower pore diameter is expected to provide better performance compared to Powder silica using Equation 7. Therefore, to reduce the gas heat transfer (close to zero), a shallow pore dimension and low pressure are required. The combination of these two items will lead to a decrease in the gashouse heat transfer. 


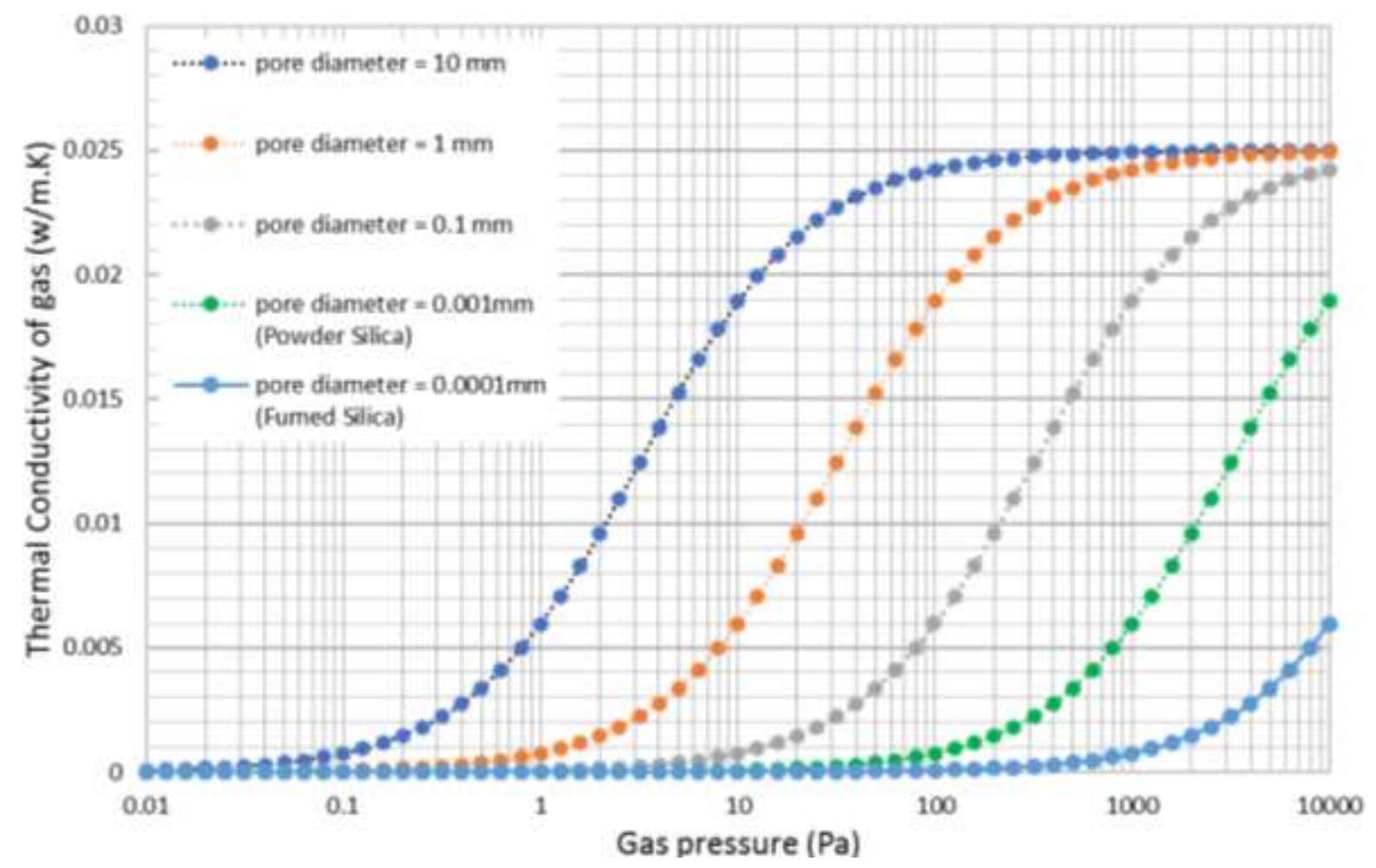

Figure 2.7: Thermal conductivity of a porous material as a function of pore size and gas pressure

\subsubsection{Radiation Thermal Conductivity}

Radiation conductivity term $\left(\lambda_{r}\right)$ in Equation 8 is calculated by applying the following equation (Rosseland approximation) for VIP (Fricke et al. 2006):

$$
\lambda_{r}=\frac{16 n^{2} k_{B} T^{3}}{3 K}=\frac{16 n^{2} k_{B} T^{3}}{3 e(T) \rho}
$$

Equation 8

Where, $K=e(T)$ represents the extinction coefficient of material $\left(\mathrm{m}^{-1}\right), \rho$ is the density of material $\left(\mathrm{kg} / \mathrm{m}^{3}\right), K_{B}$ shows the Stefan-Boltzmann constant $5.67 \times 10^{-8} \mathrm{~W} /\left(\mathrm{m}^{2} \mathrm{~K}^{4}\right)$, and $n$ is the index of refraction. Typical values for $e(T)$ are 30-60 (Hümmer et al. 1992;Duong et al., 2016). For T = $293 \mathrm{~K}$, this corresponds to the thermal conductivity of radiation, which is $0.95 \mathrm{~mW} / \mathrm{mK}$. Figure 2.8 shows the thermal conductivity as a function of temperature for two materials with a density of $150 \mathrm{Kg} / \mathrm{m}^{3}$ and $200 \mathrm{Kg} / \mathrm{m}^{3}$. As can be seen in this figure for the temperature below $150 \mathrm{~K}$, the radiation thermal conductivity values are minimal and can be neglected. 


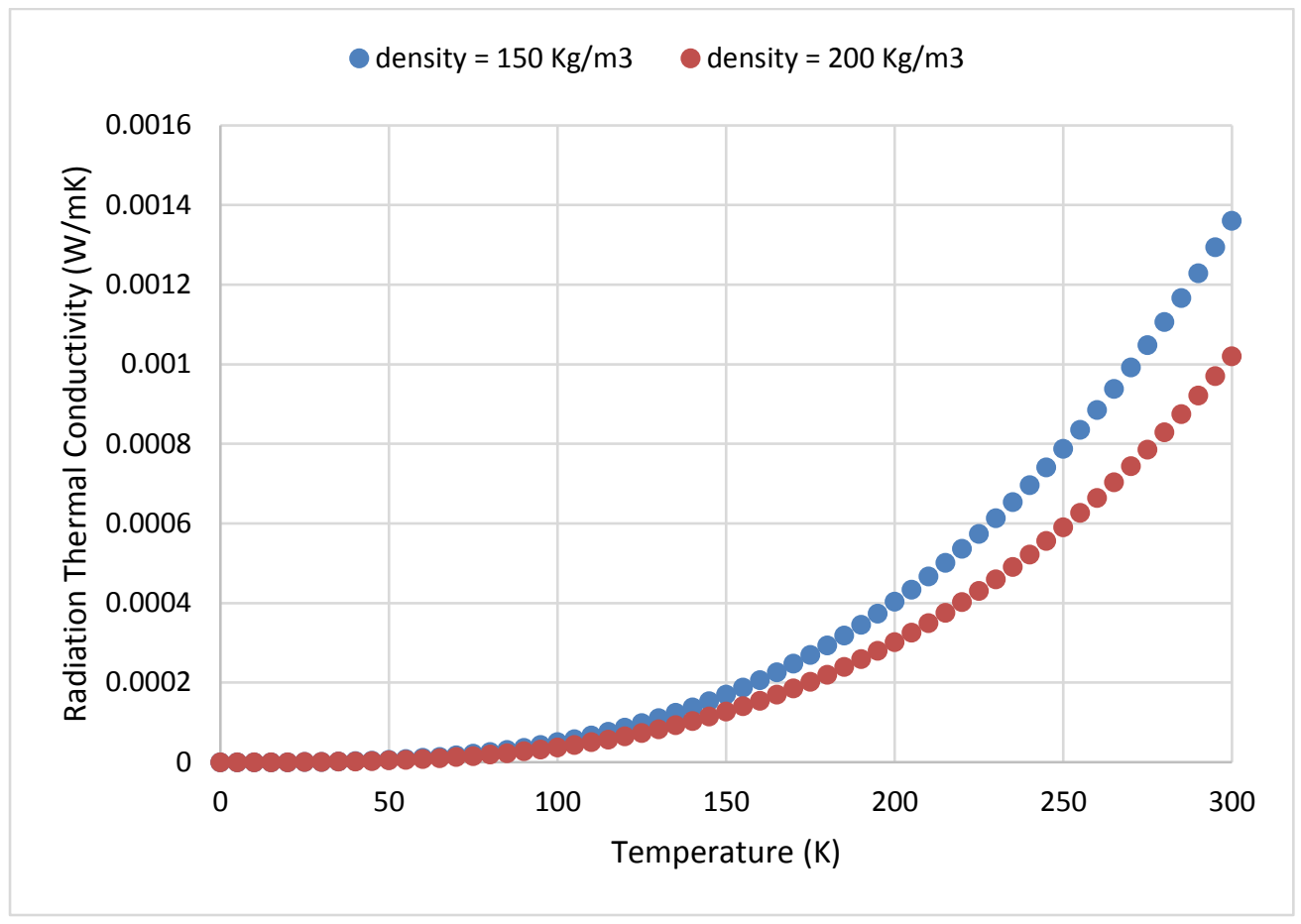

Figure 2.8: Radiation thermal conductivity versus temperature

\subsubsection{Water Accumulation}

As the water content increases inside the envelope, the contribution of the water-content thermal conductivity $\left(\lambda_{w}\right)$ has to be considered. The sorption isotherm can be approximated by a linear relation $X_{w}=k \cdot \varphi$ for relative humidifies $\varphi \leq 50 \%$ (with initial condition $X_{w}(t=0)=0$ ). For fumed silica core material, water-content thermal conductivity can be approximately modelled as a linear function of water content in the VIP. So, $\lambda_{w}$ is given by (Simmler et al., 2005):

$$
\lambda_{w}=b X_{w}(t)=b k \varphi_{\text {out }}\left(1-\exp \left(\frac{-Q_{w, \text { total }} \cdot p_{w, \text { saturated }}(T)}{m_{\text {dry }} \cdot k} \cdot t\right)\right)
$$

Equation 9

where, $b$ is a constant dependent on the sorption isotherm $(\mathrm{W} / \mathrm{mK}$ mass $\%), \mathrm{X}_{\mathrm{w}}(\mathrm{t})$ is the moisture content (mass\%), and $\varphi_{\text {out, }} \mathrm{m}_{\mathrm{VIP}}$, dry, $Q_{w, \text { total }}$, and $p_{w, \text { saturated }}(T)$ are defined as:

$\varphi_{\text {out: }}$ relative humidity, in- and outside of the VIP

mVIP, dry: a dry mass of the VIP-core

$Q_{w, \text { total }}:$ total water vapour permeance

$p_{w, \text { saturated }}(T)$ : saturated water vapour pressure 
By inserting Equation 7 and Equation 9 into Equation 3, the thermal conductivity of the VIP as a function of time can be written as:

$$
\lambda_{\text {tot }}=\lambda_{\text {init }}+\frac{\lambda_{0}}{1+\frac{0.032}{p \Phi}}+b X_{w}(t)=\lambda_{\text {init }}+\frac{\lambda_{0}}{1+\frac{0.032}{p \Phi}}+c\left(1-\exp \left(-\frac{t}{\tau_{w}}\right)\right) \quad \text { Equation } 10
$$

where, $\tau_{w}$ is a time constant, and $c$ is a constant value (Wegger et al. 2011).

Baetens et al. fitted the experiment results with a model and found that water vapour adsorption of fumed silica behaviour is a linear trend for a relative humidity up to $50 \%$ (Ruben Baetens et al. 2010).

Moreover, complex non-linear relations between thermal conductivity, relative humidity, water vapour pressure, and temperature determine the effect of the moisture content on the overall thermal conductivity of VIPs (Beck et al., 2007; Heinemann, 2008; Morel et al., 2007; Coquard et al, 2007).

\subsection{Physical Properties of VIPs}

Solid conduction, air conduction, and radiations determine the primary heat transfer mechanism that controls the insulation capacity of the panel. The solid and radiation terms are related to the density of the insulation materials. Figure 2.9 shows the effect of these three components on the thermal conductivity as a function of density (Liang et al., 2017). As can be seen in Figure 2.9, gas thermal conductivity is almost independent of density, and reducing it provides a significant opportunity to improve the performance of the thermal insulation material. Thermal conductivity of radiation is very negligible for the density of $100 \mathrm{~kg} / \mathrm{m}^{3}$ or more. The results in this figure are computed assuming $\alpha=2$ in Equation 2 . 


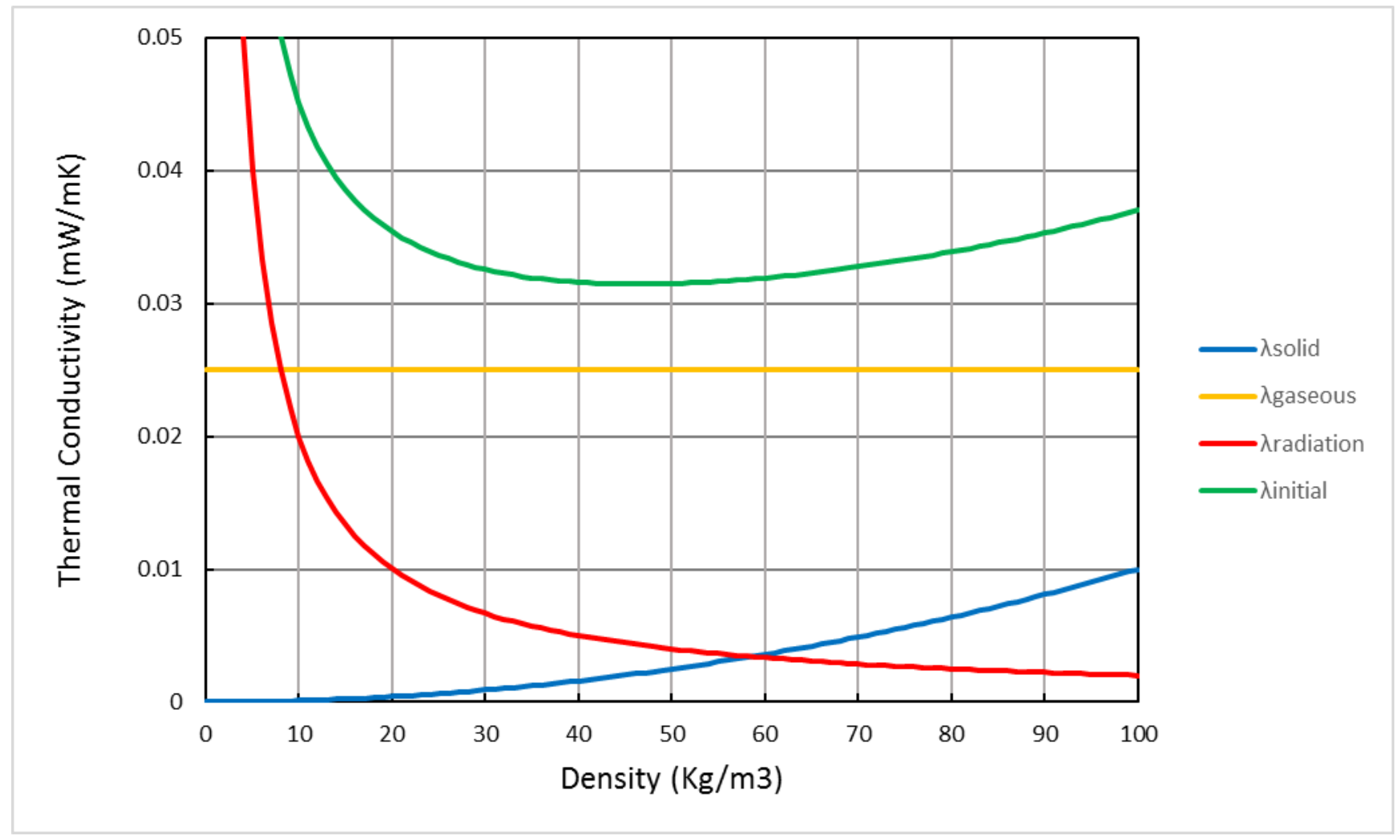

Figure 2.9: Thermal Conductivity for various density

In Equation 8, for the temperature under 150K, the thermal conductivity of radiation is extremely low and can be neglected (Peng and Yang 2016). For the sake of simplicity, most theoretical approaches neglected the coupling of $\lambda_{c o p}$ and $\lambda_{w}$ in Equation 1. In section2.4.2, the effect of $\lambda_{w}$ is briefly revisited, and it is shown that this term has a negligible impact on the total thermal conductivity. Thus, for the sake of simplicity and without loss of generality, for the rest of this research, $\lambda_{c o p}$ and $\lambda_{w}$ are omitted (Baetens et al. 2010). It is worth noting that since various materials are used as the cores of VIPs, $\lambda_{s}$ has an essential impact on the thermal conductivity calculation ( Simmler et al., 2005b; Kwon et al., 2009; Alotaibi et al., 2014; Batard et al., 2018). In other words, thermal conductivity is influenced directly by gas pressure, as it can be seen in Figure 2.9, the reduction of air conduction and moisture content are the main variables can provide an decrease on thermal conductivity value (Kwon et al., 2009; Li et al., 2014). 
When the pressure declines, the average free path length of the air molecules rises, which results in an elastic collision. In this condition, the gas conduction, which is calculated by Equation 5, goes to zero (Simmler et al., 2005). Therefore, this value is omitted for a theoretical approach of total thermal conductivity.

\subsubsection{Thermal transport through Core Material Properties}

Since, there is a relationship between the gas thermal conductivity of air and the pore diameter as it showed in Equation 7, the ideal size of the pore is $10 \mathrm{~nm}$ or less to reduce the gaseous conductivity to zero at atmospheric conditions (Alam et al., 2011). Also, it would be difficult to control pressure if the pore size is large. Moreover, the core material has to be an open cell structure to permit any gas within it to evacuate. The material has to be stable enough to tolerate the pressure load of about 1 bar or $100 \mathrm{KN} / \mathrm{m}^{2}$ for the evacuating process (Peng et al., 2016). In 2009, research was done by J. Kwon and et al. on three mechanisms of thermal transports through different filling materials: 1- powder, 2-foam and 3-fibre with the staggered beam. The results showed that fibre type presents the lowest solid thermal conductivity because of the long thermal path. Another mechanism, convection or gaseous conductivity, was in the lowest amount for powder core type since it has the smallest pore size. This paper suggests using fibre type as the most proper filling for VIPs (Kwon et al., 2009).

The impact of the core material individually does not influence the change of conductivity but, outgassing from core material has a significant effect on the conductivity variation over time. Since the vaporization of the core material occurs in exposure to the vacuum, it is challenging to calculate outgassing accurately. So, the gas adsorption from the surface and its diffusion through the material behave as illustrated in Figure 2.10. By decreasing the temperature, the outgassing decreases (C.YANG 2007). In this research, a numeric calculation is applied to find the outgassing rate, which is based on the fabrication of the core material and the initial gas concentration. The author also experimentally studies the outgassing range of rigid open-celled and demonstrates that the outgassing rate changes by temperature. Furthermore, the study shows that the outgassing rate of PU foam decreases over time (C.YANG 2007). 


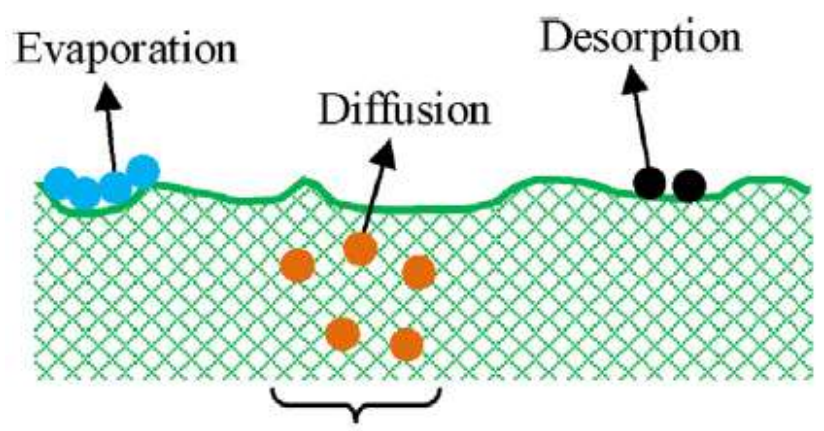

Absorbed in solid

Figure 2.10: Outgassing sources from a material in a vacuum (Li et al. 2014)

Different core materials have been used in vacuum insulation panels such as powder, glass fibers, expanded polystyrene, and fumed silica foams (Kwon, 2009). Figure 2.11 illustrates clearly that the use of conventional insulation as a core material for VIPs results in a very high quality of vacuum ( $0.1 \mathrm{mbar}$ ). As can be seen from this figure, the heat conductivity of fumed silica starts to rise only for a gas pressure above $50 \mathrm{mbar}$. The samples used in this thesis have glass fiber and fumed silica as the core. Based on Figure 2.11, it is expected that glass fibers sample has higher thermal conductivity than the fumed silica one when the internal pressure increases. However, the initial thermal conductivity at 0.1 mbar is lower than fumed silica one.

In conclusion, it is essential to reduce the gas pressure to below a certain pressure threshold. The threshold value depends on the average pore size. The smaller pore size material has a higher threshold value. Therefore, the paper (Kwon, 2009) shows that aerogel is the best core material. Typically, the most significant part of the core of VIPs belongs to the fumed silica (60\%-90\%), and it is followed by silicon carbide $(10 \%-40 \%)$, fibres $(<5 \%)$, and metalized plastic composite film (Alam et al., 2017). Since the fumed silica can absorb the water vapour, desiccants cannot be added (Schwab, Heinemann, Beck, H. Ebert, et al. 2005). 


\section{Thermal conductivity of different core materials}

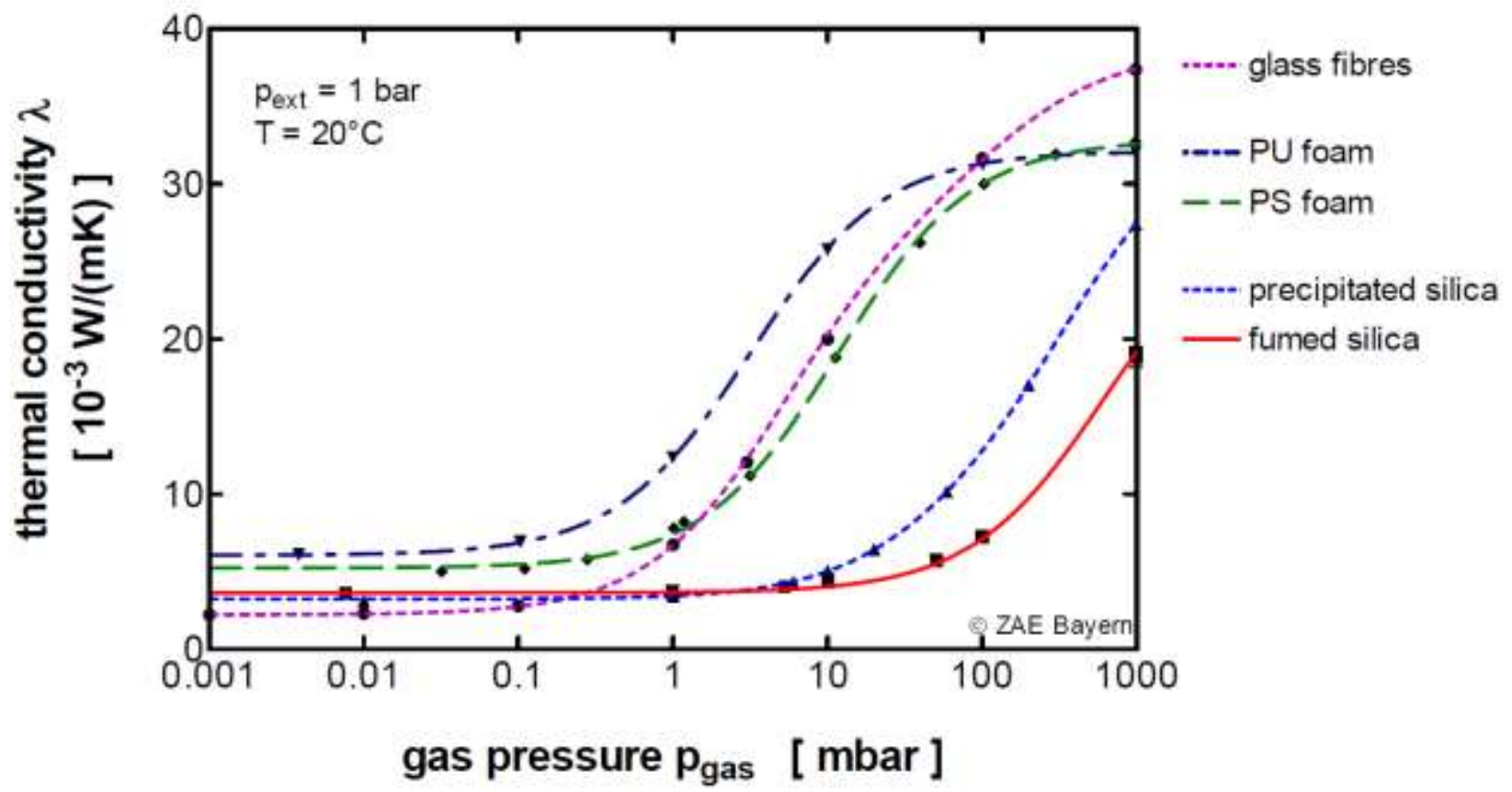

Figure 2.11: Thermal conductivity of different insulation materials as a function of the atmospheric pressure (Caps et al. 2008) (Li et al. 2014).

\subsubsection{Internal Pressure}

The increase of gas pressure inside the VIP's core material is a necessary criterion to anticipate its service life and it caused by the diffusion of ambient air through the envelope or sealants. (Caps et al. 2008; Alam et al., 2011). In other words, thermal conductivity is influenced by the looseness of the core material's vacuum. Based on Equation 1 and Equation 7, there is a relation between thermal conductivity and gas pressure for all core materials. Therefore, measuring thermal conductivity could be a method of determining the gas pressure. As can be seen from these equations, normal pressure depends on the pore size of the core material.

To determine the degradation of VIP thermal conductivity, monitoring of $\Delta \mathrm{P}_{\text {gas, }}$ change of gas, over time, could be done. Since VIP's low thermal conductivity depends on low gas pressure, accurate measurement of absolute gas pressure is a vital factor for quality control. (Caps et al. 
2008). Also, the services life of a VIP is determined by the maximum tolerance that pressure has within the core and the rate of gas pressure ride (Caps et al., 2008).

Kim (2017) studied thermal conductivity performance of fumed silica-based VIP samples and compared initial thermal conductivity and initial pressure provided by the manufactures with the ones measured in the laboratory and, found out that there is $7 \%-25 \%$ difference between these thermal conductivities. The test results showed a significant difference in internal pressure. Thus to resolve this mismatch, a standardized evaluation performance was recommended in this study (Kim 2017).

Measuring the pressure of VIPs is not a straightforward process because the core is sealed, and there is an outer envelope as well. There are four methods to measure internal pressure of VIPS as the following (Caps et al. 2008):

1. Spin router gauge

2. Foil lift off

3. Radio Frequency identification technique (RFID)

4. Thermal measurement

Each of these methods has its advantages and disadvantages which could be applied based on the circumstances (M. Alam, H. Singh 2011).

To evaluate the internal pressure and degree-of-Vacuum of VIPs, the vacuum chambers based on second method were used in Kim et al. research as it is shown in Figure 2.11 according to IEA EBC Annex 39. In this method, the internal pressure is measured by pressure compensation method. The distance between the core and envelope is measured by a laser sensor meter located on the upper side of the envelope. The result of this research shows that there is a difference between manufacture thermal conductivity and the tested, measured specimen (Kim 2017). A non-thermal method was applied in this method, which has a distinction with a thermal way such as number 1 and four methods (Baetens et al., 2010). The non- thermal method is based on RFID which receives data remotely. 


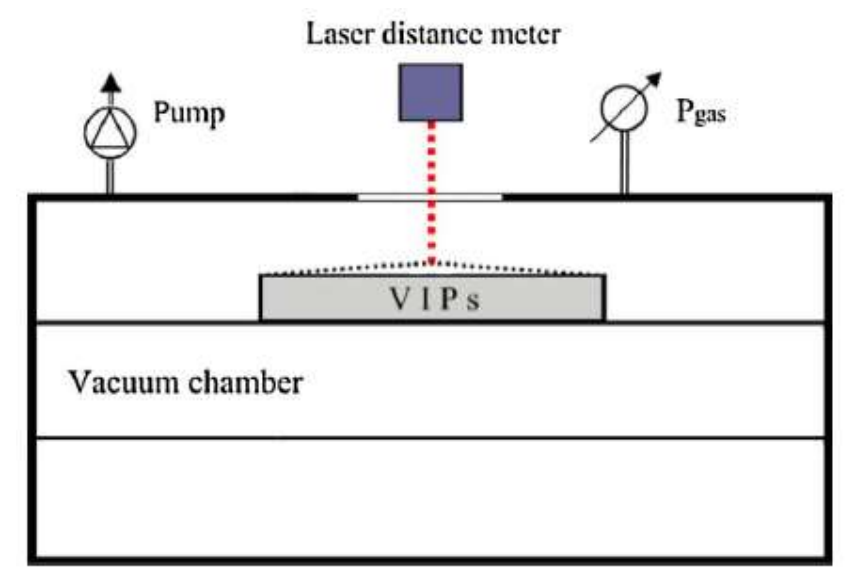

Figure 2.12: Conceptual diagram of the vacuum chamber equipment based on pressure compensate

In (Simmler et al. 2005a), a permeation term is applied for all gases, and vapour, and liquids diffused through the film or envelop. Determining the permeance of the VIP's envelope is not easy because different layers using as a laminate (envelope) of VIPs (Wegger et al. 2010) as it was discussed in 2.1.2. Therefore, two experimental values are used and suggested to determine the permeance of the envelop such as Gas Transmission Rate (GTR) or Air Transmission Rate (ATR) and Water Vapour Transmission Rate (WVTR) (Alotaibi and Riffat 2014). Both GTR and WVTR depend on Temperature and panel size of VIPs and can be resulted (Schwab, Heinemann, Beck, H. P. Ebert, et al. 2005). Both gas and moisture transports are considered for VIP performance evaluation versus time, which are clarified in the following sections (Wegger et al. 2011).

\subsubsection{Gas Transmittance Rate}

Since the envelope of VIP consists of many layers, it is difficult to determine its permeance. Thus, an empirical value referred to as the gas transmission rate (GTR) or air transmission rate (ATR) is usually used. The GTR value specifies the amount of gas permeates of the VIP over a given time duration. On the other hand, the ATR value relates to the amount of permeated gas when the VIP is exposed to the air-gas mixture. So, the total GTR is defined as (Schwab et al., 2005a, Wegger et al., 2011):

$$
G T R_{t o t}=G T R_{A}(T) \times A+G T R_{L}(T) \times L
$$


Where, GTR tot is the total gas transmission rate of material covered panel $\left(\mathrm{m}^{3} / \mathrm{m}^{2} \mathrm{~s}\right), A$ is the total surface area of the VIP with front and rear sides $\left(m^{2}\right), G T R_{L}$ the length related GTR is along the circumference of the panel $\left(\mathrm{m}^{3} / \mathrm{m} . \mathrm{s}\right)$, and $\mathrm{L}$ the length of panel circumference $(\mathrm{m})$.

The total gas permeance $\left(Q_{t o t}\right)$ is expressed as:

$$
Q_{t o t}=\frac{G T R_{t o t}}{\Delta p_{g}}
$$

Equation 12

Where, $\Delta p_{g}$ presents the pressure difference across the laminate barrier. Due to the gas permeation, the pressure inside the panel increases with time as (Wegger et al. 2011):

$$
\frac{d p_{g}}{d t}=\frac{Q_{t o t} \times \Delta p_{g}}{V_{\text {eff }}}\left(\frac{T_{m} \times p_{0}}{T_{0}}\right)=\frac{G T R_{t o t}}{V_{\text {eff }}}\left(\frac{T_{m} \times p_{0}}{T_{0}}\right)
$$

Where:

$\frac{T_{m} \times p_{0}}{T_{0}}$ : the conversion factor form standard $(0)$ to measurement $(\mathrm{m})$ condition, $V_{\text {eff: }}$ the effective pore volume in the panel.

To solve Equation 13, two approaches are considered: 1- discard the internal pressure and consider $G T R_{\text {tot }}$ a constant value over time, and 2-solve the differential equation. To predict the service life, usually, the first approach is taken. That is, it is assumed that $p_{g}$ is equal to atmospheric pressure, and the internal pressure is negligible. The solution, in this case, is a linearly increasing pressure versus time as (Schwab et al., 2005a, Wegger et al., 2011):

$$
p(t)=\frac{Q_{a i r} \times p_{a t m}}{V_{\text {eff }}}\left(\frac{T_{m} \times p_{0}}{T_{0}}\right) t=\frac{G T R_{\text {tot }}}{V_{\text {ref }}}\left(\frac{T_{m} \times p_{0}}{T_{0}}\right) t
$$

Equation 14

Equation 13 can also be analytically solved as a differential equation. In this case, the internal pressure versus time is given by (Wegger et al. 2011):

$$
p(t)=p_{a p p}+\left(p_{a p p}-p_{\text {init }}\right) \exp \left(-\frac{Q_{a i r} \times p_{a t m}}{V_{\text {eff }}}\left(\frac{T_{m} \times p_{0}}{T_{0}}\right) t\right)
$$

where, where $p_{a p p}$ is the applied external pressure $(\mathrm{Pa})$ and $\mathrm{p}_{\text {init }}$ the initial internal gas pressure of VIP (Pa). 
Figure 2.13 shows air pressure changes over the time based on various common types of barrier Inside air pressure one of the effective factor of theoretical prediction model of VIP over the service life, which was resulted from one of the most comprehensive research so far (Wegger et al. 2011).

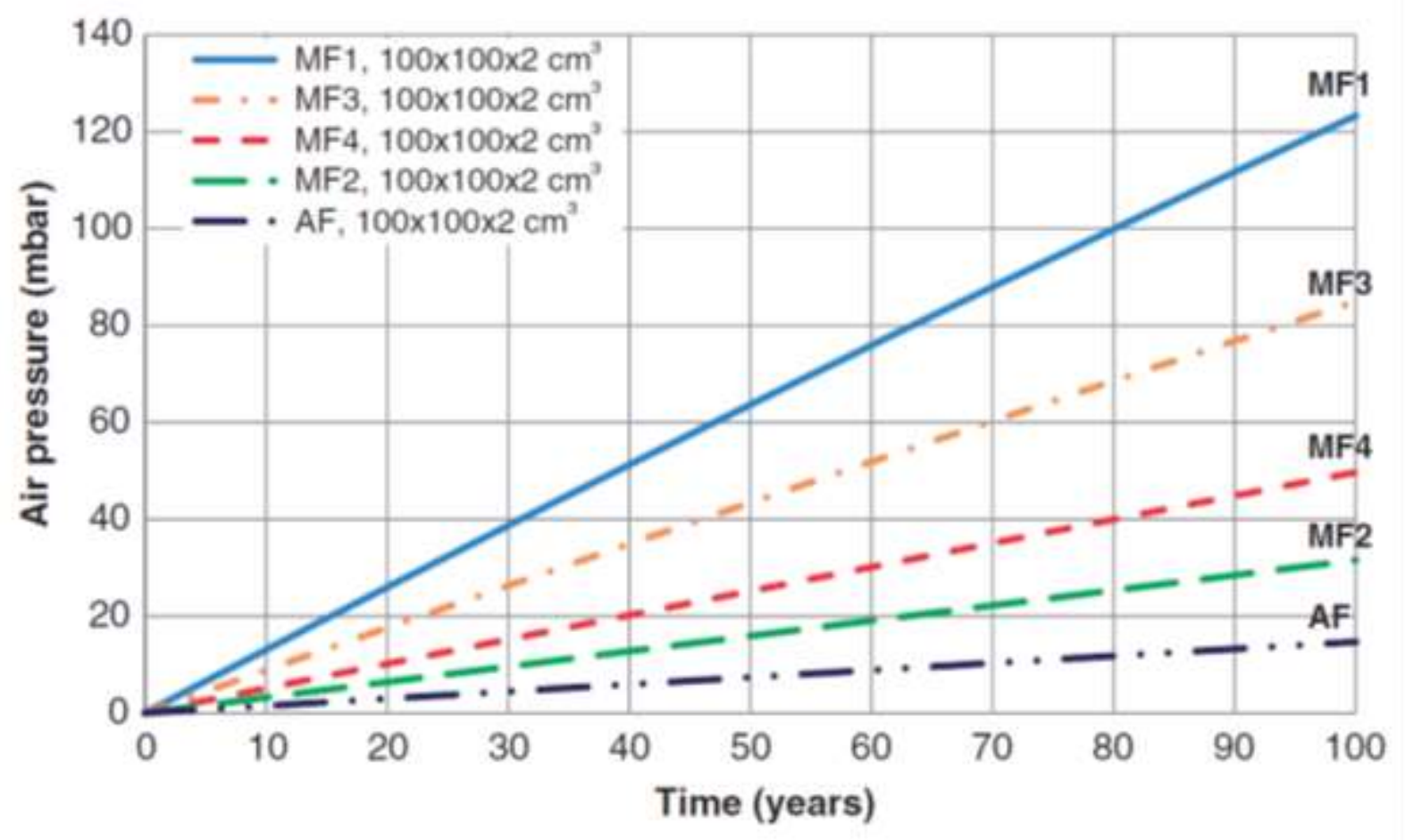

Figure 2.13: Air pressure for various laminate types

Note: The internal air pressure is assumed to be zero at to $1 \frac{1}{40}$. It is assumed that laminate properties remain the same during the entire period. No getters and desiccants have been taken into account (Wegger et al. 2011).

Figure 2.13 shows two laminates with different air transmission rates for perimeter and surface related leakage are considered ( $R$ Baetens et al. 2010). For these plots, constant climatic conditions during the entire period are used. Based on Figure 2., after 100 years, while the pressure for MF2 reaches about 30mbar, it is around $82 \mathrm{mbar}$ for MF3. Therefore, it is concluded that the MF2 performed better than MF3 for 100 years because the thickness of the aluminum foil of MF2 is more than that of the MF3. So MF2 has higher resistance against gas transmittance. The difference among various envelope was explained in section 2.1.2. there are different 
numbers of aluminum layers with various thicknesses which affect the envelope behavior against the vapour and gas transmission. Conceivably, this phenomenon is because the aluminum foils tend to have lower gas and water vapour transmission rates.

The results in that study demonstrated that the smaller size of VIPs had higher GTR and WVTR. Arrhenius equation commonly expressed the effect of temperature on both rates. However, different film types reacted with a different sensibility to Temperature changes. For instance, the MF1 type is the most sensitive one while the two other types, MF2 and AF, are less sensitive in term of a temperature change as it shows in Figure 2.13.

\subsubsection{Water Vapour transmission rate}

Another study has been carried out in polymeric films, and results demonstrated that permeation through this type of films occurred by increasing temperature and pressure and gaseous diffusion is the primary reason caused VIPs vacuum degradation (Garnier et al. 2011). In 2010, (Thorsell, 2010) conducted a research study and showed that two layers of metal coating provide a higher resistance for gaseous diffusion. However, it causes higher thermal conductivity at the edges. The total volume of water that passes through a unit area of material per unit per time is introduced by Water Vapour transmission rate (WVTR) which calculated as:

$$
W V T R=\frac{\partial m v}{\partial t}=Q_{w t o t} \times \Delta p_{w v}
$$

Equation 16

Where $\frac{\partial m v}{\partial t}$ is the panel's mass increase over time; $Q_{w t o t}$ is the total water permeance and $\Delta p_{w v}$ is the water vapour pressure across the film (Alotaibi and Riffat 2014). In Annex 39, WVRT measured for a single, two and three metallized layers of the laminate before and after ageing and concludes that the permeation behaviour is not a significant effect on ageing since the difference of WVRT before and after ageing is less than factor 2. Finally, the long-term equilibrium reached over time (Simmler et al., 2005b; Schwab et al., 2004; Schwab et al., 2005b). These experiments were done on the water vapour transmittance of the aged samples, and the results showed that there was not a noticeable effect on the permeation behaviour of the film samples. The vapour transmittance was reported less than two times after samples were aged by the aging 
process (Simmler et al. 2005b). It means that fresh samples have higher resistance against the vapour transmittance.

\subsubsection{Moisture Permeability and Water Content}

Schwab led a study on the water content in VIPs, with fumed silica, resulting in that there is a relation for their performance in different water content. The results showed that the increase of thermal conductivity roughly related to the water content as it shows in (Schwab, Heinemann, Beck, H. Ebert, et al. 2005). However, $\lambda_{w}$ could be ignored in the calculation of total thermal conductivity shown in Equation 1. That is because of the low permeability of the VIP envelope caused a minimal amount of water transmission to the core. Also, an experimental test was done in section 3 to prove this assumption (Simmler et al., 2005b; Kwon et al. 2009; Alotaibi et al., 2014; Batard et al. 2018; Baetens et al. 2010).

\subsection{Effective Thermal Conductivity and Service Life}

As discussed before, VIP is a heterogeneous material, and evaluating its thermal conductivity is different from other existing insulating materials which are often homogeneous. Durability standards are not yet available for VIPs. However, the evaluation of installed VIPs is difficult, and there are only indirect methods to present long-term performance of them (Johansson et al., 2015). As reported in IEA/EBC Annex 39, there is a calculation method of the durability period of 50 years for a panel. By using the Equation 19 assessment of durability is possible based on $10 \mathrm{kPa}$ internal pressure and an increasing rate of $200 \mathrm{~Pa} /$ year (Kim 2017).

Relevant to this study, heat resistance is one of the most critical features for evaluating the longterm behaviour of VIPs. It was discussed about the factors that could affect VIP performance in section 2.3. A study has been conducted by Wegger et al. about the effect of ageing on thermal properties and service life of the vacuum. The paper presented the factors which theoretically influence VIPs such as temperature, moisture and pressure and accelerated ageing of a VIP could occur by changing one of these factors or combination of two or three of them. Thermal conductivity measurements were done to evaluate the thermal performance, and it was found that the changes in thermal performance were small (Wegger et al. 2010). Based on Equation 1, 
when the gas conduction decreased through the core material caused high thermal performance. Therefore, maintenance of vacuum was considered as the most important ageing mechanism. (Simmler et al., 2005b) presented the ageing mechanisms of VIP for the first time and tested MF1 and MF2 film type samples in constant temperature and relative humidity as well as various pressure in a definite period, and the first model of thermal conductivity changes was expressed as Equation 17 and Equation 18:

$$
\begin{aligned}
& \lambda=\frac{\partial \lambda}{\partial p}+p(T, \varphi)+\frac{\partial \lambda}{\partial u} u(T, \varphi) \\
& \lambda=0.035 \times 1.5+0.5 \times 0.1 \approx 0.1 \quad\left(\mathrm{mWm}^{-1} \mathrm{~K}^{-1} \mathrm{a}^{-1}\right)
\end{aligned}
$$

Another research study was directed on the ageing of VIPs samples with silica core. Accelerated experiments were used as the method to evaluate the VIP performance in the short-term, and by using the results, authors generated a prediction model for that type of VIP. The simulation was completed in constant temperature and relative humidity, and it was recognized that the behaviour of VIPs conductivity could not be a merely broaden of its short-term evaluation and the core material sorption curve is also needed. Three VIPs with the same envelope, included trimetallize V08621B film from Hanita ${ }^{\circledR}$, with different silica core materials, were investigated. In the end, a dynamic model was resulted using Dymola software. Based on simulations done, the thermal conductivity was affected by ageing, and it is going to rise by the ageing mechanism, the simulation was done on $\mathrm{EMPA}^{2}$ measurement results and showed that all the measuring features are close to simulated ones for silica core type up to ten years of ageing to validate the model. But after ten years, the change of thermal conductivity grows as it can be observed as the difference between the red and green curve.

\footnotetext{
${ }^{2}$ Swiss Federal Laboratories for Materials Science and Technology
} 
The results determined that the linear model can be reasonable only for the average thermal conductivity, but cannot be applicable for the water content and the pressure (Batard et al. 2018). The importance of the external temperature and humidity was observed when the simulations performed in constant conditions. For instance, the results proved that in dry conditions, the linear model always underestimates thermal conductivity after 50 years, while overestimated the thermal conductivity in a wet condition for the same time prediction. In all research mentioned that experimental results of initial thermal conductivity and thermal conductivity after ageing can show the long-term performance of VIPs (Kim, 2017; Batard et al., 2018; Baetens et al., 2010).

In this study, Equation 19 is used to model the thermal conductivity and evaluate the measurements. Based on Wegger research, gas and moisture transport into the VIPs were considered as the most important ageing mechanism as well as mechanical stresses and production failures (Wegger et al. 2011). In 2005, a study was carried out in term of showing the relationship between thermal conductivity and time discarding the effect of water vapour as (Simmler et al., 2005b;Kim, 2017;(Pons et al. 2018):

$$
\lambda(t)=\lambda_{\text {init }}+\lambda_{p} t+c\left(1-\exp \left(-\frac{t}{\tau_{w}}\right)\right)
$$

Where $\lambda_{\text {init }}$ is the initial thermal conductivity $(\mathrm{W} /(\mathrm{mK})) . \lambda_{\text {init }}$ includes solid thermal conductivity, the thermal conductivity of radiation, and initial gas thermal conductivity.

In Equation 19, initial thermal conductivity was limited to only solid and radiative conductivities due to an increase in gas pressure (M. Alam, H. Singh 2011). Wegger plotted the predicted conductivity results according to their test condition, then measured values of the experimental tests were plotted based on Equation 1 and found that the model was viable to predict the VIP service life as it shows in Figure 2.. 


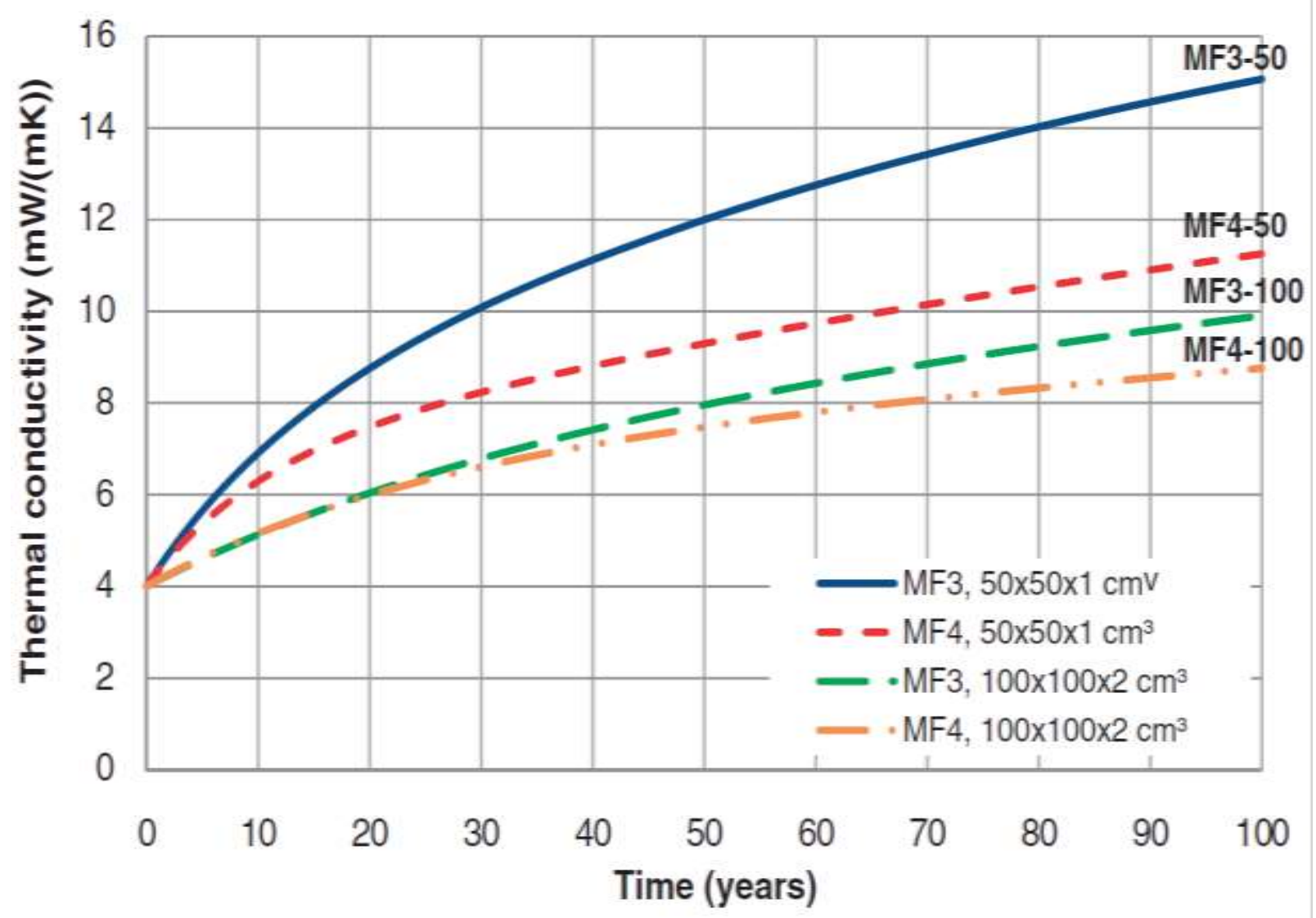

Figure 2.9: Total thermal conductivity for panels with two different sizes and two different barrier laminates (Wegger et al. 2011)

In summary, there are two major approaches for VIP ageing; first, ageing based on water and gas permeance by using American Standard C1484 for VIPs over time and the second approach is created over critical thermal conductivity value in mean-time (Alotaibi and Riffat 2014) which will be explained in the following. Figure 2. illustrates the non-linear nature of VIP ageing. 


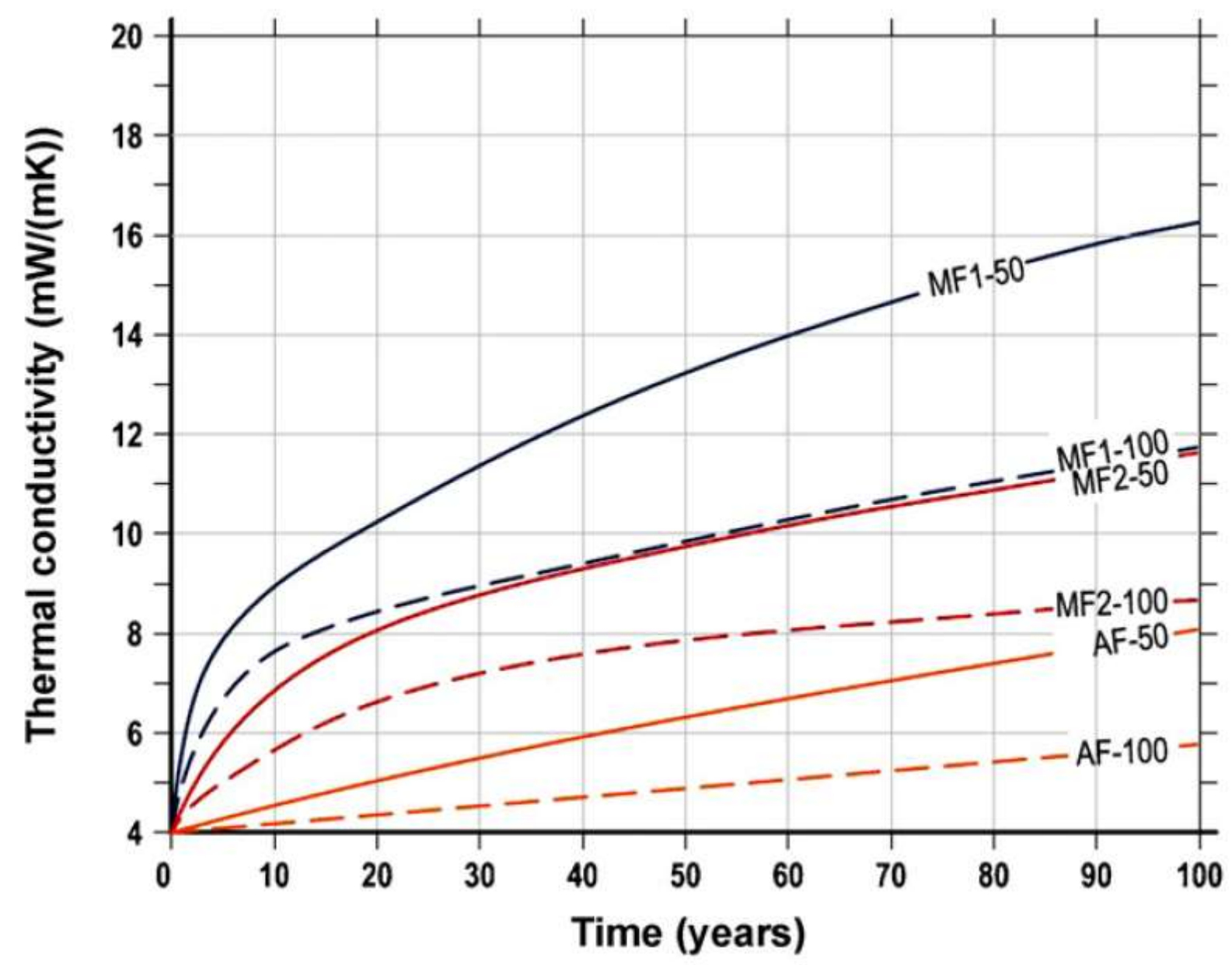

Figure 2.10: Vacuum insulation panel thermal conductivity as a function of time (Ruben Baetens et al. 2010)

The first approach is incorporated into the American Standard C1484, and it equals to the time duration from the panel production to the time that the effective thermal conductivity overdoes the recognized restrictive value:

$$
\lambda_{\text {eff }}=t S L=\lambda_{\text {lim }}
$$

In (Tenpierik et al., 2010), the maximum value of thermal conductivity determined the life service of VIPs was considered $8 \times 10^{-3} \mathrm{~W} / \mathrm{mK}$ while others allowed a conductivity of $11 \times 10^{-3} \mathrm{~W} / \mathrm{mK}$. Based on the Canadian construction industry perspective, the acceptable lifetime of a material applied in the building is at least 25-50 years of performance (Mukhopadhyaya, 2010). In this 
study, the application of VIP as insulation was investigated in the real condition in the Yukon and no failure of thermal performance in through each layer of insulation was detected over five years of study probably because of the low temperature and low humidity in cold climate.

In the second approach to calculate the effective thermal conductivity of VIPs, the time-average thermal conductivity is considered as given by the following formula (Kim, 2017):

$$
\begin{aligned}
& \lambda_{\mathrm{eff}} \mid t=t S L=\lambda_{\text {crit }} \\
& \text { where, } \quad \lambda_{\mathrm{eff}}=1 / t \int_{0}^{t} \lambda_{\mathrm{eff}}(t) d t=\lambda_{\text {crit }}
\end{aligned}
$$

The result of applying the first definitions of the service life is given in the following sections, and Figure 3.1 shows the service life for each specimen.

\subsection{Summary}

In this section, the scientific background for studying VIP's, and their long-term behaviour was presented. As explained in detail, the thermal conductivity consists of three major components: 1- solid thermal conductivity, 2- thermal conductivity of radiation, and 3- gas thermal conductivity. The significant part affecting total thermal conductivity is the gas thermal conductivity. In VIP samples due to the low pressure of inside gas, this component is minimal as the panel has been vacuumed. That is, the thermal conductivity of VIP samples is expected to be lower than other insulating materials. However, since the models are very generic and try to include most of the cases and panels with fumed silica or fiberglass, they are limited to predict the performance with appropriate accuracy for new generation of core materials such as compressed microporous silica and microporous silica with cellulose fiber. Those recent core materials are investigated to find out if the presented theoretical thermal conductivity model is accurate for them or not. This section also described how the thermal conductivity is affected by temperature, water content and internal pressure. As it is written in the next parts, these elements will determine the ageing and service life of the VIP specimen by measuring thermal conductivity over time. 


\section{Laboratory Measurement and Data Collection Methodology}

In this section, first all the samples used in this study are introduced. Afterward, specimens characteristics are explained. In order to answer the research questions, some laboratory tests need to be conducted including thermal conductivity measurement, hygroscopic sorption and accelerated ageing. The thermal conductivity measuring is done before and after ageing the samples to understand the thermal conductivity behavior over the temperature and the time. The hygroscopic sorption is done to find out the hygro-thermal behavior of the sample thermal conductivity. Different samples were choosing to see how the core material and envelope influence the thermal conductivity of VIPs. Finally, test results are used to validate the accuracy of the existing theoretical ageing model for various VIP samples. Each test is conducted based on standards and explained in detail as the follow. 


\subsubsection{Laboratory Characterization}

Laboratory characterizations include thermal conductivity, water vapour Permeation rate, and accelerated ageing, which will be discussed in the following sections. Many different companies in Europe, North America, and China were contacted to get VIPs panels. Finally, seven different Types were selected for experimentation and Figure 3.1 show the specimens and Table 3.2 characterizations provided by the manufactures.

Figure 3.1: Prepared VIP Specimen Table

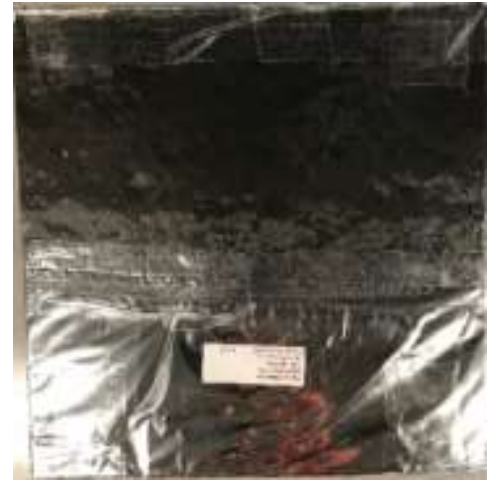

Type 1

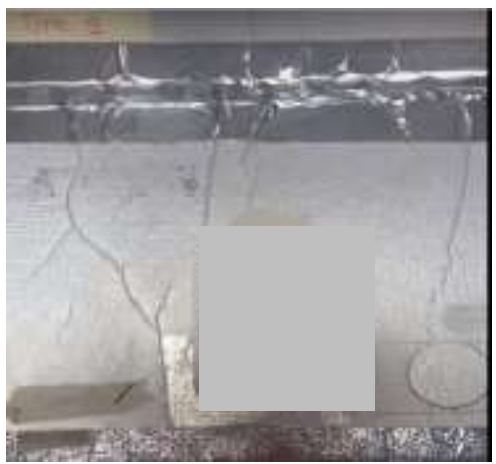

Type 4

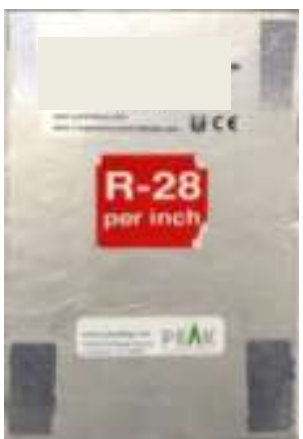

Type 2

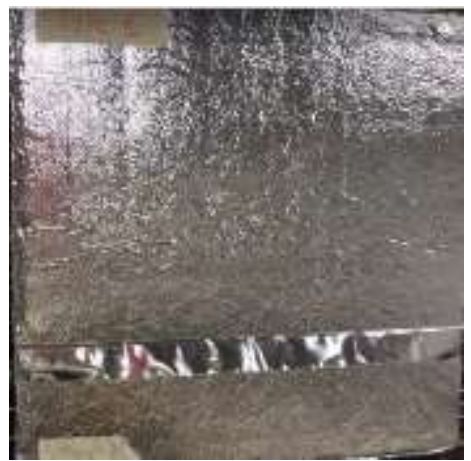

Type 5

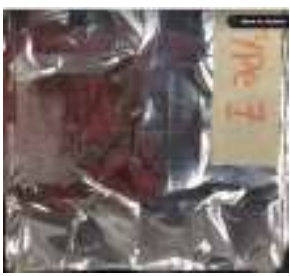

Type 5a

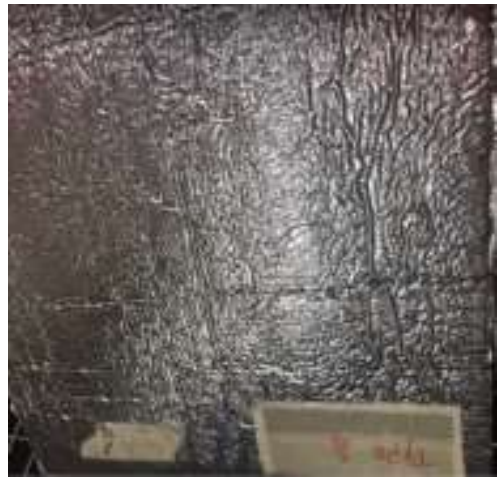

Type 3

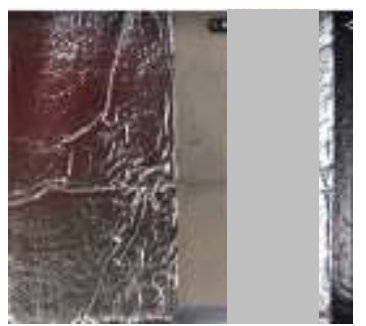

Type 3a 
Table 3.1: Experimentally assessed characteristics of VIPs provided by manufactures

\begin{tabular}{ccccc}
$\begin{array}{c}\text { Sample } \\
\text { Type }\end{array}$ & $\begin{array}{c}\text { Envelope } \\
\text { Type }\end{array}$ & $\begin{array}{c}\text { Advertised Thermal } \\
\text { Conductivity }(\mathbf{W} / \mathbf{m K})\end{array}$ & $\begin{array}{c}\text { Company density } \\
\left(\mathbf{k g} / \mathbf{m}^{\mathbf{3}}\right)\end{array}$ & $\begin{array}{c}\mathbf{P a}_{\mathbf{a}} \\
(\mathbf{m b a r})\end{array}$ \\
\hline $\mathbf{1}$ & NA & 0.002 & 250 & $\leq 5$ \\
\hline $\mathbf{2}$ & MF3 & 0.005 & 190 & $\leq 5$ \\
\hline $\mathbf{3}$ & MF2 & 0.004 & 208 & $\leq 5$ \\
\hline $\mathbf{4}$ & MF2 & 0.007 & 200 & $\leq 2$ \\
\hline $\mathbf{5}$ & MF2 & 0.007 & 250 & $\leq 5$ \\
\hline $\mathbf{3 a}$ & MF2 & NA & 208 & $\leq 5$ \\
\hline $\mathbf{5 a}$ & MF2 & NA & 250 & $\leq 5$
\end{tabular}

\subsubsection{Thermal Conductivity measurements}

In this research, measurement of center thermal conductivity of VIPs is based on heat flow meter (HFM). The sample is installed in a heat flow meter apparatus, and thermal conductivity will be assessed by the heat flux sensor to reach the thermal equilibrium at constant temperature difference and an even temperature gradient via the sample. The test sample is placed on a flat slab (30 mm X $30 \mathrm{~mm}$ ) with variable thicknesses and then contacted with upper and lower plates, which after a time alleviated at two various temperatures. The temperature difference assessed heat flow vertically through the sample from a hot face to a cold one (Gmbh 2009). Heat Flow Meter, HFM 436 Lambda from NETZSCH company was used to assess thermal conductivity of the samples as it shows in Figure 3.2 and Figure 3.3. This instrument was set up in accordance the ASTMC518,1991 Standard and calibrated with a standard fibreglass board, provided by NIST ${ }^{3}$. The accuracy of the apparatus was \pm 1 to $3 \%$. The heat flow measured for the center of samples

\footnotetext{
${ }^{3}$ National Institute of Standards and Technology
} 
in $10 \times 10 \mathrm{~cm}^{2}$. The transducer acted as an effective guard against lateral heat flow for large size samples. Therefore, a frame (with an insulation likes samples) size by $30 \times 30 \mathrm{~cm}^{2}$ as it shows in Figure 3.4 is needed to make the adiabatic condition to measure the thermal conductivity in the middle area of the specimen. The framing material is an insulation like the specimen. The frame should fit the specimen exactly, leaving no air gaps between frame and specimen. In addition, the frame must either have the exact same thickness as the specimen. All samples were tested in $10^{\circ} \mathrm{C}$ temperature difference between hot and cold plates for five temperature points in the range of $-10^{\circ} \mathrm{C}$ to $+30^{\circ} \mathrm{C}$ in every $10^{\circ} \mathrm{C}$ increase.

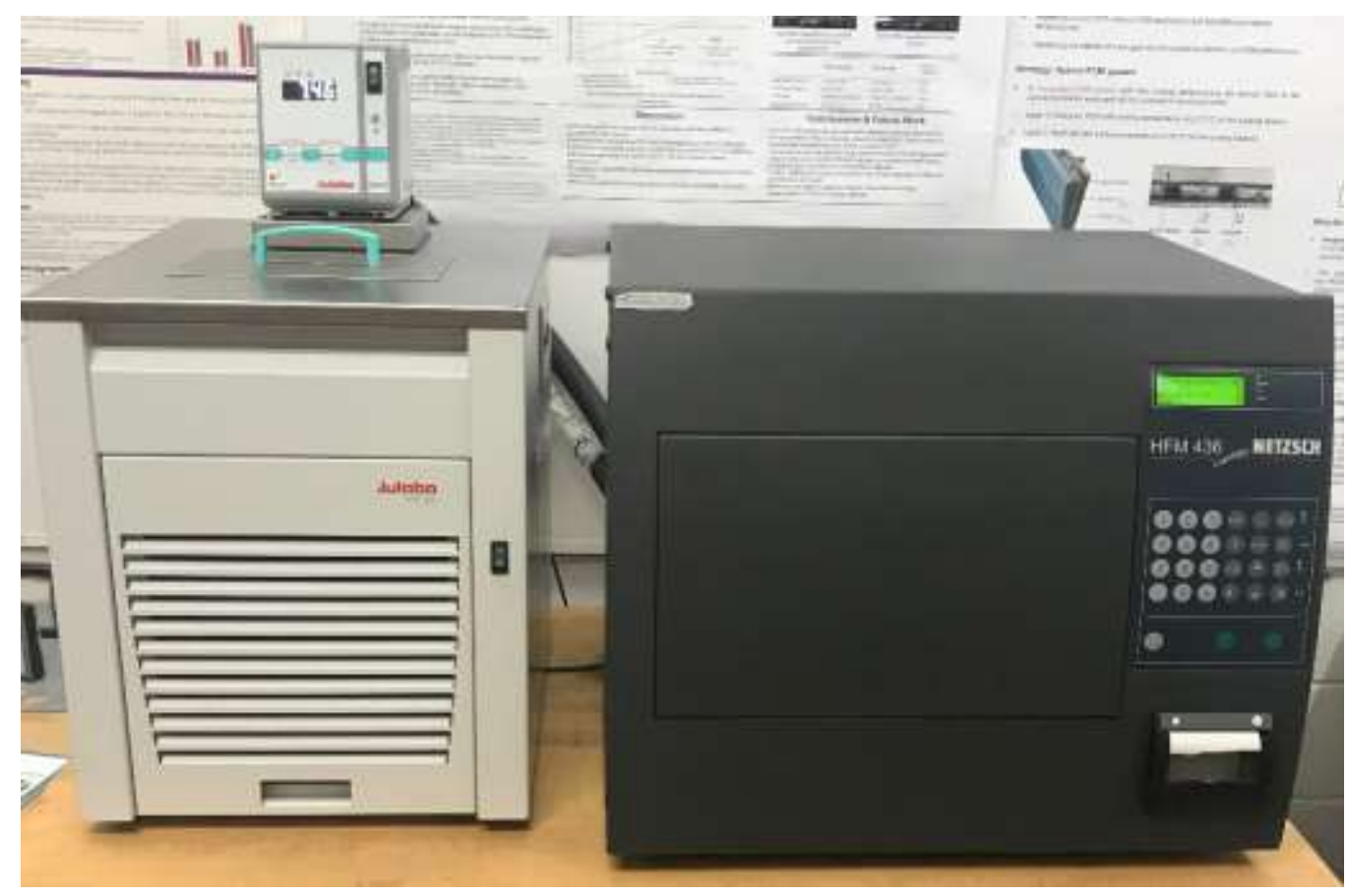

Figure 3.2: Heat flow meter NETZSCH HFM 436 Lambda apparatus 


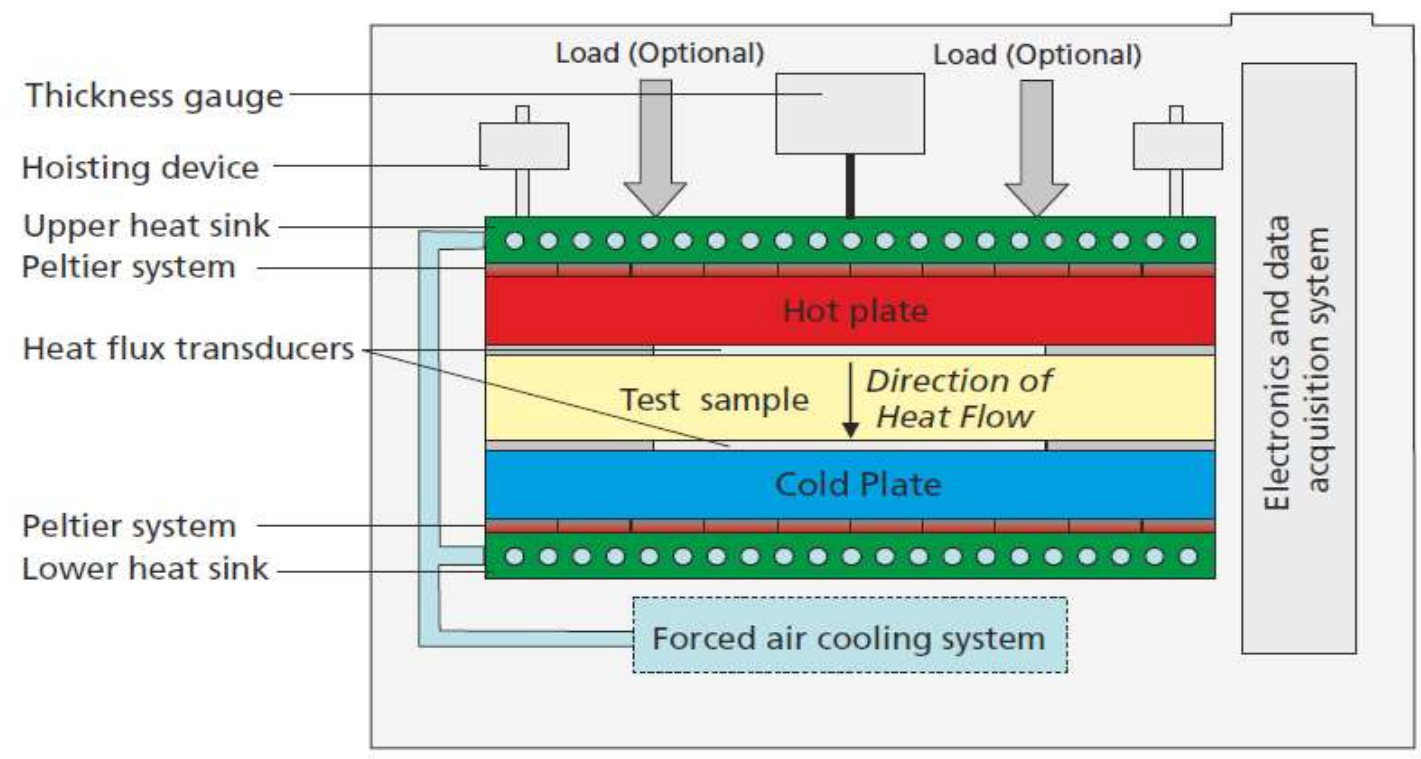

Figure 3.3: Schematic design of Heat flow meter

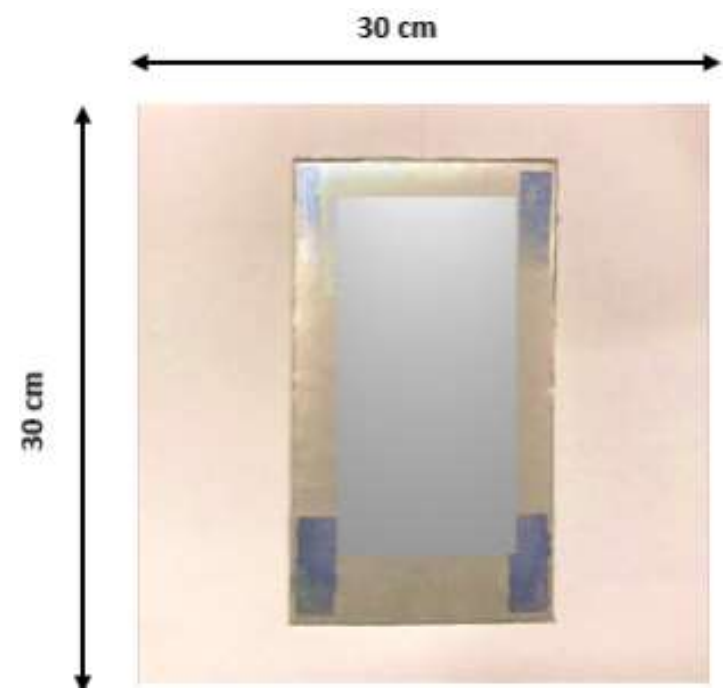

Figure 3.4: Insulating frame foam for avoiding lateral heat flow

The test results of seven different types of samples from various providers are illustrated in Table 3.2. Sample type one is consist of fiberglass as the core and a polymer film bag with no aluminum foil in size of $30 \times 30\left(\mathrm{~cm}^{2}\right)$. Sample type two is a fumed silica core one (combined by opacifier and fibers) with the MF3 film type in size of $24 \times 13.7\left(\mathrm{~cm}^{2}\right)$ with opacifier. 
Type three is made by fumed silica core and MF2 inflammable film as an envelope in $30 \times 30\left(\mathrm{~cm}^{2}\right)$ size. The next sample, Type four consists of compressed powder, whose main component is micro-porous silica (mixed by opacifier and cellulose fibres) and MF2 inflammable type as the envelope.

Type five is made by compressed powder micro-porous silica acid core and MF2 inflammable film as an envelope in $30 \times 30\left(\mathrm{~cm}^{2}\right)$ size. The main constituent of Type three(a) and Type five(a) is fumed silica with MF2 inflammable type as it is given in Table 5.

Table 3.2: Vaious types of VIP samples characterization

\begin{tabular}{|c|c|c|c|c|c|c|}
\hline Sample & Length & Width & Thickness & Weight & Core Material & Envelope \\
\hline Type & $(\mathrm{cm})$ & $(\mathrm{cm})$ & $(\mathrm{cm})$ & (g) & & \\
\hline 1 & 30 & 30 & 3 & 453.5 & Fibreglass & New \\
\hline 2 & 24 & 13.7 & 1 & 77.2 & Fumed Silica & MF3 \\
\hline 3 & 30 & 30 & 2 & 358.5 & Compressed microporous silica & MF2 \\
\hline 4 & 30 & 30 & 2 & 334 & $\begin{array}{l}\text { Compressed microporous silica } \\
+ \text { callouses fibre }\end{array}$ & MF2 \\
\hline 5 & 30 & 30 & 2 & 484.5 & Compressed microporous silica & MF2 \\
\hline $3 a$ & 10 & 10 & 2 & 58.91 & Compressed microporous silica & MF2 \\
\hline $5 a$ & 10 & 10 & 2 & 42.42 & Compressed microporous silica & MF2 \\
\hline
\end{tabular}

\subsubsection{Correlation between Thermal conductivity and Internal pressure}

As it can be seen in section 2.6, the total effectivity thermal conductivity $\left(\lambda_{\text {tot }}\right)$ can be considered as the sum of solid conductivity $\left(\lambda_{s}\right)$, gas conductivity $\left(\lambda_{g}\right)$ and radiative conductivity $\left(\lambda_{r}\right)$. Therefore, a high thermal performance VIP supposed to encompass the low $\lambda_{\mathrm{g}}$ through the pore of the core material.

When the internal pressure decreased, thermal conductivity dropped quickly. Based on the effective thermal conductivity results, the inner could be divided by three ranges as followed (Xu et al. 2018): 
Heat convection is the main factor influencing thermal conductivity for level 2. By comparison four different types of VIPs, it resulted that chopped fiber type had the best thermal conductivity since it had a large size pore. Also, tests results show that bigger pore size leads to faster degradation, which means shorter service time.

\subsubsection{Artificial Ageing}

Different ageing experiments were introduced to evaluate the performance of VIP such as temperature ageing according to CUAP 12.01/30, Cyclic climate ageing according to NT Build 495, Moisture and temperature ageing, Pressure ageing. Thermal conductivity was measured before and after ageing to assess VIP thermal performance (Wegger et al. 2011). Another study was conducted by Jelle to present the laboratory work for VIP durability evaluation (Jelle 2012). This method included the climate exposures that affect the durability and thermal performance of high-performance materials such as VIP. This research helps to evaluate long-term behaviour in building products. However, there are different ageing methods such as elevated temperature oven or climate chamber which can adjust the solar radiation, temperature change, water content over the measurement time. The elevated temperature was applied to age VIP samples in this study, which is described in details in the next part (Ruben Baetens et al. 2010). The usage of VIP as insulation of a building is recommended in the inner side of the enclosure, so that the solar radiation, water and wind-driven rain were neglected in the chosen the ageing method.

\subsubsection{Elevated temperature}

Increase of temperature could grow the kinetic reaction rate within the molecules of materials which causes chemical deprivation. However, materials never exposure to the extremely high temperature like over $100^{\circ} \mathrm{C}$ in natural outdoor climate conditions. For this purpose, accelerated ageing temperatures of building materials are often select from $60^{\circ} \mathrm{C}$ to $70^{\circ} \mathrm{C}$ (Jelle 2012). This

method of accelerated ageing method is used to find failure modes in a short time, which is resulted after many years at normal temperature. The minimum energy leads to a chemical reaction of one mole of material is called energy activation (Ea), and it defines the material characteristics as well as indirect prediction of degradation or ageing under the influence of 
external factors (Kunic 2012). A high temperature exceeds the reaction level of activation energy as it usually showed by $\mathrm{kJ} / \mathrm{mol}$. In order to evaluate the Energy activation of VIP, the VIP panel needs to be detached, and then energy activation gets calculated for each component. In this study in term of determining energy activation amount, contacted to the providers and $70 \mathrm{~kJ} / \mathrm{mol}$ was assumed. Arrhenius law is used in this study to calculate the time equivalent to 25 years of ageing

Arrhenius equation clarifies the dependence of the speed of chemical reactions on various parameters such as temperature, humidity, pressure etc. Equation 22 shows the logarithmic relationship between temperature and activation energy so that it can be sufficiently accurately describing the process of degradation.

$$
k=A \times e^{-\frac{E a}{R \cdot T}}
$$

Where $\mathrm{k}$ is the specific rate of reaction, $\mathrm{A}$ is pre-exponent factor or frequency factor of a specific reaction $(1 / \mathrm{s}), E_{a}$ is activation energy $(\mathrm{J} / \mathrm{mol}), \mathrm{R}$ is ideal gas constant, $T$ is temperature $(\mathrm{K})$ and $\mathrm{k}$ reaction constant factor or reaction speed $(1 / \mathrm{s})$.

To assess degradation at elevated temperature is determined as follow (Kunic 2012):

$$
a_{T}=\frac{k_{2}}{k_{1}}=\frac{t_{2}}{t_{1}}=e^{-\frac{E a}{R}\left(\frac{1}{T_{2}}-\frac{1}{T_{1}}\right)}=e^{-\frac{E a}{R}\left(\frac{1}{T_{2}}-\frac{1}{T_{1}}\right)}
$$

Jelle used Equation 23 and presented temperature accelerated factor $\left(A F_{\text {temp }}\right)$, which was calculated as the ratio between the reaction rate in the laboratory, and the real outdoor ageing showed in the following:

$$
A F_{\text {temp }}=e^{-\frac{E_{a}}{K}\left(\frac{1}{T_{A}}-\frac{1}{T_{U}}\right)}
$$


Where $A F_{\text {temp }}$ is the acceleration factor under stressed temperature, $E_{a}$ is the activation energy of failure mechanism, $\mathrm{k}$ is the Boltzmann constant which equals to $8.617 \times 10^{-5} \mathrm{eV} / \mathrm{K}, \mathrm{T}_{\mathrm{A}}$ is the accelerated temperature in Kelvins, and $\mathrm{T}_{\mathrm{U}}$ is the use condition temperature in Kelvin (Jelle 2012).

The accelerated temperature of VIPs samples is assumed $80{ }^{\circ} \mathrm{C}$, and the constant use condition temperature is inspected $15{ }^{\circ} \mathrm{C}$ in this research and $A F_{\text {temp }}$ is calculated using Equation 24 . The convection oven applied to get the mentioned temperature as it shows in Figure 3.5. The location of material application in the building is a significant factor which must be considered for assuming the use of condition temperature. Explained condition in detail lead to 108 for the acceleration factor for VIPs samples and 42 days was resulted to simulate and analyze 25 years of ageing VIPs samples behaviour in the laboratory or artificial condition as it is listed in Table 3.3.

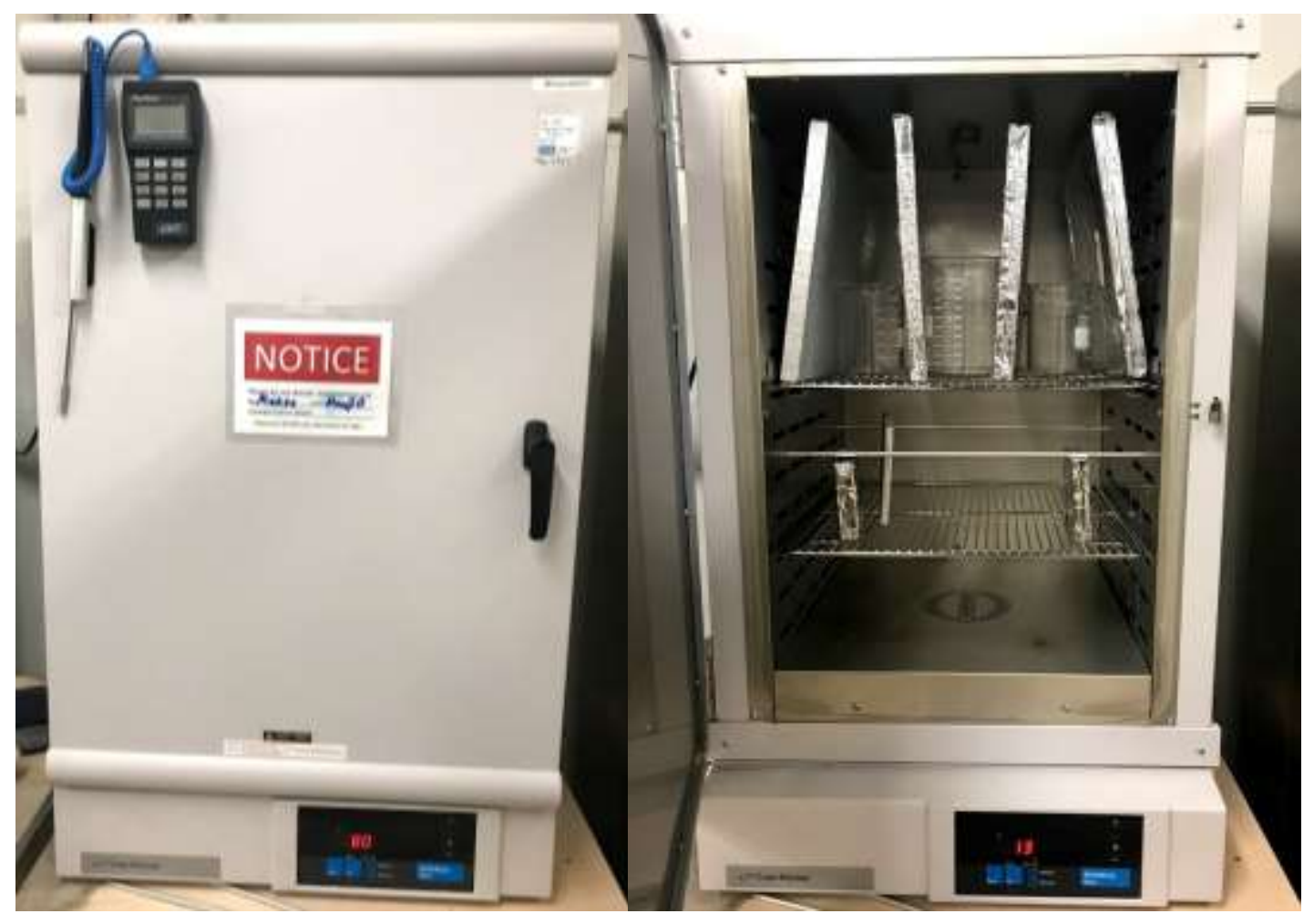

Figure 3.5: Mechanical convection oven used for elevated temperature ageing 
Table 3.3: The required stressed period based on acceleration factors( based on Equation 24)

\begin{tabular}{|l|l|}
\hline Accelerated ageing factor (AF) & 218 \\
\hline Ageing time under used condition(yrs) & 25 \\
\hline Equivalent accelerated ageing time(days) & 42 \\
\hline $\mathrm{E}_{\mathrm{a}}$ : Activation energy $(\mathrm{KJ} / \mathrm{mol})$ & 70 \\
\hline $\mathrm{k}:$ Boltzman constant $(\mathrm{eV} / \mathrm{K})$ & $8.617 \times 10^{-5}$ \\
\hline $\mathrm{T}_{\mathrm{A}}:$ Accelerated temperature $(\mathrm{K})$ & 353 \\
\hline $\mathrm{T}_{\mathrm{u}}$ : Used condition temperature $(\mathrm{K})$ & 288 \\
\hline
\end{tabular}

\subsubsection{Moisture storage function and hygroscopic sorption}

Determination of water vapour permeation of VIPs is necessary to assess its lifetime performance like other envelope building materials since the vapour at the cold surface can lead to corrosion, moisture accumulation, and mould (Pons et al. 2014).

In the case of vapour diffusion or air movement, humid air might condense at a cold surface which can lead to corrosion, condensation/absorption, moisture accumulation, toxic mould or even building failure or it may affect indoor air quality and occupant comfort level. Therefore, the water permeance of the materials in each assembly must be selected carefully concerning the permeability of the other layers within the assembly and the given climate zone.

To analyze the VIP panels to the moisture content of the air, the hygroscopic behaviours were investigated. Hygroscopic sorption of VIP samples was determined using a custom-built environmental chamber method described in the ISO 12571:2013 (“ISO 12571: Hygrothermal performance of building materials and products - Determination of hygroscopic sorption properties," 2013). This chamber consists of a silicone-sealed box, covered with a $50 \mathrm{~mm}$ layer of rigid XPS insulation board to hold a set temperature and humidity level. The humidifier and dehumidifier were installed and controlled by Inkbird programmable digital humidity controller. Another Inkbird was a programmable thermostat to control the heat source and keep the steady temperature as the following (Figure 3.6). 


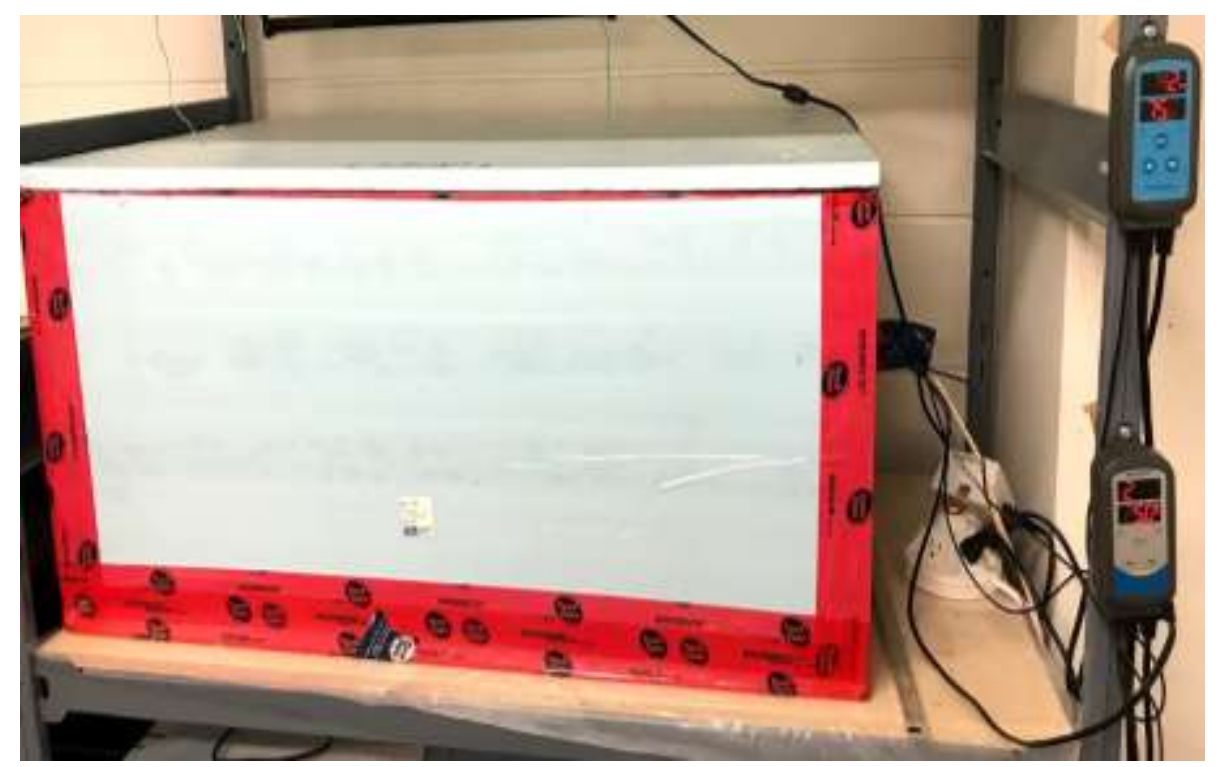

Figure 3.6: Custom Built Environmental Chamber

This chamber was used to expose the materials to the environment of $40 \%, 80 \%, 90 \%$ and $95 \%$ $( \pm 5 \% \mathrm{RH})$ and the constant temperature of $23^{\circ} \mathrm{C}\left( \pm 2^{\circ} \mathrm{C}\right)$. According to ISO $12570: 2000$ test method, all specimens were dried at temperature of $70 \pm 2^{\circ} \mathrm{C}$ and a relative humidity of less than $10 \%$. The mass was assumed to be constant when the changes in mass were less than $0.1 \%$ between three consecutive weighing 24 hours apart. Subsequently, samples were cooled in a desiccator to reach $30^{\circ} \mathrm{C}$ to $40^{\circ} \mathrm{C}$ and were weighted $\left(\mathrm{m}_{0}\right)$. After materials in the chamber acclimated to the set point of all selected relative humidity levels, the weight of each sample was measured. Samples were weighed before and after thermal measurement using a digital scale with $0.1 \mathrm{~g}$ accuracy to keep track of the moisture content. The precise dimensions of each test specimen were measured using a Vernier caliper to determine the volume of the test specimen. Periodic weighing was performed until the sample was in equilibrium with the environment, constant mass. The purpose of the test was to analyze the water vapour transfer through the panel, which is essential to manufacturing. This test method can simulate the same condition of the materials in the real situations of their using.

The following equations were used to quantify water vapour transmission through the samples: 


$$
u=\frac{m-m_{0}}{m_{0}}
$$

Where $u$ is the moisture content mass by mass $(\mathrm{kg} / \mathrm{kg}), m$ is the mass of the specimens before drying, $m_{0}$ is the mass of test specimens after drying.

Periodic weighing determined the rate of water vapour movement through the Type1, 3,4,5,3a and 5a specimens at first 64 days equal to zero g/h. $\mathrm{m}^{2}$ using Equation 25 but after 64 days it changes to $0.2315 \mathrm{~g} / \mathrm{h} \cdot \mathrm{m}^{2}$ and stays constant by the end of measuring time. For Type 2 specimen the behaviour was different, and after 24 days WVT equals to $0.065104167 \mathrm{~g} / \mathrm{h} \cdot \mathrm{m}^{2}$ and stays constant by the end of the measuring time because the core material of that specimen is fumed silica and it is a kind of hydrophilic component. Therefore, it can be concluded that thermal conductivity does not change as humidity varies. So, hereafter without loss of generality, the thermal conductivity is considered only a function of temperature, and independent of humidity. 


\section{Experimental Results and Data Analysis}

In this section, first, the results of thermal conductivity measurement at the initial state will be shown. Afterward, the ageing results of thermal conductivity over the 25 years is measured. Finally, the conclusions of the effective life service of the VIPs are drawn from the measurements. Through this section, seven different types of VIPs are used to measure the thermal conductivity performance for various temperature and over time (as explained in more details in section 3.1.1.1).

\subsection{Initial Thermal Conductivity}

The initial thermal conductivity test has been conducted to determine the thermal conductivity for various types of VIPs. The thermal conductivity values of test samples are measured using heat flowmeter equipment, HFM 436 Lambda. This measurement process is the most accurate method for measuring the thermal conductivity of VIP as it was mentioned in section 2. Samples were stored for 24 hours in the laboratory to be established. The measurement was carried out in a range of temperature from $-10{ }^{\circ} \mathrm{C}$ to $30{ }^{\circ} \mathrm{C}$ with $5{ }^{\circ} \mathrm{C}$ temperature step. In this test, the temperature difference between opposite sides of the plates is kept at $10{ }^{\circ} \mathrm{C}$ through the controlling software. This range covers the majority of actual VIP operating conditions since the VIP layers in the buildings are not directly exposed to the extreme outdoor environment. Each test takes about 4 to 5 hours to be completed to go through $-10{ }^{\circ} \mathrm{C}$ to $30^{\circ} \mathrm{C}$.

Figure 4.1 shows the results of this test for different sample types. In this figure, a third order polynomial fit is also added to depict the relationship between initial thermal conductivity and temperature. This initial thermal conductivity mostly consists of solid $\left(\lambda_{s}\right)$, radiation $\left(\lambda_{r}\right)$ and water $\left(\lambda_{w}\right)$. However, the radiation and water thermal conductivities in Equation 1 are extremely low and can be neglected (Simmler et al., 2005a; Baetens et al., 2010; Kobari et al., 2015; Peng and Yang, 2016; Fantucci et al., 2019). Also, as can be seen in this figure, the measured thermal conductivity increases as temperature rises. This behaviour is well known as it has been studied in a multitude of studies (Baetens et al., 2010;Wegger et al., 2011;Kim, 2017; Fantucci et al., 2019). For example, in the latter reference, Fantucci et al. considered $\lambda_{s}$ as a function of Water 
(W) and Temperature (T). Moreover in these studies, a third order equation is considered to model $\lambda_{\mathrm{s}}$ versus temperature which is given by Equation 8 (Simmler et al., 2005b, Fricke et al., 2008; Kwon et al. 2009; Alotaibi and Riffat 2014; Batard et al., 2018).

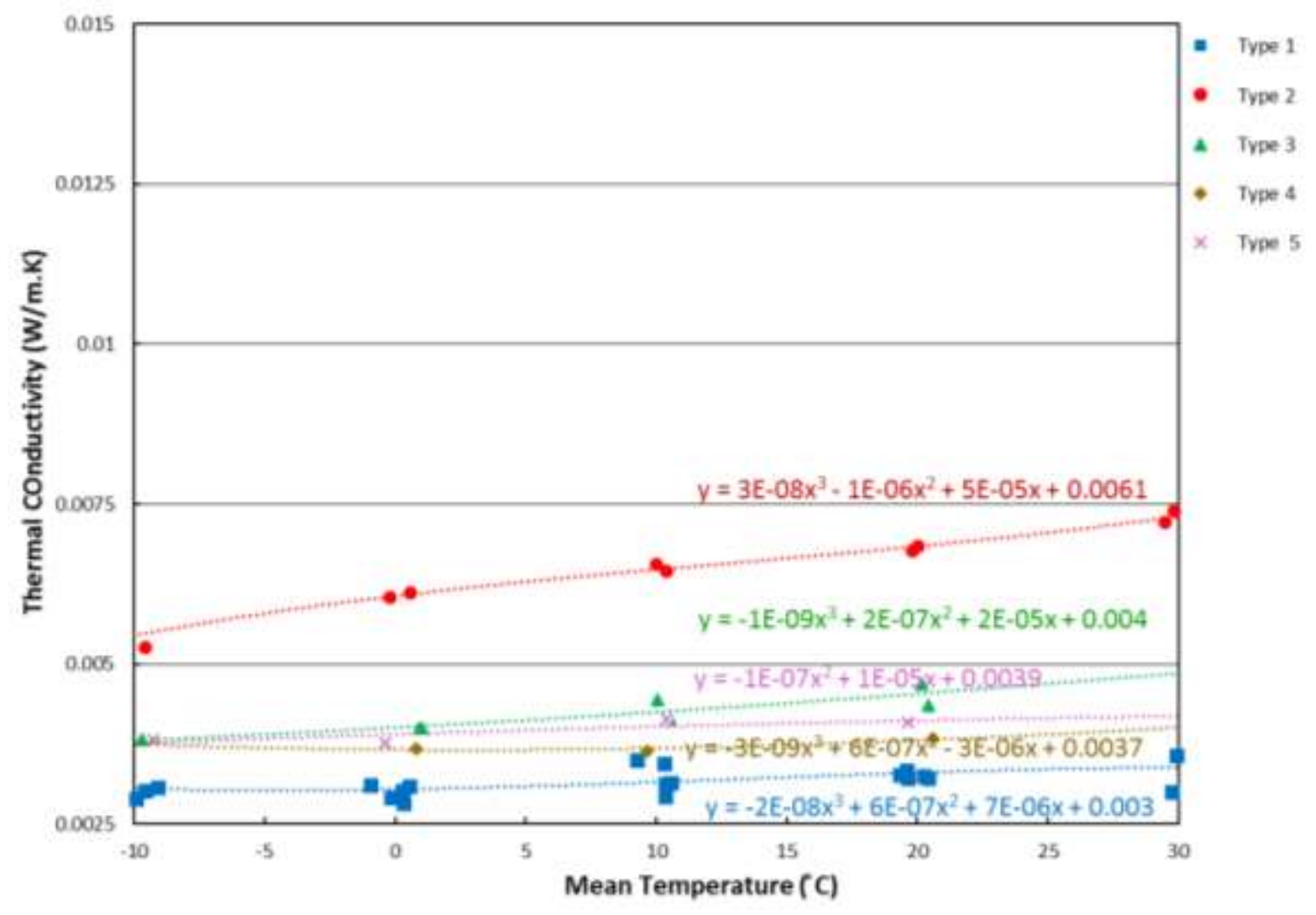

Figure 4.1: Value of thermal conductivity for five types of VIP samples

The initial thermal conductivity of Type 3a and Type 5a were measured but because their size is not common to apply in building sector and the amount of their thermal conductivity were higher than the other types, they were eliminated to prevent inaccuracy for thermal conductivity modeling. These types were costume designed and had a higher ration of edges length to area which resulted high value of initial thermal conductivity. 
Table 4.1: Measured Mean thermal conductivity in various test temperature

\begin{tabular}{|c|c|c|c|c|c|c|c|}
\hline Type & $\begin{array}{c}\text { Core } \\
\text { Material }\end{array}$ & $\begin{array}{c}\text { Thermal } \\
\text { Conductivity } \\
\text { Mean } \\
\text { (w/m.K) }\end{array}$ & $\begin{array}{l}\text { Standard } \\
\text { Deviation } \\
\text { (w/m.K) }\end{array}$ & $\begin{array}{l}\text { Lengt } \\
\text { h (cm) }\end{array}$ & $\begin{array}{l}\text { Width } \\
\text { (cm) }\end{array}$ & $\begin{array}{c}\text { Thicknes } \\
\text { s (cm) }\end{array}$ & $\begin{array}{c}\text { Weight } \\
\text { (g) }\end{array}$ \\
\hline Type 1 & Fibreglass & 0.0032 & 0.00023 & 30 & 30 & 3 & 453.5 \\
\hline Type 2 & Fumed Silica & 0.0064 & 0.00068 & 24 & 13.7 & 1 & 77.2 \\
\hline Type 3 & Fumed Silica & 0.0044 & 0.00041 & 30 & 30 & 2 & 358.5 \\
\hline Type 4 & $\begin{array}{l}\text { Compressed } \\
\text { microporous } \\
\text { silica with } \\
\text { cellules fibre }\end{array}$ & 0.0038 & 0.00014 & 30 & 30 & 2 & 334 \\
\hline Type 5 & $\begin{array}{l}\text { Compressed } \\
\text { microporous } \\
\text { silica }\end{array}$ & 0.0040 & 0.00019 & 30 & 30 & 2 & 484.5 \\
\hline Type 3a & Fumed Silica & 0.0132 & 0.00120 & 10 & 10 & 2 & 58.91 \\
\hline Type 5a & $\begin{array}{l}\text { Compressed } \\
\text { microporous } \\
\text { silica }\end{array}$ & 0.0084 & 0.00068 & 10 & 10 & 2 & 42.42 \\
\hline
\end{tabular}

Table 4.1 lists the mean and standard deviation of initial thermal conductivity over this temperature range $\left(-10^{\circ} \mathrm{C}\right.$ to $\left.30^{\circ} \mathrm{C}\right)$. As can be seen, Type $1,3,4$ and 5 has a more stable thermal conductivity over this temperature range compared to other types since the value of their standard deviation is lower. In this regard, the worst performance belongs to 3a. Also, the standard deviation is more extensive for smaller size samples. Therefore, the recent types $(3 a, 5 a)$ of samples were disregarded because of having different boundary condition. Moreover, while the structure of sample 3, 3a and 5, 5a are identical, their size is different. From Table 4.1, it is concluded that the smaller panel size provides higher thermal conductivity. 
Interestingly, although the thermal conductivity of sample types 1, 3, 4 and 5 are close to each other, they consist of different core materials. Similar to the research conducted by Kwon and et al. (Kwon et al., 2009), the experiments in this study validate that Fibreglass provides the lowest thermal conductivity and so, it is the best material as VIP core compared to aerogel, fumed silica and powder. Because fibreglass is an open puros composite, air evacuation is perfectly performed. Pressed powder microporous silica would be the second option according to Table 4.1 since it has a small size of porous, causing low convection, conduction and radiation heat transfer. This result is aligned with the results reported in (Wegger et al. 2011).

\subsection{Ageing Results of Thermal Conductivity}

Since the long-term performance of the material is one of the important factors for choosing the material, a series of accelerated ageing experiments were performed in the laboratory. The accelerated ageing method can help determine the material property in a shorter time than the actual outdoor climate ageing, and yet deliver an accurate estimation of material thermal performance. However, there are various ageing methods for materials which are used in accordance to different aspects such as 1- the status of the material in the building, 2- the accuracy of requirement and, 3- physiochemical characteristic of the material.

Although different combinations of climatic strains occur in real condition, it was observed that the permeability of the envelope is zero. Therefore, the moisture or vapour cannot pass through the envelope unless there is a scratch or a hole in the envelope. Also, since the literature review shows that the suitable use case of VIPs location is inside the assembly of the building, the UV effect on ageing can be neglected. Thus, only the temperature is considered as the main parameter determining VIP samples ageing. Therefore, all the samples were aged with an oven to assess their thermal performance over 25 years of equivalent natural outdoor condition.

In order to collect data for each sample, Arrhenius law was applied to calculate the equivalent time for accelerated ageing, as explained in section 3.1.3. Based on this method, 25 years of actual ageing is equivalent to 42 laboratory days (refer to Equation 24). Moreover, since 
datasheet of samples showed their maximum heat resistance as $120^{\circ} \mathrm{C}$, the oven temperature was set at $80^{\circ} \mathrm{C}$ condition temperature $\left(T_{u}\right)$.

Results of temperature $18{ }^{\circ} \mathrm{C}$ is considered from now on since the real condition of applying VIPs in the building is recommended in the middle of the wall assembly. Therefore, the temperature of its use is not directly influenced by radiation or outside temperature.

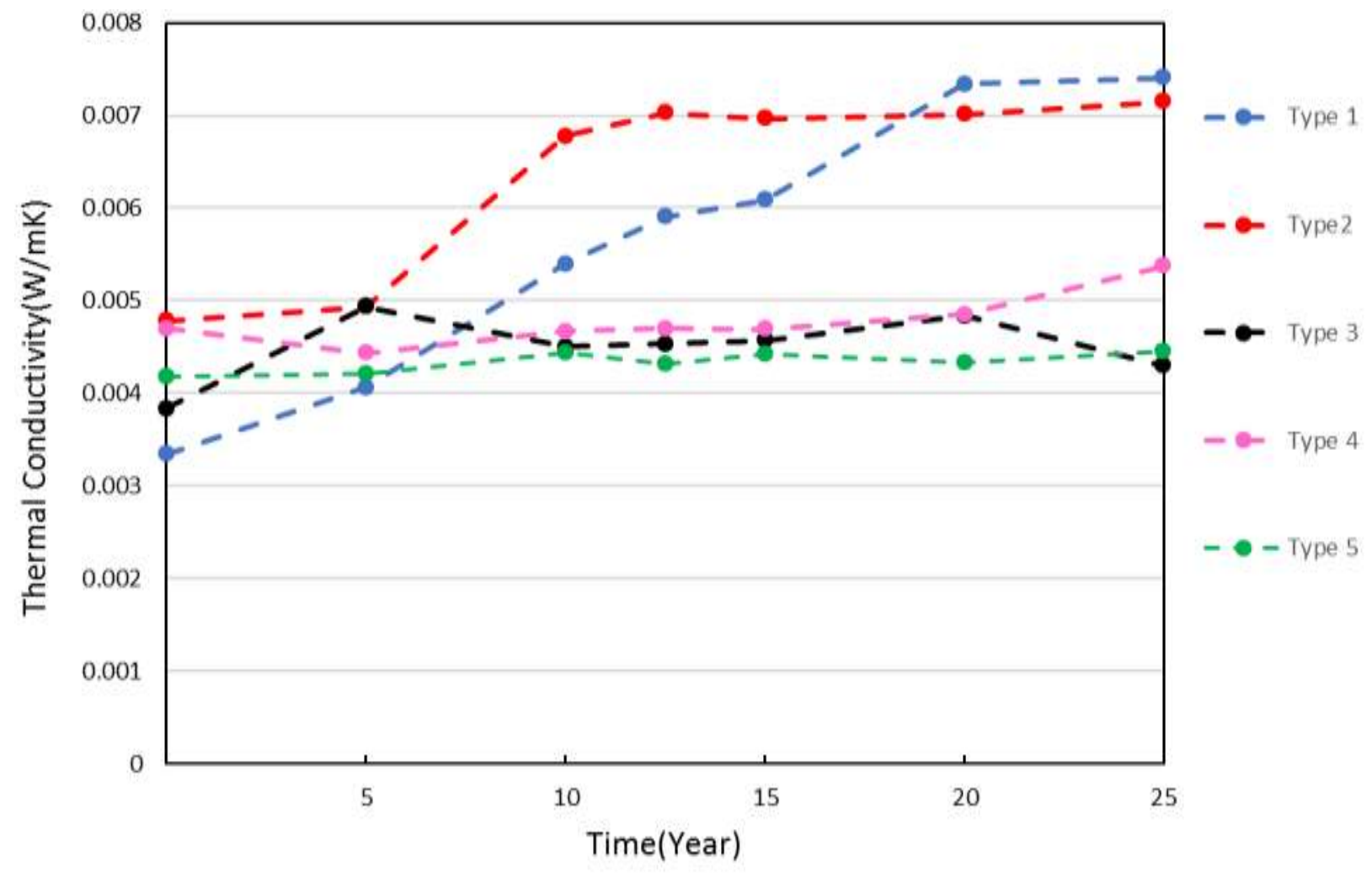

Figure 4.2: The results of thermal conductivity changes over 25 years of ageing

As it can be seen in Figure 4.2, Type 1, 2, 3, 4 and 5 have a close initial thermal conductivity in the range of $0.003-0.0045 \mathrm{~W} / \mathrm{mK}$ as their size is all $30 \times 30 \mathrm{~cm}^{2}$. While Type 1 with fibreglass core has the lowest initial thermal conductivity in comparison to the other samples, an increasing trend of thermal conductivity occurred compared to the other types in the same size, since glass fiber adsorbs water vapour.

Type 3, 4 and 5 have an approximately constant thermal conductivity over 25 years. In other words, their gas permeation and water permeation are very small. 
Type $3 a$ and $5 a$ are 10 by $10 \mathrm{~cm}^{2}$ and have higher initial thermal conductivity and have a dramatic increase over five years.

Also, the type of the envelope and the thickness of the foil through the laminate affect the thermal conductivity. For instance, Type 5, with the MF3 envelope, has the lowest permeation against gas and vapour.

The following figures show the changes in thermal conductivity over a range of Temperature from $-10{ }^{\circ} \mathrm{C}$ to $30^{\circ} \mathrm{C}$.
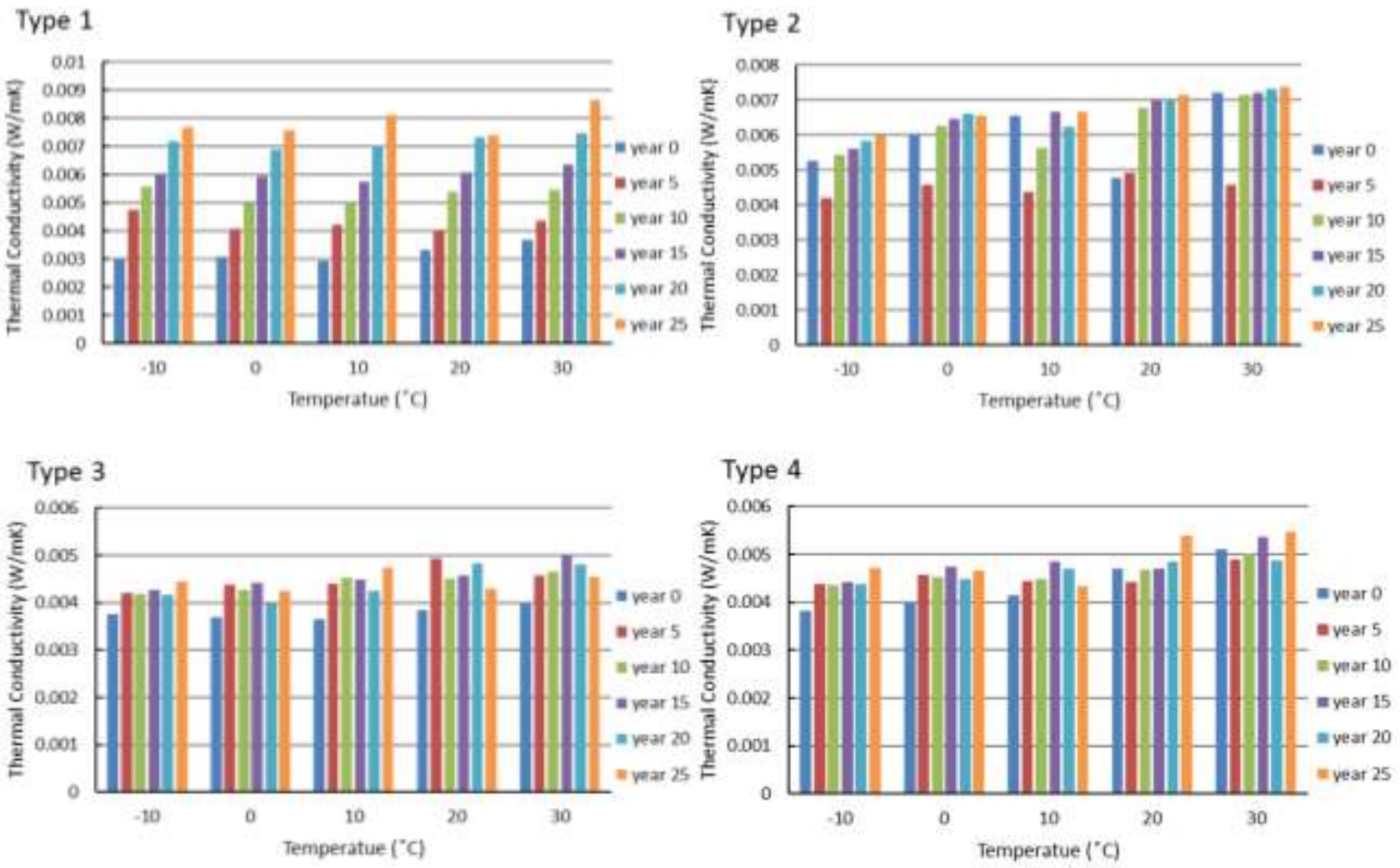

Type 5
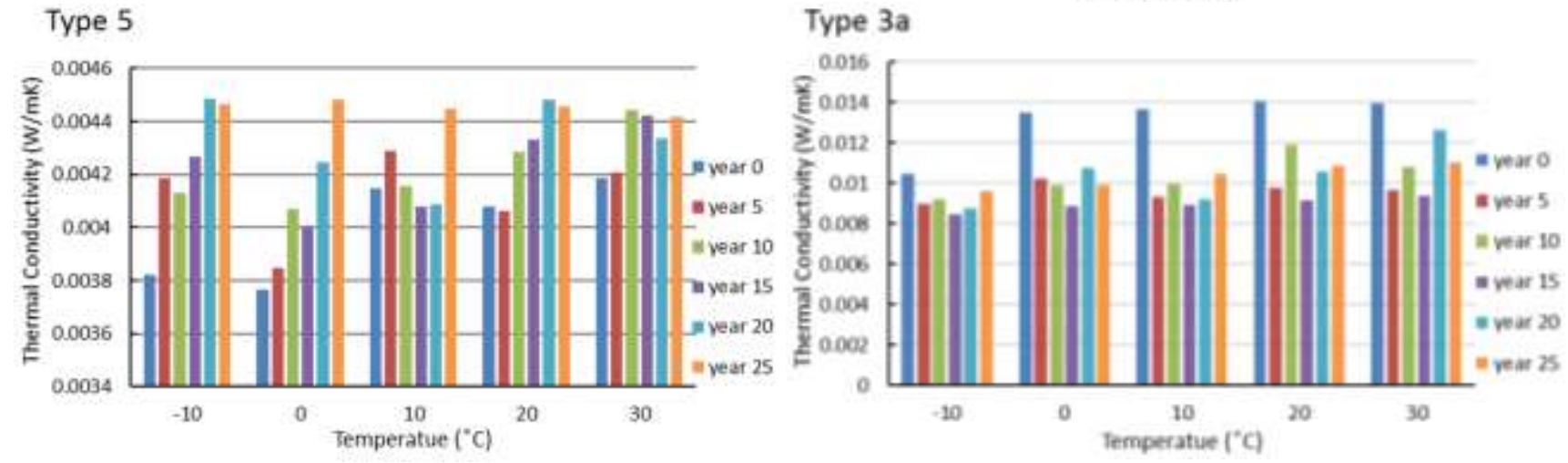


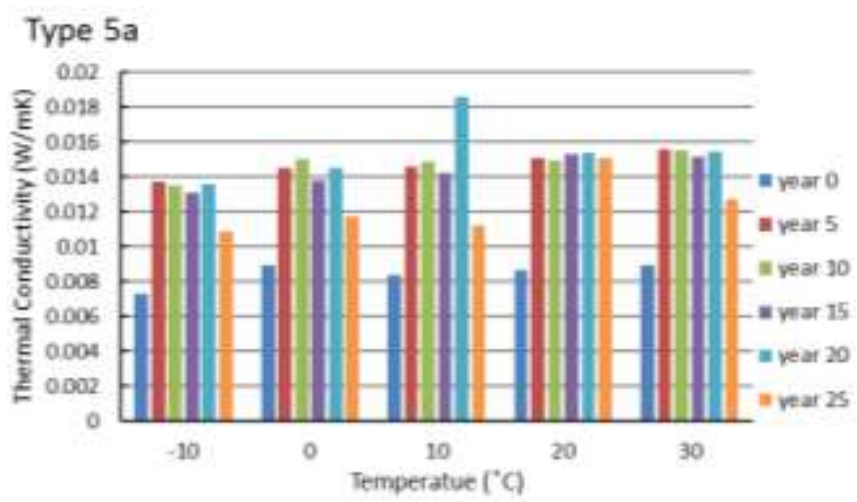

Figure 4.3: Thermal Conductivity of different samples over 25 years in different temperature

As it can be seen in

Figure 4.3, in lower temperatures the gas convection and conduction rates are small, the variation of thermal conductivity is lower over 25 years, especially for sample 2, 5,. The size and form of the panels also could affect the thermal performance of the panel, since there is additional heat loss at the panel edge as the results demonstrate. However, the smaller sample than 30 by $30 \mathrm{~cm}^{2}$ is not recommended to be applied in building sector as an insulation.

\subsubsection{Thermal Conductivity Ageing Model Verification}

In this section, the thermal conductivity trend of each sample is estimated. The samples had significantly different appearances, depending on the manufacturer. It could be concluded that a larger panel will have a longer expected lifetime than a smaller panel. The effect of the panel size is simply because of the relationship between volume and seam length, as well as the changes in volume to barrier surface relationship. These changes can be produced by the surface roughness and the evenness of the finishing on the sides. The initial thermal conductivity values of the samples mentioned in Table 4.1. Here, the studies in (Simmler et al. 2005b; Kim 2017) are used as a reference for computing the thermal conductivity trend. A simpler version of the ageing thermal conductivity equation (Equation 10) given by:

$$
\lambda_{\text {tot }}=\lambda_{\text {init }}+\lambda_{p} t+c\left(1-\exp \left(-\frac{t}{\tau_{w}}\right)\right)
$$


Where, $\lambda_{\text {init }}(\mathrm{mW} / \mathrm{mK}), \lambda_{p}(\mathrm{~mW} /(\mathrm{m} . \mathrm{K}$. year $)), c(\mathrm{~mW} / \mathrm{mK})$, and $\tau_{w}$ (year) are regression parameters depending on the envelope and core material. These parameters as verified in (Simmler et al. 2005b) (Kim 2017) are given in

Table 4.2.

Table 4.2: Parameters used for silica core material (Kim 2017)

\begin{tabular}{|c|c|c|c|c|}
\hline Parameters & $\lambda_{\text {init }}(\mathbf{m W} / \mathbf{m ~ K})$ & $\boldsymbol{\lambda} p$ & $\boldsymbol{c}$ & $\tau_{w}$ \\
\hline Sample 1,2 & 3.9 to 4.8 & 0.07 & 3.2 & 35.6 \\
\hline
\end{tabular}

In this research, the mentioned parameters are derived from experimental result using Python curve fitting library. Table 4.3 lists these parameters for each sample. Also, Equation 11 depicts thermal conductivity trends.

Table 4.3: Parameters estimated for samples under test

\begin{tabular}{ccccc}
\hline Parameters & $\begin{array}{c}\lambda_{\text {init }} \\
(\mathbf{m W} / \mathbf{m ~ K})\end{array}$ & $\begin{array}{c}\lambda p \\
(\mathbf{m W} / \mathbf{m} . \mathbf{K} . \mathbf{y e a r})\end{array}$ & $\begin{array}{c}\mathrm{c} \\
(\mathbf{m W} / \mathbf{m ~ K})\end{array}$ & $\begin{array}{c}\boldsymbol{\tau}_{\boldsymbol{w}} \\
\text { (year) }\end{array}$ \\
\hline Type 1 & 3.20 & 0.17 & 1.30 & 35.6 \\
\hline Type 2 & 4.20 & 0.07 & 2.20 & 20.0 \\
\hline Type 3 & 4.00 & 0.05 & 0.66 & 35.6 \\
\hline Type 4 & 4.00 & 0.05 & 0.66 & 35.6 \\
\hline Type 5 & 4.08 & 0.019 & 0.02 & 35.6 \\
\hline Type 3a & 8.69 & 0.01 & 2.92 & 35.6 \\
\hline Type 5a & 11.20 & 0.03 & 5.70 & 20.0 \\
\hline
\end{tabular}

Figure 4.4 illustrates Type 1 thermal conductivity measurements follow the reference model very well. The curve starts from $0.003 \mathrm{~W} / \mathrm{mK}$ and uniformly increases to $0.008 \mathrm{~W} / \mathrm{mK}$ at year 25 . This thermal conductivity shows a linear trend with a slope of $0.0002 \mathrm{~W} / \mathrm{mK}$ per year. That is, the 
thermal conductivity in this Type increases about $0.0002 \mathrm{~W} / \mathrm{mK}$ after each year, and approximately increases by $160 \%$ over 25 years time period. In this type, based on Table 4.3, the effect of $\lambda_{p}$ is dominant.

Thermal conductivity behaviour of Type 2 is shown in Figure 4.5. As can be seen in this figure, the thermal conductivity starts from $0.0044 \mathrm{~W} / \mathrm{mK}$ and rises to $0.0075 \mathrm{~W} / \mathrm{mK}$ at year 25 . Thermal conductivity value increases by about $70 \%$ over 25 years.

Type 3 behaviour is shown in Figure 4.6. Thermal conductivity begins with $0.0041 \mathrm{~W} / \mathrm{mK}$ and reaches to $0.0045 \mathrm{~W} / \mathrm{mK}$ at the end of measurement time. It increases very slowly (10\%), which shows a proper thermal performance of that material over the test time. The reference curve does not model this type reasonably. The reason is that it has low gas permeance and its $\lambda_{p}$ in Table 4.3 proves the low permeance against gas. The envelop has a low permeation.

Figure 4.7 shows a small increase for Type 4 thermal conductivity measurement over time. Thermal conductivity starts from $0.0041 \mathrm{~W} / \mathrm{mK}$ and reaches to $0.0055 \mathrm{~W} / \mathrm{mK}$ over the test time. It shows $34 \%$ of thermal conductivity increase at year 25 . This thermal conductivity shows a linear trend with a slope of $0.00006 \mathrm{~W} / \mathrm{mK}$ per year.

Then Figure 4.8 shows Type 5 thermal conductivity trend. Its initial thermal conductivity starts from $0.0041 \mathrm{~W} / \mathrm{mK}$ and goes up very slightly to $0.0045 \mathrm{~W} / \mathrm{mK}$ at year 25 . It equals to $10 \%$ increase. Based on Table 4.3, it has a low gas thermal conductivity, and it might be the reason for the small value of the slope. Therefore, it is concluded that Type 5 has a reliable performance over time as it can be observed a flat linear model in Figure 4.2, so the deterioration of the thermal performance remains very low.

However, because of the high quality of the envelope, they have low permeance $\left(\lambda_{p}\right)$. As a result, the deterioration of the thermal performance remains very high, as the conductivity increases of 0.01 W/ (m.K) (25\%- $68 \%)$ over 25 years. 


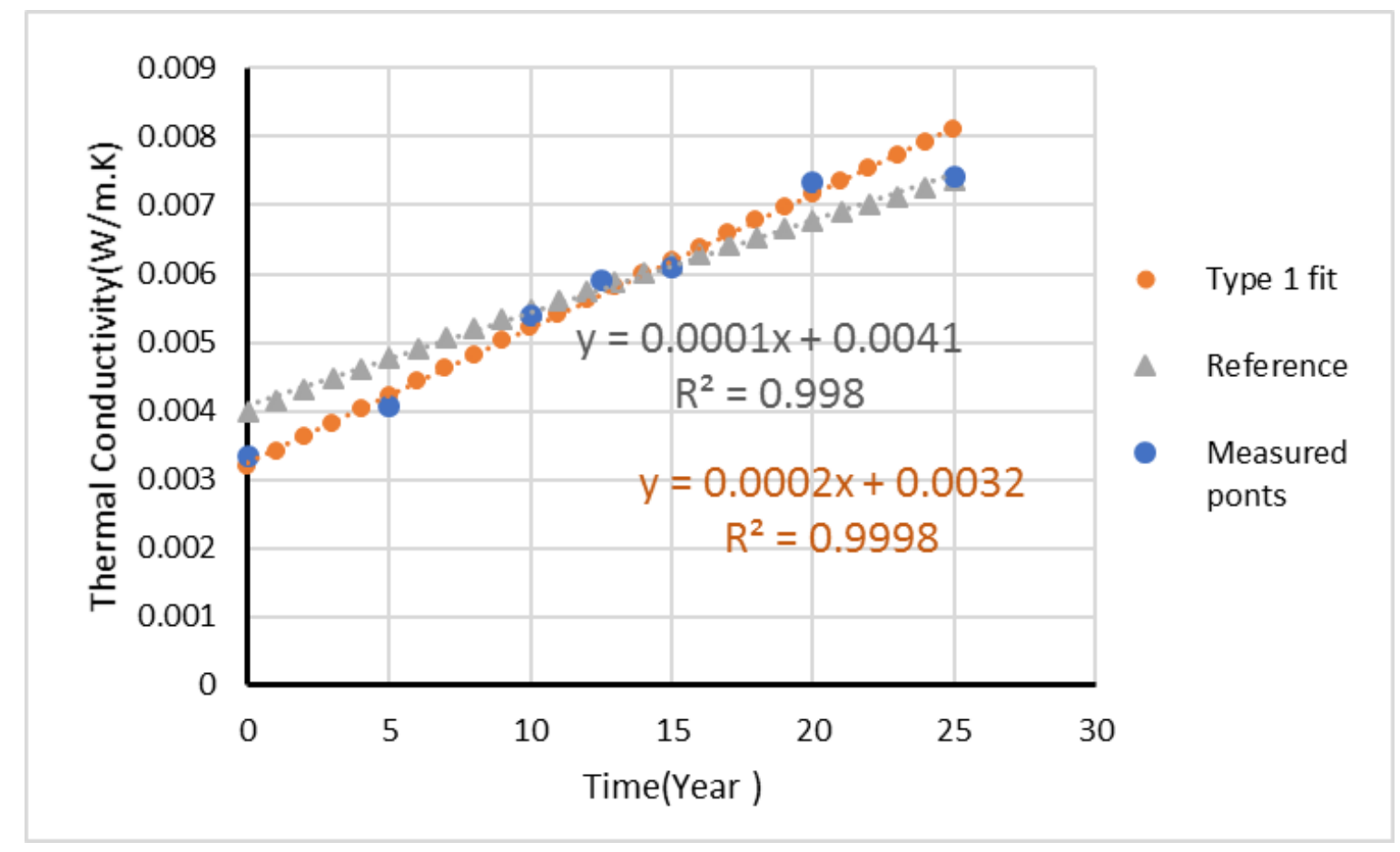

Figure 4.4: Thermal Conductivity trend for Type 1 Versus time (year)

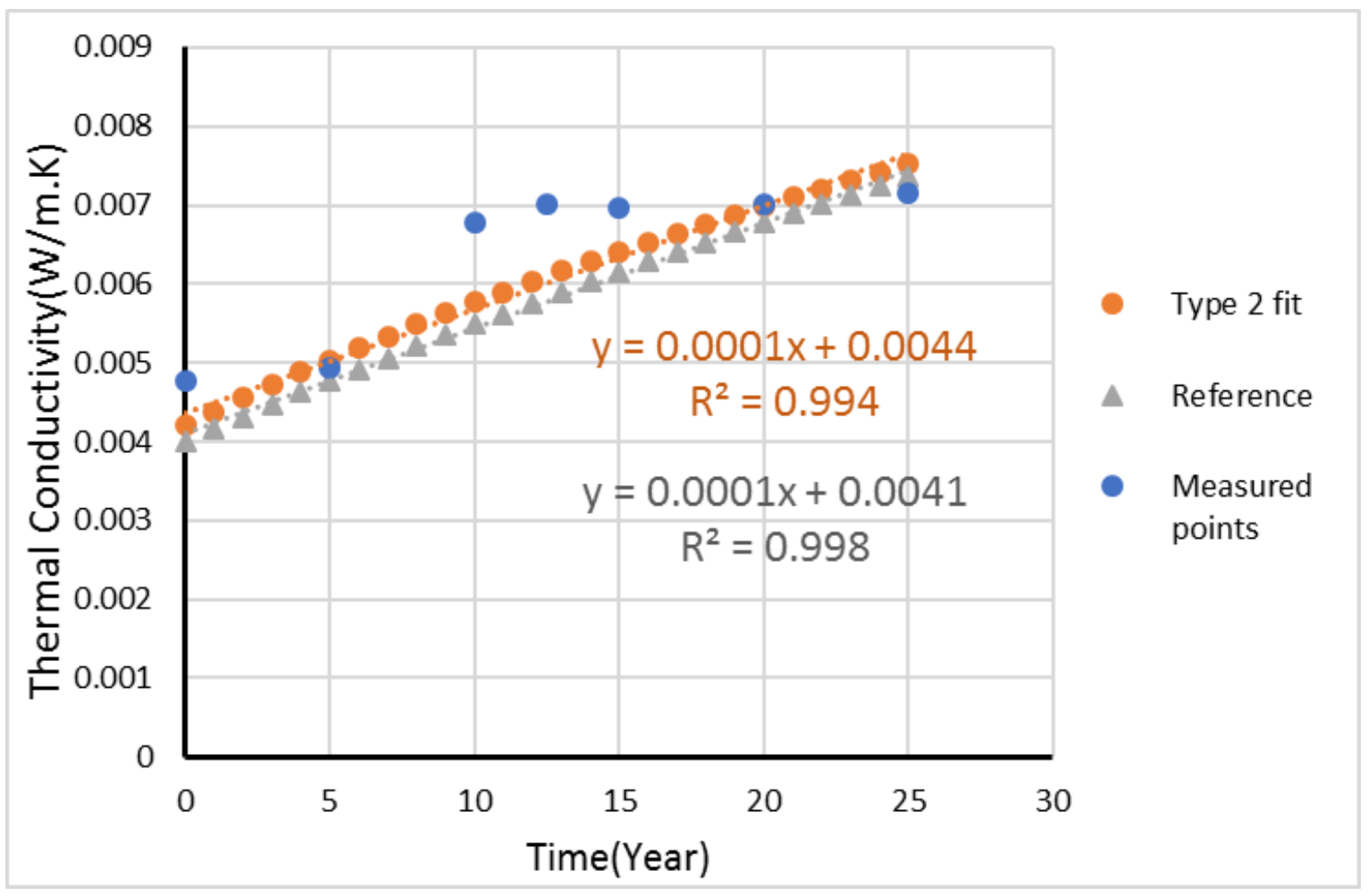

Figure 4.5: Thermal Conductivity trend for Type 2 Versus time (year) 


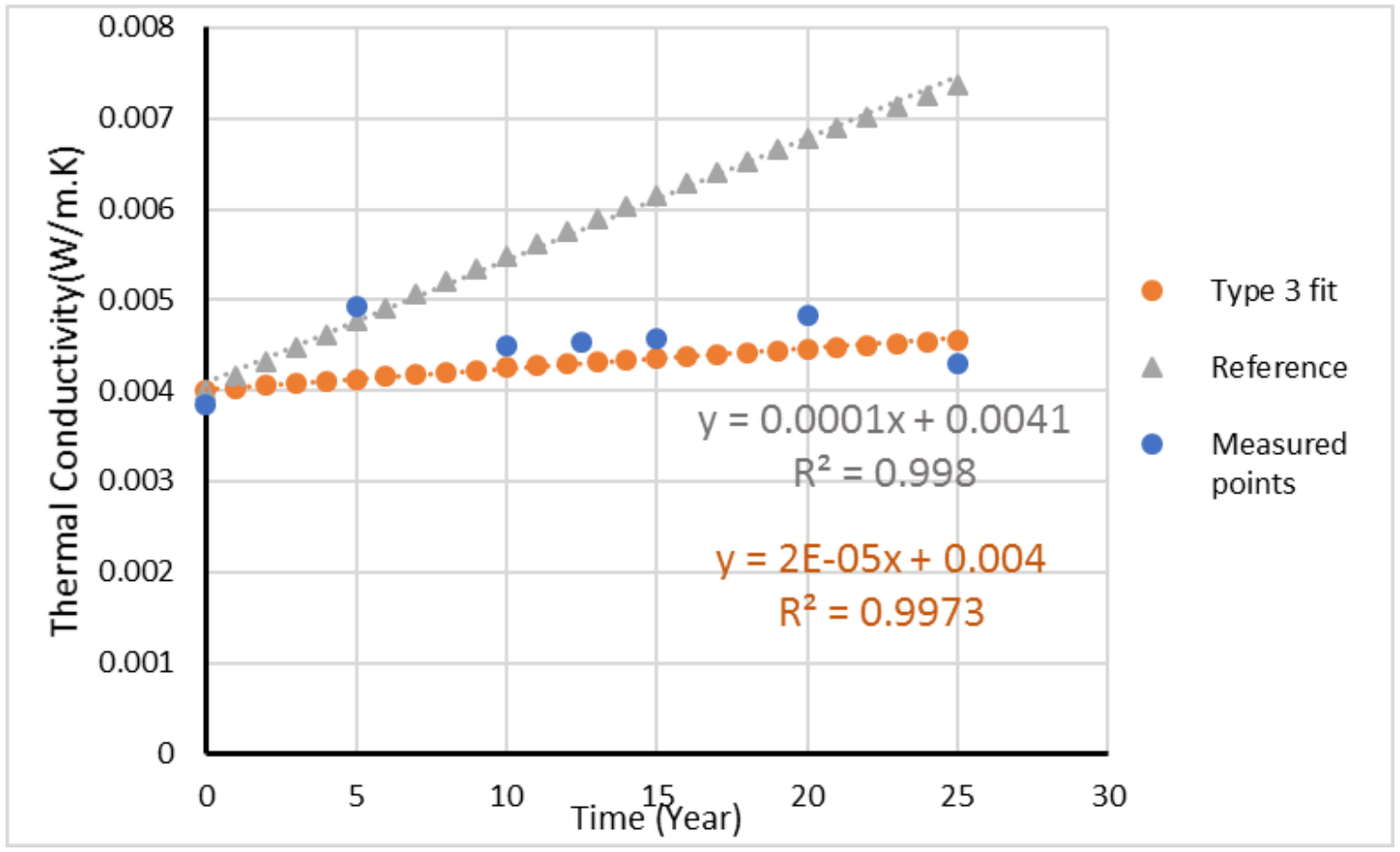

Figure 4.6: Thermal Conductivity trend for Type 3 Versus time (year)

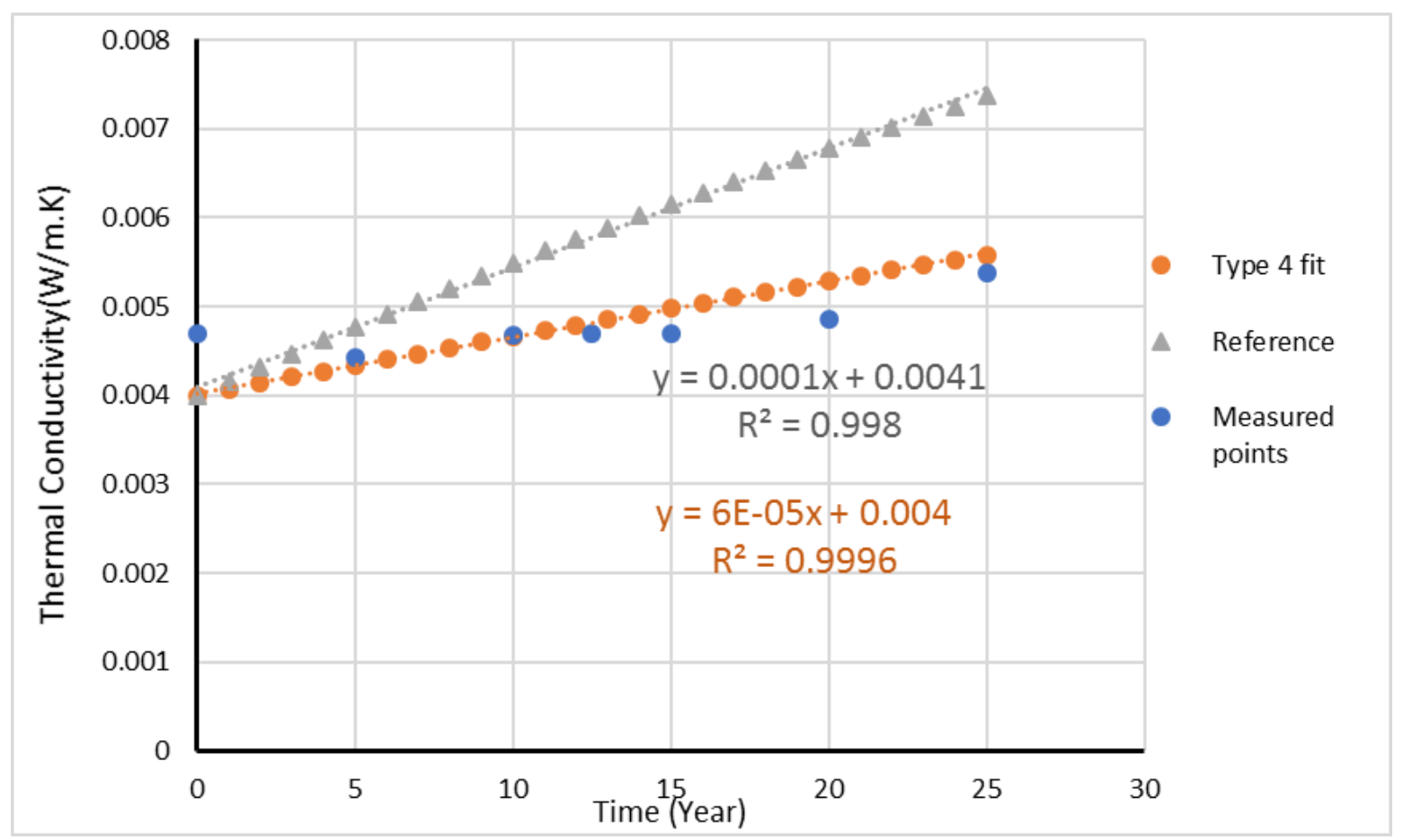

Figure 4.7: Thermal Conductivity trend for Type 4 Versus time (year) 


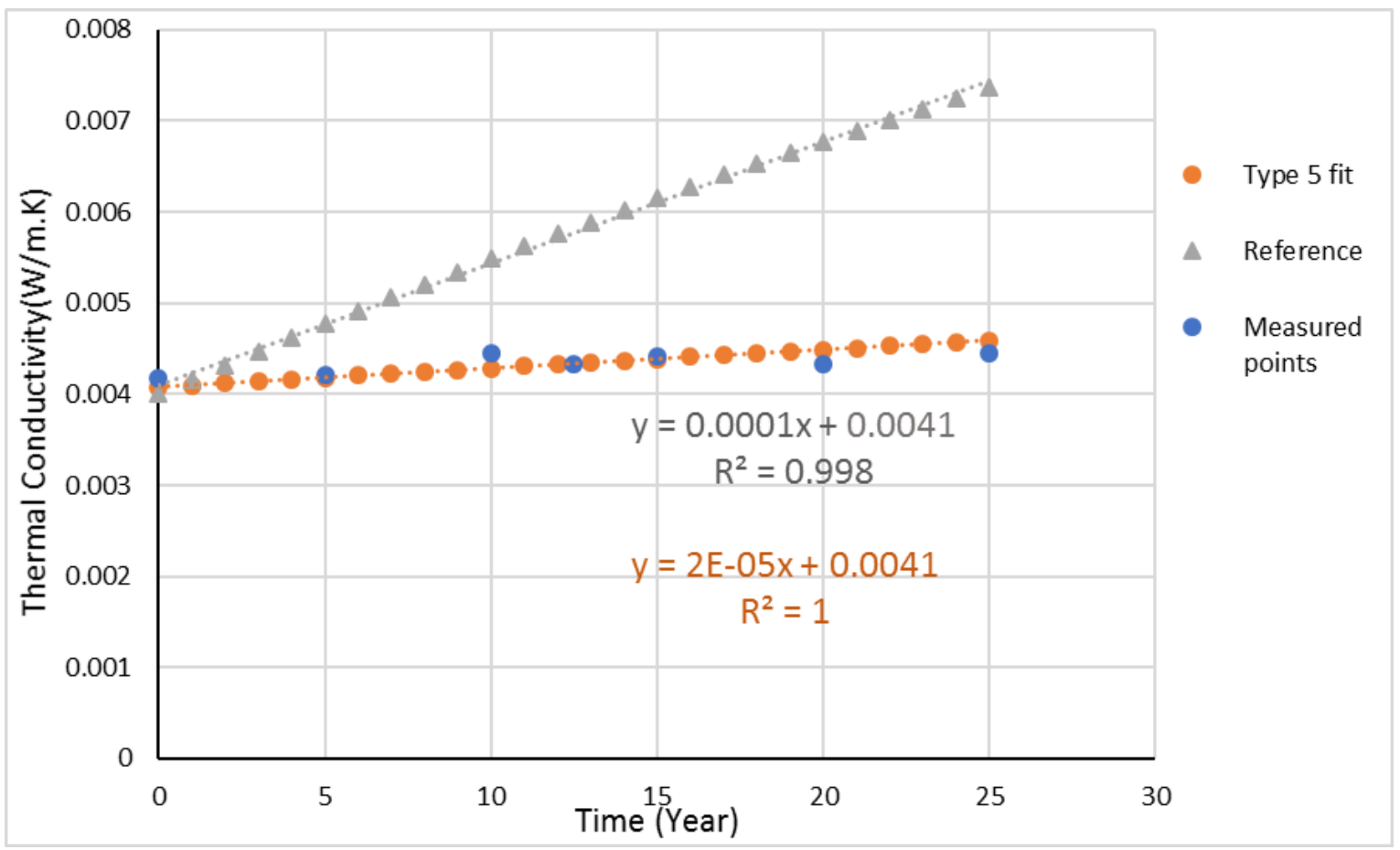

Figure 4.8: Thermal Conductivity trend for Type 5 Versus time (year)

As it can be seen in Figure 4.4 to Figure 4.8, Sample 1,2, and closely follow the reference model, but sample type 3, 4 and 5 demonstrate a better ageing performance for VIPs as it can be seen they have a flat trend in their figures. However, they do not follow the reference model, and further investigation is required. Since, $\lambda_{\text {init }}$ for sample 3 and 5 are close to the $\lambda_{\text {init }}$ of the reference model as $\left(R^{2} \sim 1\right)$ and their value of $\lambda_{p}$ are better than the samples of the refence. The difference in $\lambda_{\text {init }}$ is because of the envelope type difference (i.e. they have the same range of foil thickness and similar core material).

According to Table 4.3, Type 2 has another envelope type which is MF3, so it can be concluded from Figure 2.13 that the gas permeability (GTR) of MF3 envelope is higher than types with MF2 envelope.

For long-term performance, not only $\lambda_{\text {init }}$ plays an important role but also $\lambda_{p}$ makes a massive difference in total thermal conductivity over time. For example, Type 1 consists of a fibreglass core with lower initial thermal conductivity $(3.20 \mathrm{~mW} / \mathrm{mK})$ in comparison to Type 2 
$(4.20 \mathrm{~mW} / \mathrm{mK})$, but because of its higher gas permeability coefficient $(0.17)$, its total thermal conductivity after ten years $(5.5 \mathrm{~mW} / \mathrm{mK})$ is comparable to that of Type 2 , as it can be seen in Figure 4.4 and Figure 4.5.

According to the calculation of effective core volume given in Table 4.4, Type 1, 3, 4 and 5 have a lower amount of gas. Therefore, their thermal conductivity is lower than the others.

Table 4.4: Volume of porosity for various specimens

\begin{tabular}{ccccc}
\hline $\begin{array}{c}\text { Sample } \\
\text { Type }\end{array}$ & $\begin{array}{c}\text { V silica } \\
\mathbf{m}^{\mathbf{3}}\end{array}$ & $\begin{array}{c}\text { Pros } \\
\text { Volume}\left(\mathbf{m}^{\mathbf{3}}\right)\end{array}$ & $\begin{array}{c}\text { 1-Pros } \\
\text { Volume(m3) }\end{array}$ & $\begin{array}{c}\text { Veff } \\
\text { Volume(m3) }\end{array}$ \\
\hline $\mathbf{1}$ & 0.0027 & 0.18740 & 0.81259 & 0.002194 \\
\hline $\mathbf{2}$ & 0.00039 & 0.02222 & 0.97777 & 0.000385 \\
\hline $\mathbf{3}$ & 0.0018 & 0.10790 & 0.89209 & 0.00160 \\
\hline $\mathbf{4}$ & 0.00189 & 0.06878 & 0.93121 & 0.00176 \\
\hline $\mathbf{5}$ & 0.0018 & 0.1111 & 0.88888 & 0.0016 \\
\hline $\mathbf{3 a}$ & 0.0002 & 0.04 & 0.96 & 0.00019 \\
\hline $\mathbf{5 a}$ & 0.0002 & 0.0625 & 0.9375 & 0.00018 \\
\hline
\end{tabular}

\subsection{Effective Thermal Conductivity and Service Life}

Service life is one of the main characteristics of VIP assessment to find its reliability over the life cycle. It is assumed that that temperature loads have the main impact on VIP failure and thus deserve a detailed investigation as it has been conducted in section 4.2. In this research to define the maximum allowable degradation of a product to see if it is still acceptable to users, as well as the appearance, functionality was presented for each specimen in this section to evaluate their service life (Kunic 2012; Wegger et al. 2010).

Based on the experimental results of the VIPs thermal conductivity over time and using extrapolation techniques, the predicted VIPs service life is listed in Table 4.5. The threshold value for the first definition of service life (American Standard C1484) is assumed to be $0.008 \mathrm{~W} / \mathrm{mK}$ 
and $11 \times 10^{-3} \mathrm{~W} / \mathrm{mK}$ (Tenpierik et al., 2010). Based on this threshold in different references, plotted on thermal conductivity, the threshold limitation and the service life of each specimen results in Table 4.5. The thermal conductivity model illustrated in Figure 4.4 to Figure 4.8 , then the service life of each sample shows that Typ3 and Type 5 have the most extended service life among other types, formerly it follows with Type 4, 2 and 1.

Table 4.5: The service life of samples under test

\begin{tabular}{|c|c|c|c|c|c|}
\hline Sample & Type 1 & Type 2 & Type 3 & Type 4 & Type 5 \\
\hline Service Life for & 25 years & 30 years & > 100 years & 70 years & $>100$ years \\
\hline \multicolumn{6}{|l|}{$0.008 \mathrm{~W} / \mathrm{mK}$} \\
\hline Service Life for & 40 years & 65 years & $>100$ years & $>100$ years & $>100$ years \\
\hline $0.011 \mathrm{~W} / \mathrm{mK}$ & & & & & \\
\hline
\end{tabular}

In these models, similar values are found for MF2-VIPs as the MF3-VIPs, while for MF1-VIPs an unacceptable service life of fewer than ten years was found.

\subsection{Summary and Discussion}

A state-of-the-art insulation system provides a lower degree of thermal conductivity than traditional insulation materials. They facilitate the achievement of the desired energy standards while at the same time saving living space due to thinner building walls. Materials, considered to be VIPs, are still new to the market and their price is high. Due to their high price, it is important to assess VIP long term behaviour over a lengthy process of natural ageing. In this study, accelerated laboratory ageing was employed to simulate the effect of several years of ageing under use condition in only a few months. The life span of VIPs depends upon different parameters such as size, manufacturing quality, core materials, physical handling and conditions of use.

The primary variables which define the quality of these materials are: (1) the density of the core, (2) the transmission rates of gas and, (3) water vapour through the film barrier (which can be 
controlled by improving the fabrication process of these films). Here, the sample thermal conductivity test was conducted under various temperatures. The test results show that the thermal performance of the samples is mainly affected by temperature and, the amount of effect by moisture is minimal as they exposure to a different level of humidity in the chamber (as explained in 2.5.5). The focus of experimental measurements and mathematical analysis in this study was on the thermal load of VIP panels during accelerating ageing tests based on Arrhenius law (as explained in section 3.1.3.1). Gas permeance is the main factor that has the most considerable influence on performance and, the results also compare to the reference model. Through this analysis, it is evident that the thermal resistance of the vacuum insulation panels reduces over time for Type 1, 2, because of their higher gas and moisture transmittance. Thermal performance of Type 3, 4 and 5 is proper as they meet the thermal conductivity requirement for VIPs over a hundred years. By comparing Type 1 and 3 , it is obvious that the core materials with lower pore sizes have longer life spans. Also, the panels with larger size have longer life span base on measurement results. 


\section{Conclusions}

Since thermal conductivity values of insulating materials are playing a significant role in energy saving in buildings, the long-term performance of this material must be analyzed to determine the benefits of VIPs used. Also, to provide useful insight for material performance, it is necessary to model the performance and test the material for a long duration of time before determining its potential in building applications.

Through empirical examination, this work investigates the influence of operating temperatures condition of VIPs $\left(-10^{\circ} \mathrm{C}\right.$ to $\left.30^{\circ} \mathrm{C}\right)$ on the thermal conductivity at the center. Afterwards, the effect of accelerated ageing on thermal conductivity performance of VIPs has been analyzed to determine which VIPs perform effectively over 25 years or more of ageing.

Seven specimens of fumed silica and fiberglass-based VIPs characterized by two different envelopes were analyzed. The performance of the samples was measured when they were fresh (as delivered by the producer) and after they were aged in a laboratory for 42 days to simulate 25 years of ageing (with elevated temperature method and Arrhenius law).

The experimental analysis shows that:

- The thermal conductivity increases about $1 \%-2.5 \%$ on average for compressed microporous silica-based (panel size: $30 \times 30 \mathrm{~cm}^{2}$ ) when the average temperature is $20^{\circ} \mathrm{C}$ for 25 years.

- The thermal conductivity increases about $2 \%$ on average for compressed microporous silica with cellulose fiber based (panel size: $30 \times 30 \mathrm{~cm}^{2}$ ) when the average temperature is $20^{\circ} \mathrm{C}$ for 25 years.

- The thermal conductivity increases about $5 \%-11 \%$ on average for compressed microporous silica with cellulose fiber based (panel size: $10 \times 10 \mathrm{~cm}^{2}$ ) when the average temperature is $20^{\circ} \mathrm{C}$ for 25 years.

- A small variation of thermal conductivity for compressed microporous silica, compressed microporous silica and fiberglass based (panel size: $30 \times 30 \mathrm{~cm}^{2}$ ) cores were observed at negative temperatures. However, since their core material porosity is dissimilar, they present different thermal conductivity behaviour. The performance of the VIP microporous silica type is moderately better than that of the fibreglass over time. 
- The temperature increase influences gaseous thermal conductivity. However, the temperature dependent contribution of the gaseous condition cannot be measured individually. Experimental results show that compressed microporous silica and compressed microporous silica with cellulose has a steady thermal conductivity over 25 years.

- Although the initial thermal conductivity of fiberglass based is less than that of the compressed microporous silica one, fiberglass shows a significant increase in thermal conductivity after ten years. However, this type is recommended for building sectors, because it lasts about 40 years satisfying the standard thermal conductivity threshold.

- Larger and thicker panels with compressed microporous silica (with cellulose) relatively have a longer service life.

- This information was then used within a numeric model to validate accelerated ageing experiments conducted by the NRC, to identify unknown material properties. Upon evaluating the results, it was determined that VIPs have the potential to be used in building applications; however, the development of standards in material fabrication and testing are necessary to ensure that the quality of material produced is enough to achieve the adequate performance.

- The numerical reference model used by NRC is adapted for VIPs with fumed silica and fibreglass-based core material. However, a different mathematical model needs to be developed for compressed microporous silica and compressed microporous silica with cellulose. A significant mismatch is observed between the theoretical model of NRC and the measurement results of these types.

\subsection{Limitations of the study}

Although this research provides new insights into the thermal performance and long-term behaviour of VIP products, various problems and shortcomings were encountered in conducting the investigation, which must be viewed as caveats. These limitations are as the following:

- The standards and literature on the ageing of building materials are limited and difficult to find. 
- Most of the literature is related to appliances and quality assurance, which reduces the scope of research.

- The available number of the specimens for the test is limited, and it is a challenge to get enough number of samples from the manufacturers, which do not offer a lot of commercially available samples for different types of core and envelope. Also, because the materials are high-performance, most companies deny providing technical information such as the exact thickness and layers of the envelope; this information is confidential to the companies.

- Measuring the pressure during the accelerated ageing procedure is another limitation. As the specimens should not be destroyed by the employed pressure measurement method, the companies need to install a pressure sensor before they send out their product. Furthermore, companies must provide or sell data collector systems to monitor the internal gas pressure changes during accelerated ageing.

- There is a limitation of testing VIP specimens larger than $30 \mathrm{~cm}$, as the existing heat flowmeter machines can measure samples geometries up to $30 \times 30 \mathrm{~cm}^{2}$.

- Besides, the measurements are prone to error due to the uncertainty of the test apparatus. Although measuring erroneous data is unavoidable, utilization of more accurate and high-quality devices with smaller uncertainties would reduce experimental errors.

\subsection{Future work}

The main objective of this thesis is the assessment and quantification of thermal performance and service life of VIPs over 25 years. Future research topics and projects in the direction of this study include:

- Out of range values for some Types: As explained before and for some thermal tests, some out of range values were observed. More tests over a longer period of time (e.g. 50 to 100 years) are required to investigate these phenomena. 
- Some types do not follow the mathematical model correctly. It is recommended to collect more data to obtain a deeper understanding of material properties and to improve the model.

- Investigate on VIPs samples with AF, MF1 and MF4 envelope and the various core material is required to assess their thermal behaviour and service life.

- Another topic is assessment of VIPs thermal performance in different climate zone, design and model assemblies retrofitted by VIPS in WUFI and comparing them to the traditional ones.

- It is necessary to measure the internal gas pressure and water vapour during the ageing of VIPs and evaluate their impact on VIP ageing to get a clearer idea regarding the independent effect of gas pressure and water vapour.

- To simulate a more realistic conditions in terms of coupling temperature and humidity effect on VIPs thermal performance and service life, thus employing a Climate chamber is required. 


\section{References}

Abdul Mujeebu, Muhammad, Noman Ashraf, and Abdulkarim Alsuwayigh. 2016. "Energy Performance and Economic Viability of Nano Aerogel Glazing and Nano Vacuum Insulation Panel in Multi-Story Office Building." Energy 113:949-56.

Aegerter, Michel, Nicholas Leventis, and Matthias M. Koebel. 2011. Aerogel Hanbook. NewYork, Springer.

Alam, M., H. Singh, S. Suresh, and D. A. G. Redpath. 2017. “Energy and Economic Analysis of Vacuum Insulation Panels (VIPs) Used in Non-Domestic Buildings." Applied Energy 188:1-8.

Alotaibi, Sultan Sanat and Saffa Riffat. 2014. "Vacuum Insulated Panels for Sustainable Buildings: A Review of Research and Applications." INTERNATIONAL JOURNAL OF ENERGY RESEARCH.

Baetens, R, B. P. Jelle, J. V Thue, M. J. Tenpierik, S. Grynning, S. Uvslokk, and A. Gustavsen. 2010. "Vacuum Insulation Panels for Building Applications: A Review and Beyond." Energy and Buildings 42(2):147-72.

Baetens, Ruben, Bjørn Petter Jelle, Jan Vincent Thue, Martin J. Tenpierik, Steinar Grynning, Sivert Uvsløkk, and Arild Gustavsen. 2010. “Vacuum Insulation Panels for Building Applications: A Review and Beyond." Energy and Buildings 42(2):147-72.

Baldinelli, Giorgio, Francesco Bianchi, Stanislavs Gendelis, Andris Jakovics, Gian Luca Morini, Stefania Falcioni, Stefano Fantucci, Valentina Serra, M. A. Navacerrada, C. Díaz, Antonio Libbra, Alberto Muscio, and Francesco Asdrubali. 2019. "Thermal Conductivity Measurement of Insulating Innovative Building Materials by Hot Plate and Heat Flow Meter Devices: A Round Robin Test." International Journal of Thermal Sciences 139(February):25-35.

Batard, A., T. Duforestel, L. Flandin, and B. Yrieix. 2018. “Modelling of Long-Term HygroThermal Behaviour of Vacuum Insulation Panels." Energy and Buildings 173:252-67. 
Berge, Axel and PÄR Johansson. 2012. "Literature Review of High Performance Thermal Insulation." Building Physics (Report 2012:2) (January 2012):40.

C.YANG, L. XU. 2007. “Outgassing of Rigid Open-Celled.” CELLULAR PLASTICS 43(January 2007).

Caps, Roland, Hermann Beyrichen, Daniel Kraus, and Stephan Weismann. 2008. "Quality Control of Vacuum Insulation Panels : Methods of Measuring Gas Pressure." 82:691-99.

Cho, Kyuman, Yesim Hong, and Janghoo Seo. 2014. "Assessment of the Economic Performance of Vacuum Insulation Panels for Housing Projects." Energy and Buildings 70:45-51.

Duong, Hai M. and Son T. Nguyen. 2016. Nanocellulose Aerogels as Thermal Insulation Materials.

Fantucci, Stefano, Alice Lorenzati, Alfonso Capozzoli, and Marco Perino. 2019. "Analysis of the Temperature Dependence of the Thermal Conductivity in Vacuum Insulation Panels." Energy and Buildings 183:64-74.

Fricke, J., U. Heinemann, and H. Ebert. 2008. "Vacuum Insulation Panels-From Research to Market." Vacuum 82(7):680-90.

Fricke, J., H. Schwab, and U. Heinemann. 2006. "Vacuum Insulation Panels - Exciting Thermal Properties and Most Challenging Applications." International Journal of Thermophysics 27(4):1123-39.

Ghazi Wakili, K., T. Stahl, and S. Brunner. 2011. “Effective Thermal Conductivity of a Staggered Double Layer of Vacuum Insulation Panels." Energy and Buildings 43(6):1241-46.

Gmbh, Hasomed. 2009. “Operating Manual -.” (December).

Hümmer, E., X. Lu, Th Rettelbach, and J. Fricke. 1992. “Heat Transfer in Opacified Aerogel Powders." Journal of Non-Crystalline Solids 145(C):211-16.

Isaia, Francesco and, Stefano. Fantucci, Alfonso. Capozzoli, and Marco. Perino. 2015. "Vacuum Insulation Panels: Thermal Bridging Effects and Energy Performance in Real Building 
Applications." Energy Procedia 83:269-78.

Jelle, Petter. 2012. "Evaluation of Building Products by Conducting Accelerated Climate Ageing in the Laboratory." (7465):1-9.

Johansson, Pär, Bijan Adl-Zarrabi, and Axel Berge. 2015. “Evaluation of Long-Term Performance of VIPs." Energy Procedia 78(0):388-93.

Kalnæs, Simen Edsjø and Bjørn Petter Jelle. 2014. "Vacuum Insulation Panel Products: A Stateof-the-Art Review and Future Research Pathways." Applied Energy 116(7465):355-75.

Kalnæs, Simen and Bjørn Jelle. 2014. "Vacuum Insulation Panel Products: A State-of-the-Art Review and Future Research Pathways." Applied Energy 116(7465):355-75.

Karami, Peyman, Nadia Al-Ayish, and Kjartan Gudmundsson. 2015. "A Comparative Study of the Environmental Impact of Swedish Residential Buildings with Vacuum Insulation Panels." Energy and Buildings 109:183-94.

Kim, Jin-Hee. 2017. “Aging Performance Evaluation of Vacuum Insulation Panel (VIP) T.” Elsevier 7(June):329-35.

Kobari, Tatsuya, Junnosuke Okajima, Atsuki Komiya, and Shigenao Maruyama. 2015.

“Development of Guarded Hot Plate Apparatus Utilizing Peltier Module for Precise Thermal Conductivity Measurement of Insulation Materials." International Journal of Heat and Mass Transfer 91:1157-66.

Kucukpinar, Esra, Oliver Miesbauer, Yoash Carmi, Marc Fricke, Leif Gullberg, Can Erkey, Roland Caps, Malcolm Rochefort, Araceli Galvez Moreno, Clara Delgado, Michael Koehl, Paul Holdsworth, and Klaus Noller. 2015. “Development of Transparent and Opaque Vacuum Insulation Panels for Energy Efficient Buildings." Energy Procedia 78:412-17.

Kunic, Roman. 2012. "Vacuum Insulation Panels -an Assessment of the Impact of Accelerated Ageing on Service Life." Strojniski Vestnik/Journal of Mechanical Engineering 58(10):598606. 
Kwon, Jae-sung, Choong Hyo Jang, Haeyong Jung, and Tae-ho Song. 2009. “International Journal of Heat and Mass Transfer Effective Thermal Conductivity of Various Filling Materials for Vacuum Insulation Panels." International Journal of Heat and Mass Transfer 52(2324):5525-32.

Kwon, Jae Sung, Choong Hyo Jang, Haeyong Jung, and Tae Ho Song. 2009. "Effective Thermal Conductivity of Various Filling Materials for Vacuum Insulation Panels." International Journal of Heat and Mass Transfer 52(23-24):5525-32.

Li, Cheng-dong, Zhao-feng Chen, Fred Edmond Boafo, Teng-zhou Xu, and Lu Wang. 2014. "Journal of Materials Processing Technology Effect of Pressure Holding Time of Extraction Process on Thermal Conductivity of Glassfiber VIPs." Journal of Materials Processing Tech. 214(3):539-43.

Lorenzati, Alice, Stefano Fantucci, Alfonso Capozzoli, and Marco Perino. 2015. "VIPs Thermal Conductivity Measurement: Test Methods, Limits and Uncertainty." Energy Procedia 78:418-23.

M. Alam, H. Singh, M. C. Limbachiya. 2011. "Vacuum Insulation Panels (VIPs) for Building Construction Industry - A Review of the Contemporary Developments and Future Directions." 88(11):3592-3602.

MacLean, Doug, Phalguni Mukhopadhyaya, Juergen Korn, and Stephen Mooney. 2017. “Design Details and Long-Term Performance of VIPs in Canada's North." Energy Procedia 111:48189.

Marouani, S. 2012. "Investigation of the Resistance Welding of Multilayers Aluminum-Coated Polymer Complexes Used as Envelopes of Vacuum Insulation Panels." Materials and Design 36:546-56.

Mathias Bouquerel, Thierry Duforestel, Dominique Baillis and and Frédéric Kuznik. 2011. “HEAT AND MASS TRANSFER MODELING IN VACUUM INSULATION PANELS, TOWARDS LONG TERM THERMAL PERFORMANCE SIMULATION EDF R \& D , Moret-Sur-Loing, France Heat 
Transfer in the Core Material." Heat and Mass Transfer (2):14-16.

Meersman, Glenn De, Nathan Van Den Bossche, and Arnold Janssens. 2015. "Long Term Durability of Vacuum Insulation Panels : Determination of the Sd-Value of MF-2 Foils." 78:1574-80.

Molleti, Sudhakar, Dominique Lefebvre, and David van Reenen. 2018. "Long-Term in-Situ Assessment of Vacuum Insulation Panels for Integration into Roofing Systems: Five Years of Field-Performance." Energy and Buildings 168:97-105.

Morel, Benoît, Laurence Autissier, Denis Autissier, and Daniel Quenard. 2007. "Modifications of a Pyrogenic Silica Exposed to Moist Air." 8th International Vacuum Insulation Symposium 8.

Natural Resources Canada. 2014. “Energy Use Data Handbook: 1990 - 2011.” 1-95.

Nussbaumer, T., K. Ghazi Wakili, and Ch Tanner. 2006. “APPLIED Experimental and Numerical Investigation of the Thermal Performance of a Protected Vacuum- Insulation System Applied to a Concrete Wall." 83:841-55.

Peng, Changhai and Jianqiang Yang. 2016. "Structure, Mechanism, and Application of Vacuum Insulation Panels in Chinese Buildings." Advances in Materials Science and Engineering 2016.

Pons, E., B. Yrieix, L. Heymans, F. Dubelley, and E. Planes. 2014. “Permeation of Water Vapor through High Performance Laminates for VIPs and Physical Characterization of Sorption and Diffusion Phenomena." Energy and Buildings 85:604-16.

Pons, Emmanuelle, Bernard Yrieix, and Samuel Brunner. 2018. "Evaluation of VIPs after Mild Artificial Aging during 10 Years : Focus on the Core Behavior." 162:198-207.

Saber, Hamed H., Wahid Maref, Ganapathy Gnanamurugan, and Mike Nicholls. 2015. “Energy Retrofit Using Vacuum Insulation Panels: An Alternative Solution for Enhancing the Thermal Performance of Wood-Frame Walls." Journal of Building Physics 39(1):35-68. 
Schwab, Hubert, Ulrich Heinemann, Andreas Beck, Hans-peter Ebert, and Jochen Fricke. 2005. “Dependence of Thermal Conductivity on Water Content in Vacuum Insulation Panels with Fumed Silica Kernels Dependence of Thermal Conductivity on Water Content in Vacuum Insulation Panels with Fumed Silica Kernels." (April).

Schwab, Hubert, Ulrich Heinemann, Andreas Beck, Hans Peter Ebert, and Jochen Fricke. 2005. "Dependence of Thermal Conductivity on Water Content in Vacuum Insulation Panels with Fumed Silica Kernels." Journal of Thermal Envelope and Building Science 28(4):319-26.

Schwab, Hubert, Ulrich Heinemann, Johannes Wachtel, Hans Peter Ebert, and Jochen Fricke. 2004. "Predictions for the Increase in Pressure and Water Content of Vacuum Insulation Panels (VIPs) Integrated into Building Constructions Using Model Calculations." Journal of Thermal Envelope and Building Science 28(4):327-44.

Simmler, H. and S. Brunner. 2005. "Vacuum Insulation Panels for Building Application: Basic Properties, Aging Mechanisms and Service Life." Energy and Buildings 37(11 SPEC. ISS.):1122-31.

Simmler, Hans, Ulrich Heinemann, Hubert Schwab, Daniel Quénard, Esra Kücükpinar-niarchos, and Cornelia Stramm. 2005a. "Vacuum Insulation Panels- Study on VIP- Components and Panels for Service Life Prediction of VIP in Buikding Applications ( Subtask A)."

Simmler, Hans, Ulrich Heinemann, Hubert Schwab, Daniel Quénard, Esra Kücükpinar-niarchos, and Cornelia Stramm. 2005b. "Vacuum Insulation Panels." (September 2005).

Sultan Sanat Alotaibi, Saffa Riffat. 2014. “Drying and Quality Characteristics and Models of Carrot Slices under Catalytic Infrared Heating." International Agricultural Engineering Journal 23(2):70-79.

Tenpierik, Martin, Arjan Van Timmen, Wim Van der Spoel, and Hans Cauberg. 2009. "Vacuum Insulation Panels and Architecture: Cradle-to-Cradle Façade Systems." 3rd International Conference on Smart and Sustainable Built Environments (May 2014).

Thorsell, T. I. 2006. “Edge Loss Minimization in Vacuum Insulation Panels." 3rd International 
Building Physics Conference - Research in Building Physics and Building Engineering 25156.

Thorsell, Thomas. 2012. Advances in Thermal Insulation - Vacuum Insulation Panels and Thermal Efficiency to Reduce Energy Usage in Buildings. Vol. ISBN 978-9.

Wegger, Erlend, Bjørn Petter Jelle, Erland Sveipe, Steinar Grynning, Arild Gustavsen, Ruben Baetens, and Jan Vincent Thue. 2011. "Aging Effects on Thermal Properties and Service Life of Vacuum Insulation Panels." Journal of Building Physics 35(2):128-67.

Wegger, Erlend, Bjørn Petter, Erland Sveipe, and Steinar Grynning. 2010. “Ageing Effects on Thermal Properties and Service Life of Vacuum Insulation Panels." Building Physics 35:128167.

Winsniak, Jaime. 2003. "James Dewar-More than a Flask." 10:424-34.

Xu, Tengzhou, Zhaofeng Chen, Yong Yang, Zhou Chen, Junxiong Zhang, Cao Wu, and Yang Liu. 2018. "Correlation between the Thermo-Physical Properties and Core Material Structure of Vacuum Insulation Panel: Role of Fiber Types." Fibers and Polymers 19(5):1032-38.

Yuying Liang, Huijun Wu, Gongsheng Huang, Jianming and Yunfei Ding Yang. 2017. “Prediction and Optimization of Thermal Conductivity of Vacuum." 2588-2562. 